\title{
Shoulder disorder treatment : efficacy of ultrasoundtherapy and electrotherapy
}

Citation for published version (APA):

van der Heijden, G. J. M. G. (1996). Shoulder disorder treatment : efficacy of ultrasoundtherapy and electrotherapy. [Doctoral Thesis, Maastricht University]. Universiteit Maastricht. https://doi.org/10.26481/dis.19961219gh

Document status and date:

Published: 01/01/1996

DOI:

10.26481/dis.19961219gh

Document Version:

Publisher's PDF, also known as Version of record

\section{Please check the document version of this publication:}

- A submitted manuscript is the version of the article upon submission and before peer-review. There can be important differences between the submitted version and the official published version of record.

People interested in the research are advised to contact the author for the final version of the publication, or visit the DOI to the publisher's website.

- The final author version and the galley proof are versions of the publication after peer review.

- The final published version features the final layout of the paper including the volume, issue and page numbers.

Link to publication

\footnotetext{
General rights rights.

- You may freely distribute the URL identifying the publication in the public portal. please follow below link for the End User Agreement:

www.umlib.nl/taverne-license

Take down policy

If you believe that this document breaches copyright please contact us at:

repository@maastrichtuniversity.nl

providing details and we will investigate your claim.
}

Copyright and moral rights for the publications made accessible in the public portal are retained by the authors and/or other copyright owners and it is a condition of accessing publications that users recognise and abide by the legal requirements associated with these

- Users may download and print one copy of any publication from the public portal for the purpose of private study or research.

- You may not further distribute the material or use it for any profit-making activity or commercial gain

If the publication is distributed under the terms of Article $25 \mathrm{fa}$ of the Dutch Copyright Act, indicated by the "Taverne" license above, 


\section{Shoulder disorder treatment}

Efficacy of ultrasoundtherapy and electrotherapy 
The main study of this thesis, the randomized placebo-controlled clinical trial on ultrasoundtherapy and electrotherapy for shoulder disorders, was funded by the National Insurance Council (Ziekenfondsraad), Amstelveen, the Netherlands.

Lay-out: Thum Aarts, Maastricht

Productie: Datawyse / University Press Maastricht

• G.J.M.G. van der Heijden, Maastricht 1996

ISBN 90-74910-14-9

This thesis was performed at the Maastricht Research Institute for Extramural and Transmural Health Care, which participates in The Netherlands School of Primary Care Research (CaRe), acknowledged in 1995 by the Royal Dutch Academy of Science (KNAW). 


\title{
Shoulder disorder treatment
}

\section{Efficacy of ultrasoundtherapy and electrotherapy}

\author{
Proefschrift
}

ter verkrijging van de graad van doctor

aan de Universiteit Maastricht, op gezag van de Rector Magnificus, Prof. Mr. M.J. Cohen, volgens het besluit van het College van Decanen,

in het openbaar te verdedigen

op donderdag 19 december 1996

om 10.00 uur

door

Geert J.M.C. van der Heijden 
Promotoren:

Prof. Dr. P.G. Knipschild

Prof. Dr. L.M. Bouter (Vrije Universiteit, Amsterdar)

Beoordelingscommissie: Prof. Dr. J.A. Knottnerus (Voorzitter)

Prof. Dr. J. Drukker

Prof. Dr. H. Philipsen

Prof. Dr. M. Roland (University of Manchester, UK)

Dr. G.H.I.M. Walenkamp

Drs. Ir. P. Leffers leverde een belangrijke bijdrage aan de totstandkoming van dit proefschrift. 


\section{Contents}

Chapter

page

1 Introduction

2 Physiotherapy for soft-tissue shoulder disorders:

a systematic review of randomized clinical trials

Submitted for publication

3 Steroid injections for shoulder disorders:

a systematic review of randomized clinical trials

British Journal of General Practice 1996; 46: 309-316

4 Non-steroidal anti-inflammatory drugs (NSAIDS)

for shoulder complaints: a systematic review

Journal of Clinical Epidemiology 1995; 48: 691-704

5 Efficacy of ultrasoundtherapy and electrotherapy for shoulder disorders: results of a randomized placebo-controlled clinical trial

Submitted for publication

6 Shoulder disability questionnaire: design and responsiveness of a functional status measure Submitted for publication

7 General discussion

Summary

Samenvatting

Dankwoord

Curriculum vitae

List of publications 


\section{Chapter 1}

\section{Introduction}

\section{Shoulder disorders}

Pain and stiffness in the deltoid region are the main symptoms of patients with shoulder disorders. In about $30 \%$ of all cases in general practice these symptoms limit daily activities'. Many patients have paraesthesia or pain that radiates to below the elbow. Pain during movement usually limits the active range of motion, while in severe cases the passive range of motion is also restricted. Pain when lying on the impaired shoulder is a common complaint that often results in problems with sleeping ${ }^{24}$. Up to $20 \%$ of all cases originate from neurological or generalized musculoskeletal conditions, neoplasms or referred pain from the neck or from internal organs ${ }^{5}$. The remainder of all shoulder disorders is reported to originate from entesopathies within the shoulder girdle, such as tendinitis, bursitis and capsulitis ${ }^{4,5}$. An inflammatory reaction of soft tissue, due to subacromial impingement of articular and peri-articular structures, appears to be the common pathologica! mechanism behind these entesopathies ${ }^{3,4}$.

\section{Occurrence}

Shoulder disorders constitute a frequently occurring health problem. About $10 \%$ of the general population suffer from one or more episodes of shoulder disorders in the course of their life $\mathrm{e}^{2}$. The annual cumulative incidence is estimated at about $2 \%$. The one-year period prevalence is highest at about $25 \%$ during the $4^{\text {th }}$ decade of life ${ }^{6}$. Little is known about the magnitude of the socio-economic impact, e.g. cost of health care and sick leave, but working capacity is reported to be reduced in more than $50 \%$ of all working, patients ${ }^{1,7}$.

The majority of all new episodes that occur disappear within a few weeks, and therefore shoulder disorders are usually considered to be self-limiting ${ }^{2,69}$. A good shortterm outcome is reported to be associated with the acute onset of symptoms or with an antecedent trauma of the upper extremity ${ }^{10.11}$, short duration of symptoms before first. presentation to the general practitioner $r^{11-13}$ and overuse during leisure or sports activities $^{12}$. A poor long-term prognosis is reported to be associated with involvement of the non-dominant side or both sides ${ }^{12,14}$, being female ${ }^{15}$, co-existent diabetes mellitus ${ }^{16,17}$, a prolonged immobility and passive abduction range of less than $90^{\circ 18}, \mathrm{co}-$ existent cervical spine disorders and radiating pain below the elbow ${ }^{16,19}$, an increasing number of prior episodes ${ }^{20}$ and advanced age ${ }^{10,2 !}$. 


\section{Treatment}

About $50 \%$ of all patients with shoulder disorders consult a physician ${ }^{22}$. After low back and neck disorders, they constitute the third most largest group of patients with locomotor disorders in primary care ${ }^{23-26}$. Approximately $5 \%$ of all consultations of general practitioners concern shoulder disorders $2,8,23-26$. Yet, in spite of their frequent presentation, there is no consensus about the optimal management of either acute or persistent shoulder disorders. A variety of therapies is provided in primary care, such as rest, a sling, analgesics, NSAIDS, steroid injections, thermotherapy, exercises, electrotherapy, ultrasoundtherapy, short-wave diathermia and advice about daily living. Many patients who consult their general practitioner for a new episode of shoulder disorders recover within a few weeks ${ }^{18,19,22}$. About half of all newly presented episodes are reported to last for 6 months, but a considerable number may even last. over a year $^{18,19,22}$. In addition, the recurrence rate is reported to be high ${ }^{9,22}$. When the course of the complaints is protracted, general practitioners tend to refer patients to other health care workers. Consequently, about $1 \%$ of all referrals to orthopaedic surgeons and about $10 \%$ of all referrals for physiotherapy concern shoulder disorders ${ }^{8,12,22-26}$.

\section{Efficacy of treatment}

The purpose of treatment of patients with shoulder disorders is to increase the extent and speed of recovery. In spite of the wide variety of existing therapies, many patients suffer from persistent or recurrent symptoms. Randornized clinical trials offer the best possibility for a valid evaluation of treatment effects ${ }^{27}$. Although to date many trials of common primary care treatments such as analgesics, NSAIDS, steroid injections and physiotherapy for shoulder disorders, have been published, conclusive evidence on their efficacy is still lacking. Therefore, there is a need for systematic reviews on the efficacy of these frequently applied primary care treatments.

Ultrasoundtherapy and electrotherapy are believed to promote recovery of soft tissue shoulder disorders. Their frequent use in physiotherapy, usual as adjuvants to exercise therapy, has been reported for the Netherlands, but also for the United Kingdom, Canada, United States, Australia and New Zealand ${ }^{28-32}$. Biological studies report promising effects of ultrasoundtherapy and electrotherapy, such as pain threshold elevation and promotion of muscle relaxation ${ }^{33-35}$. However, controversy over their efficacy persists ${ }^{36}$. Therefore, there is a need for a new trial in primary care on the efficacy of ultrasoundtherapy and electrotherapy for shoulder disorders.

\section{Content of thesis}

This thesis reports on the design and results of studies about the treatment of soft-tissue shoulder disorders in primary care. Chapters 2 through 4 contain systematic reviews of randomized clinical trials. on the efficacy of common approaches in physiotherapy, and of steroid injections and non-steroidal anti-inflammatory drugs (NSAIDS) for shoulder disorders. Chapter 5 presents, the design and results of a randomized placebo-controlled clinical trial on the efficacy of ultrasoundtherapy and electrotherapy as adjuvants to exercise therapy for patients with soft-tissue shoulder disorders in primary care physiotherapy. The research question is whether these therapies contribute to the extent and speed of recovery from shoulder disorders. We compare the effect of active versus dummy treatments in a two by two factorial design. In order to estimate the placebo effect of the adjuvant treatments, an extra control group is added which only receives exercise therapy. 
Chapter 6 describes the design of the shoulder disability questionnaire (SDQ). This chapter also includes an evaluation of the SDQ responsiveness compared with four other outcome measures that were used simultaneously.

Chapter 7, the general discussion, provides a critical review of the principles of design and conduct of our clinical trial. Furthermore, the results of the systematic reviews and the performance of the outcome measures are discussed. The general discussion concludes with recommendations for clinical practice and suggestions for future clinical trials on shoulder disorders.

Comprehensive Dutch and English summaries follow and the thesis ends with some acknowledgements, a curriculum vitae and a list of publications.

\section{References}

1 Makela M, Heliovaara M, Sievers K, Knekt P, Maatela I. Aromaa A. Musculoskeletal disorders as determinants of disability in Finns aged 30 years or more. Journal of Clinical Epidemiology $1993 ; 46$ : 549-59.

2 Croft P. Soft tissue rheumatism. In: Epidemiology of the theumatic diseases, Silman A, Hochberg MC (eds). University Press, Oxford, 1993: 375-421.

3 Jayson MIV. Frozen shoulder: adhesive capsulitis. British Medical Journal 1981; 283: 1005-6.

4 Bland JH, Merit JA, Boushey, DR. The painful shoulder. Seminars in Arthritis and Rheumatism 1977; 7: 21-47.

5 Uthoff HK, Sarkar K. An algorithm for shoulder pain caused by soft-tissue disorders. Clinical Orthopaedics and Related Research: 1990; 254: 121-7.

6 Bjelle A. Epidemiology of shoulder problems, Ballieres Clinical Rheumatology 1989; 3: 437-51.

7 Bergenudd $\mathrm{H}$, Lindgärde F, Nilsson B, Peterson C. Shoulder pain in middle age. A study of prevalence and relation to occupational work load and psychosocial factors. Clinical Orthopaedics 1988; $231: 234-8$.

8 Windt DAWM van der, Koes BW, Jong BA de, Bouter LM. Shoulder disorders in general practice: incidence, patients characteristics, and management. Annals of Rheumatic Diseases 1995; $54: 959$. 64.

9 Nash P, Hazleman BL. Frozen shoulder. Balliéres Clinical Rheumatology 1989; 3: 551-66.

10 Yamanaka K, Matsumoto T. The joint side tear of the rotator cuff. A follow-up study by arthroghraphy. Clinical Orthopaedics and Related Research 1994; 304: 68-73.

11 Hazleman BL. The painful stiff shoulder. Rheumatology and Physical Medicine 1972; 11: 413-20.

12 Chard MD, Sattele LM, Hazleman BL. The long term outcome of rotator cuff tendinitis. A review study. British Journal of Rheumatology 1988; 27: 385-9.

13 Bulgen DY, Binder AI, Hazleman BL, Dutton 1, Roberts S. Frozen shoulder: prospective clinical study with an evaluation of three treatment regimens. Annals of Rheumatic Diseases 1984; 43: 353-60.

14 Binder AI, Bulgen DY, Hazleman BL, Roberts S. Frozen shoulder: a long term prospective study. Annals of Rheumatic Diseases 1984; $43: 361-4$.

15 Bjelle A. Scapulohumeral syndromes. Ballières Clinical Rheumatology 1987; 1: 547-59.

16 Loew M. Uber den spontanverlauf der shultersteife. Krankengymnastik 1994; 46: 432-8.

17 Pollock RG. Duralde XA, Flatow EL, Bigliani LU. The ușe of arthroscopy in the treatment of resistant frozen shoulder. Clinical Orthopaedics and Related Research 1994; 304: 30-6.

18 Reeves B. The natural history of the frozen shoulder syndrome. Scandinavian lournal of Rheumatology $1975 ; 4 ; 193-6$.

19 Windt DAWM van der, Koes BW, Boeke AJP, Devillé W', Jong BA de, Bouter LM. Shoulder disorders in general practice. Prognostic indicators of outcome. British Journal of Ceneral Practice 1996; 46: 519-23.

20 Rizk TE, Pinals RS. Frozen shoulder. Seminars in Arthritis and Rheumatism 1982; 11:440-52.

21 Mucahy KA, Baxter AD, Oni OOA, Finlay D. The value of shoulder distension arthrography with intra-articular injection of steroid and local anaesthetic: a follow-up study. British journal of Radiology 1994; 67: 263-6.

22 Meantime HS. Rheuma-intersex meerdere echelons (ROME): basisrapport. Leiden, Nederlands Instituut voor Praeventieve Gezondheidszorg TNO, 1994. 
23 Grundemeijer HGLM, Brouwer HJ. De betekenis van fysiotherapie bij aandoeningen aan het bewegingsapparaat. Nederlands Tijdschrift voor Fysiotherapie 1989; 99: 33-9.

24 Peters D, Davies P, Pietroni P. Musculoskeletal clinic in general practice: study of one year's referrals. British Journal of Ceneral Practice 1994; 44: 25-9.

25 Hackett GI, Bundred P, Hutton JL, O'Brien I, Stanley IM. Management of joint and soft tissue injuries in three general practices: value of on-site physiotherapy. British Journal of General Practice 1993; 43: 61-4.

26 Gentle PH, Herlihy PI, Roxburgh IO. Controlled trial of an open-access physiotherapy service. British Journal of Ceneral Practice 1994; 34: 371-6.

27 Pocock SJ. Clinical trials. A practical approach. John Wiley \& Sons, Chichester, 1991.

28 Lindsay DM, Dearness J, McGinley CC. Electrotherapy usage trends in private practice in Alberta. Physiotherapy Canada 1995; 47: 30-4.

29 Pope GD, Mocket SP, Wright JP. A survey of electrotherapeutic modalities: ownership and use in the NHS in England. Physiotherapy 1995; 81: 82-91.

30 Robinson A, Snyder-Mackler L. Clinical application of electrotherapeutic modalities. Physical Therapy 1988; 68: 1235-38.

31 Health Insurance Council (Ziekenfondsraad). Annual Report. Klomp and Bosman, Amstelveen, The Netherlands 1990.

32 Haar G ter, Dyson M, Oakley EM. The use of ultrasoundtherapy by physiotherapists in Britain, 1985. Ultrasoundtherapy in Medicine and Biology 1987; 13: 659-63.

33 Maxwell L. Therapeutic ultrasound. Its effects on the cellular and molecular mechanisms of inflammation and repair. Physiotherapy 1992; 78: 421-6.

34 Hayes KW. The use of ultrasoundtherapy to decrease pain and improve mobility. Critical Reviews in Physical and Rehabilitation Medicine 1992; 3: 271-87.

35 Devor M. Peripheral and central nervous system mechanisms of sympathetic related pain. Pain Clinic 1995; 8: 5-14.

36 Rush PJ, Shore A. Physician perceptions of the value of physical modalities in the treatment of musculoskeletal disease. British Journa! of Rheumatology 1994; 33: 566-8. 


\section{Chapter 2}

\section{Physiotherapy for soft-tissue shoulder disorders}

A systematic review of randomized clinical trials

GJMG van der Heijden ${ }^{1,2}$, DAWM van der Windt', AF de Winter'

1 Institute for Rehabilitation Research, Hoensbroek, The Netherlands

2 Department of Epidemiology, University Maastricht, The Netherlands

3 Institute for Research in Extramural medicine, Vrije Universiteit, Amsterdam, The Netherlands 


\section{Abstract}

Purpose The study was designed to assess the efficacy of physiotherapy for soft-tissue shoulder disorders.

Data sources A systematic computerized literature search in Medline and Embase was conducted, supplemented with citation tracking of all relevant publications.

Study selection Trials on physiotherapy for soft-tissue shoulder disorders published before 1996 were selected if treatment was randomly allocated and if success rates, pain, mobility or functional status were used as outcome measures.

Data extraction The validity of trial methods was systematically assessed by independent reviewers. Trials were ranked according to the extent to which bias was considered to be unlikely. Next, differences between groups in outcome and $95 \%$ confidence intervals were calculated.

Results The methods assessment was frequently hampered by insufficient information on various criteria. Furthermore, trials were often flawed by lack of blinding and a high incidence of treatment withdrawals and missing values. Trial sizes were small: only 4 trials included intervention groups of at least 25 patients. Ultrasoundtherapy, evaluated in 6 trials, was not shown to be efficacious. Only 4 other trials favoured the efficacy of physiotherapy (lasertherapy or manipulation), but the validity of their methods was unsatisfactory.

Conclusions Ultrasoundtherapy does not appear to be efficacious in the treatment of soft-tissue shoulder disorders. Due to small trial sizes and unsatisfactory methods, evidence for the efficacy of other physiotherapeutical interventions is inconclusive. Future trial should study whether these interventions are superior to treatment with analgesics, non-steroidals, steroid injections or a wait-and-see policy. 


\section{Introduction}

Pain is the primary complaint of most patients with soft-tissue shoulder disorders. In many patients pain restricts the range of shoulder movement, causing limitations of daily activities. Estimates of the cumulative annual incidence of shoulder disorders range from 7 to 25 per 1000 general practice consultations ${ }^{i-3}$. Five per cent of all general practice consultations is reported to be related to shoulder disorders ${ }^{4.3}$. Fifty per cent of all presented episodes resolve within 6 months, but some may last over a year or more. The majority of patients with soft-tissue shoulder disorders is treated in primary care. Their management includes advice, analgesics, non-steroidals, steroid injections and physiotherapy. Randomized clinical trials on shoulder disorders show. small effects in favour of the efficacy of non-steroidals ${ }^{6}$ and steroid injections ${ }^{7}$. A wide array of physiotherapy modalities is used for the treatment of shoulder disorders ${ }^{0.9}$. Patients are frequently referred for physiotherapy ${ }^{10,11}$, in Dutch primary care as many as $20 \%$ to $33 \%$ of all patients with shoulder disorders $2,1,12$. So far, little effort has been invested in establishing the efficacy of common physiotherapy management before implementation in practice. The purpose of this systematic review, based on the reports of 20 randomized clinical trials, is to assess whether physiotherapy is efficacious for patients with soft-tissue shoulder disorders.

\section{Methods}

\section{Study selection}

Relevant trial reports were harvested from Medline (Index Medicus 1/1966-12/1995) and Embase (Excerpta Medica 1/1984-12/1995) according to the computerized search strategy of Dickersin et $\mathrm{al}^{13}$. This strategy was supplemented with citation tracking of relevant publications. GJMGH identified trial reports that met the following conditions: [1] patients had shoulder pain at inclusion; [2] treatments were allocated by a random procedure; [3] at least one of the treatments included physiotherapy; [4] success rate, pain, mobility or functional status were included as outcome measures; [5] results were published as a full report before January 1996. From this selection DAWMW and AFW independently selected the trials that included patients with soft-tissue shoulder disorders.

\section{Methods assessment}

Eight validity criteria were used for the assessment of trial methods (Table i-A). These criteria are based on generally accepted methodological requirements for intervention research ${ }^{14-17}$. In addition, five data extraction criteria were used (Table 1-B) that provide information on the external validity and possibilities for statistical pooling ${ }^{18}$. DAWMW, AFW and GJMGH independently analyzed the selected trial reports for completeness of information. For each criterion they logged whether incomplete information had hampered the methods assessment. If sufficient information was reported they judged and logged whether bias was likely or not. For criteria for which consensus could not be reached, the presented results are based on agreement of 2 reviewers. The trials were subsequently ranked according to the number of validity criteria for which bias was considered to be unlikely. 
Table 1a. Validity criteria for the methods assessment of randomized clinical trials of physiotherapy for shoulder disorders.

V1 Enrolment:

Restriction to a population homogeneous for prognosis and susceptibility to the allocated. interventions by means of explicit selection criteria. Prognostic markers used: age, duration of complaints, painful arc, pain at night, number of prior episodes, radiating pain, prior treatment.

V2 Randomization:

Adequate procedure for generation of a random numbers list and concealed allocation of interventions.

V3 Baseline similarity:

Similarity of intervention groups at baseline with respect to prognosis and susceptibility to allocated interventions. Prognostic markers used: baseline scores for outcome measures, age, duration of complaints, painful arc, pain at night, number of prior episodes, radiating pain, prior treatment.

V4 Treatment withdrawals:

No patients withdrew from allocated treatment, or the number of patients was; $<10 \%$ in each intervention group, with comparable reasons for withdrawal.

V5 Missing data (e.g due to loss-to-follow-up):

The number of randomized patients minus the number of reported patients at the main moment of effect measurement for the main outcome measure (if not stated according to the reviewers) divided by all randomized patients, times $100 \%:<10 \%$ in each group.

V6 Co-interventions:

Either standardized or excluded in trial design.

V7 Blinded application of interventions:

Therapists: blinding by a credible placebo.

Patients: blinding by a credible placebo or by enrolment of patients who were unaware of the identity of the allocated interventions.

V8 Blinded outcome assessment:

Assessor of effect parameters (e.g. patient, therapist, physician or research staff) blinded for allocated interventions.

Table 1b. Data extraction criteria for the methods assessment of randomized clinical trials of physiotherapy for shoulder disorders.

D1 Sample size of groups at baseline

D2 Standardization of allocated interventions:

Adequate description of intervention type, modality, application technique, intensity, and of duration, number and frequency of sessions for all allocated interventions.

D3 Reported outcome parameters:

Success rate (e.g. proportion of patients cured or improved); pain; functional status (activities of daily living); mobility (range of motion); non-trial co-interventions (e.g. medication, surgery)

D4 Outcorne assessments:

Identical timing of assessment for all intervention groups; immediately after the last treatment or $>$ 3 months.

D5 Actual data for outcome parameters:

An adequate point estimate is presented for each intervention group - with corresponding

distribution measure - for success rate or improvement for pain or most important outcome measure on the most important moment of effect measurement.

Success rates were determined for each intervention group by dividing the number of documented successes at the end of the intervention period, by the number of patients randomly allocated to the intervention (i.e. intention-to-treat analysis). When success rates could not be calculated, change scores for pain and mobility ratings were determined. Missing values for outcome measures were assumed to represent failures 
(i.e. worst-case assumption). Next, the differences between groups for outcome measures were calculated, along with the $95 \%$ confidence intervals. Finally, the efficacy of physiotherapy was judged by relating these confidence intervals to the number of validity criteria satisfied.

\section{Results}

\section{Study selection}

GJMGH identified 47 trial reports that met the 5 conditions for further selection.

DAWMW and AFW excluded 23 trials: 7 because the results of patients who received physiotherapy for shoulder disorders were not presented separately; 1 because similar physiotherapy was given as a co-intervention to all patients; 4 on exercise therapy after mastectomy; 4 on physiotherapy for post-fracture shoulder pain; 7 on physiotherapy for shoulder pain in hemiplegics; and 1 trial on rheumatoid arthritis. The methods of the remaining 23 trial reports were assessed ${ }^{194}$. Information was combined for 3 trials that were reported twice $23+24,33+34,40+41$. Hence, 20 trials on the efficacy of physiotherapy for patients with soft-tissue shoulder disorders were included in this systematic review.

\section{Methods assessment}

In Table 2 the validity criteria for which bias was considered likely are listed for each trial. This table also presents the validity and data extraction criteria for which incomplete information hampered the methods assessment. The trials are ranked according to the number of validity criteria satisfied. Equally ranked trials are ordered alphabetically.

Table 2. Methods assessment. Validity criteria for which bias must be considered likely, and validity and data extraction criteria for which incomplete information hampered assessment.

\begin{tabular}{|c|c|c|c|}
\hline First author'te! & $\begin{array}{l}\text { Bias conșidered } \\
\text { likely }\end{array}$ & $\begin{array}{l}\text { Incomplete information. } \\
\text { for validity assessment. }\end{array}$ & $\begin{array}{l}\text { Incomplete information } \\
\text { for data extraction }\end{array}$ \\
\hline Downing $^{19}$ & - & - & - \\
\hline Binder ${ }^{20}$ & - & $\vee 2,3$ & D 5 \\
\hline Leclaire $^{21}$ & $=$ & $\vee 2,3$ & - \\
\hline Saunders 22 & - & $\vee 2,3$ & D 3 \\
\hline Berry ${ }^{23,24}$ & - & $\vee 1,2,3$ & D 2 \\
\hline Brox 25 & $\vee 7,8$ & V 2 & D. 5 \\
\hline Chard $^{26}$ & V 5 & V $2,3,6$ & - \\
\hline Dacre $^{27}$ & V7 & $\vee 2,3,6$ & D. 2,5 \\
\hline Herrera-Lasso 20 & $\vee 4,7$ & $V_{1,2}$ & - \\
\hline Nykanen ${ }^{2 s}$ & - & V $1,2,3,4$ & . \\
\hline Vecchio $^{30}$ & - & V $1,2,4,5$ & - \\
\hline Bulgen"11 & $\vee 4,7$ & $V 2,3,6$ & D. $2,3,5$ \\
\hline England $^{32}$ & - & $\vee 1,2,3,4,6$ & D 5 \\
\hline Gudmundsen ${ }^{33,34}$ & $\vee 8$ & V $1,2,3,6$ & 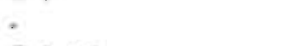 \\
\hline Knüsel $^{\text {is }}$ & - & $V_{1} 1,2,3,6,7$ & D $3,4,5$ \\
\hline Thomas ${ }^{36}$ & V 7 & V $1,2,3,6,8$ & - \\
\hline Biwas $^{17}$ & $\vee 4,5,7$ & $\vee 1,2,3,8$ & D $2,3,5$ \\
\hline Delacerda & V 7 & V $1,2,3,4,6,8$ & D. $3,4,5$ \\
\hline Knorre $^{39}$ & V $1,7,8$ & $\vee 2,3,4,5,6$ & D 5 \\
\hline $\operatorname{Lee}^{40,41}$ & $\mathrm{~V} 1,7$ & $\vee 2,3,4,5,6,8$ & D. 3,5 \\
\hline
\end{tabular}




\section{Validity criteria}

In many trials the information on several validity criteria was poorly reported. The randomisation procedure [V2] was adequately reported for 1 trial only ${ }^{19}$, and prognostic status at baseline [V3] for no more than 3 trials ${ }^{19,25,28}$. In addition, information on cointerventions was often insufficient [V6].

Only 1 trial $^{19}$ satisfied all 8 validity criteria, another 3 trials ${ }^{20-22}$ satisfied 6 validity criteria. Three trials ${ }^{28,31,37}$ appeared to be flawed by al large proportion of treatment withdrawals [V4], 2 trials ${ }^{26,37}$ by a large proportion of missing values [V5], 9 trials $25,27,28,31,34-39$ by lack of blinding of intervention [V7] and 3 trials $\mathrm{s}^{25,30,39}$ by lack of blinding of outcome assessment [V8].

\section{Data extraction criteria}

Study sizes [D1] were small: 6 trials s, $26,29,33-35,39$ compared groups of 25 patients or

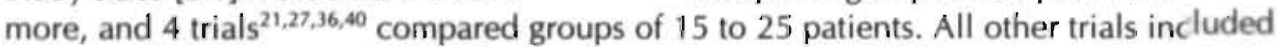
even smaller study populations. Data on outcome measures [D5] were poorly reported. Eleven ${ }^{19,24-26,30,32 \cdot 36,38,39}$ trials provided sufficient data for the calculation of $95 \%$ confidence intervals.

\section{Trial characteristics}

Table 3 outlines the study population, intervention, follow-up and reported results of the assessed trials. Again, the trials are ordered by the number of fulfilled validity criteria.

In 9 trials $^{19,20,22,23,25,26,28,30,33}$ participation was restricted to narrowly defined diagnostic categories (e.g. rotator cuif tendinitis), while other trials inciuded a wide variety of softtissue disorders (e.g. painful shoulder, periarthritis humeroscapularis).

For 8 trials $^{23,26-28,35,37,38,40}$ symptom duration at baseline was not specified as an entry criterion. Another 8 trials $^{19,21,22,29,31-33,36}$ included patients with a symptom duration of less than 3 months at baseline, whereas in the remaining 4 trials symptom duration at baseline had to exceed 3 months.

Ultrasoundtherapy was studied in 6 trials $19,23,28,29,38,39$, different modalities of thermotherapy in 4 trials $^{26,37,38,40}$, and low-level-lasertherapy in 4 trials ${ }^{22,30,32,33}$. Three trials concerned magnetotherapy ${ }^{20,21,26}$ or manipulations or mobilisations $27,31,36,2$ trials involved electrotherapy ${ }^{28,35}$ or coldtherapy ${ }^{31,39}$, and 1 trial evaluated an exercise program $^{25}$.

Six Irials ${ }^{26,28,31,35,38,39}$ compared two or more modalities of physiotherapy, 7 trials ${ }^{19,20,22,25,29,32,33}$ compared physiotherapy with placebo treatment, while 9 trials ${ }^{24,25,27,31,32,37-40}$ compared physiotherapy with another intervention (mainly analgesics, NSAIDS and steroid injections). Furthermore, 3 trials $\mathrm{s}^{21,31,36}$ included a control group without any treatment.

Results from long-term follow-up assessment (at least 2 months after randomization) were available from 4 trials ${ }^{21,25,36,39}$. Follow-up in all other trials was restricted to outcome assessment directly after completion of treatment, usually 3 or 4 weeks after randomisation.

\section{Treatment efficacy}

Four ${ }^{19,23,28,29}$ out of 6 trials that studied the effect of ultrasoundtherapy satisfied 4 or more validity criteria, although none of the trials demonstrated evidence in favour of ultrasoundtherapy. Ultrasoundtherapy was not found to be superior to coldtherapy and 
steroid injections ${ }^{39}$, NSAIDS and acupuncture ${ }^{23}$, TENS ${ }^{20}$, analgesics and iontophoresis ${ }^{30}$. Moreover, ultrasoundtherapy did not appear to be efficacious in placebo-controlled trials $19,21,29$.

Two ${ }^{22.30}$ of the 4 trials that studied the efficacy of low-level-lasertherapy satisfied 4 or more validity criteria. Saunders et al $^{22}$ could not demonstrate significant differences between active and placebo laser. Although $\mathrm{Vechio}^{10}$ did not report any significant differences, our calculations of the $95 \% \mathrm{Cl}$ demonstrate very small differences in favour of active low-level-lasertherapy. Two other trials with unsatisfactory methods reported effects in favour of the short-term efficacy of low-level-lasertherapy compared with placebo $^{12,3}$ or with NSAIDS ${ }^{12}$.

Transcutaneous electrical stimulation did not appear to be more effective than ultrasoundtherapy ${ }^{28}$ or than another electric modality". We could not find any placebocontrolled trial on electrotherapy.

Two placebo-controlled trials on pulsed electromagnetic fields ${ }^{20,26}$ satisfied 4 or more validity criteria and reported favourable results for active treatment. However, when analyzed according to the intention-to-treat principle, the results of Chard ${ }^{26}$ appeared to be not statistically significant. Magnetic treatment did not appear to be efficacious when compared with no treatment ${ }^{21}$.

Coldtherapy did not prove to be more efficacious than ultrasoundtherapy ${ }^{39}$, steroid injection $^{31.39}$, mobilisations or no intervention". Different thermotherapy modalities did not show superior efficacy when compared with placebo ${ }^{26.37 .30}$, steroid injections and analgesics ${ }^{40}$.

Exercises were equally effective as surgery in patients with a stage II impingement syndrome, but proved to be efficacious when compared with placebo lasertherapy ${ }^{25}$. When compared to no intervention ${ }^{31,36}$, mobilisations and manipulations did not contribute to recovery, nor did they prove to be superior to steroid injections ${ }^{27.31}$ or coldtherapy ${ }^{3 !}$.

\section{Discussion}

This systematic review is based on the reports of 20 randomized clinical trials. Its purpose is to assess whether physiotherapy contributes to the recovery of patients suffering from soft-tissue shoulder disorders. A standardized methods assessment is used in order to minimize bias.

\section{Methods assessment}

The methods assessment revealed that for only one trial ${ }^{19}$ all information was reported that was needed for validity assessment and data extraction. Many trials provided insufficient information for at least 2 validity criteria. Poor reporting might hide flaws, and so hinders the interpretation of trial results. Lack of information was most prominent for the randomisation procedure [V2], baseline similarity of treatment groups [V3] and co-interventions [V6].

Schulz et a ${ }^{42}$ provided empirical evidence of bias for trials with inadequate concealment of treatment allocation [V2] and lack of blinding [V7,V8]. There is reason to believe that lack of prognostic comparability at baseline [V3], withdrawals [V4] and missing data [V5] are also related to success of treatment and therefore represent major sources of bias ${ }^{43,44}$. 
Table 3. Trial characteristics: study populations, interventions and results.

\begin{tabular}{|c|c|c|}
\hline Fist author ${ }^{\text {nd }}$ & $\begin{array}{l}\text { Diagnosis } \\
\text { Symptom duration }\end{array}$ & $\begin{array}{l}\text { Interventions } \\
\text { (number of randomized patients) }\end{array}$ \\
\hline Downing ${ }^{19}$ & $\begin{array}{l}\text { Supraspinatus tendinitis, } \\
\text { Subacromial bursitis, } \\
\text { Adhesive capsulitis } \\
\text { 2 1 month }\end{array}$ & $\begin{array}{l}\text { i Ultrasound, continuous, } 1 \mathrm{MHz}, 1.2 \mathrm{~W} \text { per } \mathrm{cm}^{2}, 6 \text { minutes, } \\
3 \text { times per week, } 4 \text { weeks (11) } \\
\text { ii Placebo ultrasound, } 3 \text { times per week, } 4 \text { weeks (9) }\end{array}$ \\
\hline Binder ${ }^{20}$ & $\begin{array}{l}\text { Rotator cuff tendinitis, } \\
\geq 3 \text { months }\end{array}$ & $\begin{array}{l}\text { i Pulsed electromagnetic fields (PEMF; } 73 \mathrm{~Hz} \text { ), } 4 \text { weeks: } 1 \text { hour, } 5-9 \\
\text { times daily (15) } \\
\text { ii Placebo PEMF, } 4 \text { weeks: } 1 \text { hour, } 5-9 \text { times daily (14) }\end{array}$ \\
\hline Leclaire?1 & $\begin{array}{l}\text { Painful shoulder with } \\
220 \% \text { ROM limitation }\end{array}$ & $\begin{array}{l}\text { i Magnetotherapy, session 1-6: } 10 \mathrm{~Hz}, 30 \text { Gauss; session: } 7-17: 15 \\
\mathrm{~Hz}, 40 \text { Gauss; session z17:30 } \mathrm{Hz}, 60 \text { Gauss; } 30 \text { minutes per } \\
\text { session (22) } \\
\text { ii No magnetotherapy (25) } \\
\text { - Both groups: } 3 \text { sessions per week } \leq 12 \text { weeks; adjuvant hot packs } \\
\text { (20 minutes) plus manual stretching ( } 5 \text { minutes) and daily home } \\
\text { exercises ( } 20 \text { minutes) }\end{array}$ \\
\hline
\end{tabular}

$\begin{array}{ll}\text { Saunders }^{23} & \begin{array}{l}\text { Supraspinatus tendinitis } \\ >4 \text { weeks }\end{array} \\ \text { Berry }^{m, 34} & \text { Shoulder-cuff lesions }\end{array}$

Not specified

i Laser, Ga-Al-As diode, $820 \mathrm{~nm}, 40 \mathrm{~mW}, 5 \mathrm{kHz}$ probe, $30 \mathrm{~J} / \mathrm{cm}^{2}$ (12)

ii Placebo laser (12)

- Both groups: 9 sessions of 3 minutes, 3 per week

i Ultrasound therapy (12)

ii Tolmetin sodium $1200 \mathrm{mg}$ daily for 4 weeks plus prednisolone injection (12)

ii Tolmetin placebo tablets plus prednisolone injection (12)

iv Iolmetin placebo tablets plus placebo ultrasoundtherapy (12)

$\checkmark$ Acupuncture (12)

Brox $25 \quad$ Rotator cuff disease; stage It impingement syndrome

23 months $(<1$ year:

$10 \%$; $1-3$ years: $22 \%$;

$>3$ years $47 \%$ l

i Daily home exercises with 2 supervised sessions per week; 6 weeks (50)

ii Placebo soft laser 2 session per week; 6 weeks (30)

iii Arthroscopic bursectomy and resection of acromion (partial) and coracoacromial ligament (45)

\begin{tabular}{|c|c|c|c|}
\hline Chard $^{26}$ & $\begin{array}{l}\text { Rotator cuff tendinitis } \\
>3 \text { months }\end{array}$ & ii & $\begin{array}{l}\text { Puised electromagnetic fields (PEMF; } 72 \mathrm{~Hz} \text { ), } 8 \text { weeks, } 8 \text { hours } \\
\text { daity (25) } \\
\text { PEMF ( } 72 \mathrm{~Hz}), 8 \text { weeks, } 2 \text { hours daily (25) }\end{array}$ \\
\hline Dacre $^{27}$ & $\begin{array}{l}\text { Painful stiff shoulder } \\
\text { Not specified }\end{array}$ & $\begin{array}{l}\text { i } \\
\text { ii } \\
\text { iii }\end{array}$ & $\begin{array}{l}\text { Physiotherapy only (mainly mobilisations) (20) } \\
\text { Triamcinolone injection only } 1 \times 20 \mathrm{mg}(22) \\
\text { Physiotherapy plus triamcinolone injection (20) }\end{array}$ \\
\hline Herrera-Lasso: & $\begin{array}{l}\text { Bicipital tendinitis } \\
\text { Supraspinatus tendinitis } \\
\text { Subdeltiod bursitis- } \\
\text { Periarthritis } \\
\text { Humeroscapularis } \\
\text { Not specified }\end{array}$ & $\begin{array}{l}\text { i } \\
\text { ii } \\
- \\
-\end{array}$ & $\begin{array}{l}\text { Ultrasound, } 10 \text { minutes, progressive dosage } 0.5 \text { to } 1 \mathrm{~W} / \mathrm{cm}^{2}(15) \\
\text { TENS }(50 \mathrm{~Hz}), 20 \text { minutes (15) } \\
\text { Both groups: } 2 \text { to } 5 \text { sessions per week, } 13 \text { sessions } \\
\text { 8oth groups: adjuvant pendular exercises plus infrared heat } \\
(240 \mathrm{~W}), 20 \text { minutes, } 60-90 \mathrm{~cm} \text { distance }\end{array}$ \\
\hline Nykänen's & $\begin{array}{l}\text { Painful shoulder } \\
\text { Not specified }\end{array}$ & i & $\begin{array}{l}\text { Ultrasound, } 1 \mathrm{MHz}, 1: 4 \text { on-off pulse ratio, } 1 \mathrm{~W} / \mathrm{cm}^{2}, 5 \mathrm{~cm}^{2} \text { ERA, } \\
10 \text { minutes (35) } \\
\text { Placebo ultrasound (37) } \\
\text { Both groups: } 10-12 \text { sessions, } 3-4 \text { per week } \\
\text { Both groups: In-patient rehabilitation exercise program }\end{array}$ \\
\hline
\end{tabular}




\begin{tabular}{ll}
\hline Results (intentions-to-treat) & Differences between groups
\end{tabular}

(95\% confidence interval)

Success rates at 4 weeks: free from pain or minimal inference of paint with Success rates: $20 \%(-23,63)$ daily living in: (i) 7 ; (ii) 4 , Internal rotation: $9(6,12)$

Changes since baseline at 4 weeks:

Internal rotation $\bar{x} \pm$ sd) (i) $10^{*} \pm 4$ (ii) $1^{*} \pm 2$

No significant differences for flexion, abduction or extemal rotation.

Pain and ROM median improvement at 4 weeks: significant differences in favour of active PEMF.

No significant differences:

Pain at 12 weeks $\left(0-4\right.$ scale, $\bar{x}_{ \pm}$sd) (i) $1.6 \pm 0.6$ (ii) $1.4 \pm 0.7$

Abduction $\overline{\mathrm{x}}_{ \pm}$sd) $\quad 4$ weeks (i) $115^{\circ} \pm 17$ (ii) $120^{\circ} \pm 13$;

8 weeks (i) $130^{*} \pm 22$ (ii) $136^{\circ} \pm 15$

12 weeks (i) $135^{\circ}+20$ (ii) $142^{\circ}+13$

Flexion $\left(\mathrm{x}_{ \pm}\right.$sd $\quad \quad 4$ weeks (i) $149^{\circ} \pm 15$ (ii) $145^{*} \pm 10^{\circ}$

8 weeks (i) $159^{\circ} \pm 19$ (ii) $167^{*} \pm 13$;

12 weeks (i) $163^{*} \pm 17$ (ii) $171^{*} \pm 12$

ADL: no significant differences, but no data presented.

No significant differences between groups for pain and muscle force.

Only graphical data presentation

Success rates (n) after 4 weeks: (i) 6 (ii) 5 (iii) 6 (iv) 9 (v) 5

Significant improvement of mean pain and ROM scores; no significant

differences between groups.

Success rates:

i versus iv: $-25 \%(-62,12)$

i versus if: $8 \%(-32,48)$

$i$ versus $v: 8 \%(-32,48)$

Neer score (medians) 3 months (i) 74 (ii) 6 ! (iii) B4;

6 months (i) 86 (ii) 66 (iii) 87

Pain (medians) $\quad 3$ months (i) 15 (ii) 15 (iii) 25 ;

6 months (i) 25 (ii) 15 (iii) 25

Function (medians) $\quad 3$ months (i) 24 (ii) 20 (iii) 28 ;

6 months (i) 25 (ii) 15 (iii) 28

ROM (medians) $\quad 3$ months (i) 22 (ii) 19 (iii) 21 :

6 months (i) 23 (ii) 19 (iii) 22

No improvement scores, only

absolute values

:

Median pain score: iii versus ;

3 months: 5 (0,10);

6 months: $5\{0,10\}$

Median Neer score: iii versus i

3 months: $7.5(0,15)$;

6 months: $4 \quad(-2,11)$

Success rates after 4 weeks (i) 12 (ii) 14

Success rates after 8 weeks (i) 13 (ii) 17

Success rates: 4 weeks: $-8 \%(-36,20)$

8 weeks: $-16 \%(-43,11)$

Improvement of ROM in al! directions. No significant differences between groups for pain and ROM.

Only graphical data presentation

No significant differences for improvement of pain, abduction and flexion.

Only graphical data presentation

No significant differences:

Pain ( $1-5$ scale, $\bar{x}_{ \pm}$sd $) \quad 4$ weeks (i) $2.5 \pm 0.7$ (ii) $2.4 \pm 0.9$

Pain (4-20 scale, $x \pm s d$ ) 4 months (i) $13 \pm 5$ (ii) $13 \pm 4$;

ADL $(2-10$ scale)

ADL (3-14 scale)

12 months (i) $13 \pm 5$ (ii) $13 \pm 4$

4 weeks (i) $4.2 \pm 1.3$ (ii) $4.4 \pm 1.4$

4 months (i) $6.9 \pm 2.4$ (ii) $7.4 \pm 2.0$;

12 months (i) $7.0 \pm 2.4$ (ii) $7.3 \pm 2.3$

Abduction $(\bar{x} \pm s d)$
No improvement scores, only

absolute values 
Table 3 (continued)

\begin{tabular}{|c|c|c|}
\hline First author ${ }^{\text {nt. }}$ & $\begin{array}{l}\text { Diagnosis } \\
\text { Symptom duration }\end{array}$ & $\begin{array}{l}\text { Interventions } \\
\text { (number of randomized patients) }\end{array}$ \\
\hline Vecchio ${ }^{10}$ & $\begin{array}{l}\text { Rotator cuff tendinitis } \\
\text { Not specified }\end{array}$ & $\begin{array}{l}\text { i Laser (Ga-AS-AL) } 830 \mathrm{nM}, 30 \mathrm{MW}, 3 \mathrm{~J} / \mathrm{cm}^{2} \text { (19) } \\
\text { ii Placebo laser (Ga-AS-AL) } 830 \mathrm{nM}, 30 \mathrm{MW}, 3 \mathrm{~J} / \mathrm{cm}^{2}(16) \\
\text { - Both groups } 8 \text { weeks, } 2 \text { sessions of } 10 \text { minutes per week }\end{array}$ \\
\hline Bulgen" & $\begin{array}{l}\text { Frozen shoulder } \\
>1 \text { month }\end{array}$ & $\begin{array}{l}\text { i Intra-articular plus intrabursal methyl-prednisolone } 20 \text { mg and } \\
\text { lignocaine; } 3 \text { in } 1 \text { week ( } 11 \text { ) } \\
\text { ii Maitland mobilisations; } 3 \text { sessions per week, } 6 \text { weeks (11) } \\
\text { iii Ice packs plus proprioceptvie neuromuscular faciliation; } 3 \text { sessions } \\
\text { per week, } 6 \text { weeks (12) } \\
\text { iv No intervention (8) } \\
\text { - All groups: analgesics, diazepam and pendular exercises, } \\
\text { daily: } 3 \text { minutes per hour }\end{array}$ \\
\hline England ${ }^{32}$ & $\begin{array}{l}\text { Supraspinatus or bicipital } \\
\text { tendonitis } \\
\text { Not specified }\end{array}$ & $\begin{array}{l}\text { i Laser, infrared } 904 \mathrm{nM}, 3 \mathrm{~mW}, 5 \text { minutes, } 3 \text { times per week, } 2 \\
\text { weeks (10) } \\
\text { ii Placebo laser, } 5 \text { minutes, } 3 \text { times per week, } 2 \text { weeks (10) } \\
\text { ii Naproxen sodium, } 550 \text { mg tablets, twice daily, } 2 \text { weeks (10) }\end{array}$ \\
\hline Gudmundsen 3,34 & $\begin{array}{l}\text { Rotator cuff tendinitis } \\
\leqslant 6 \text { months }\end{array}$ & $\begin{array}{l}\text { i Laser (Ga-As), pulsed } 904 \mathrm{nM}, 7,2 \mathrm{~J} / \mathrm{cm}^{2}(47) \\
\text { ii Placebo laser (He-Ne), continuous } 632 \mathrm{nM}, 2,4 \mathrm{~J} / \mathrm{cm}^{2}(44) \\
\text { - Both groups: } 8 \text { sessions of } 8 \text { minutes }\end{array}$ \\
\hline Knüsel" & $\begin{array}{l}\text { Levator scapulae } \\
\text { syndrome } \\
\text { Not specified }\end{array}$ & $\begin{array}{l}\text { i Electrotherapy, constant current TENS, } 60 \mathrm{~Hz}(30) \\
\text { ii Electrotherapy, constant voltage Dynatronic, } 100 \mathrm{~Hz}(30) \\
\text { - Both groups: } 12 \text { sessions, } 3 \text { weeks }\end{array}$ \\
\hline Thomas ${ }^{16}$ & $\begin{array}{l}\text { Frozen shoulder } \\
\geq 2 \text { months }\end{array}$ & $\begin{array}{l}\text { i Manipulation: forced abduction to } 90^{\circ} \text { with full internal and } \\
\text { external rotation (15) } \\
\text { ii No manipulation (15) } \\
\text { - Both groups: started with subacromial injection } 50 \mathrm{mg} \\
\text { hydrocortisone acetate and } 20 \mathrm{mg} \text { intravenous valium }\end{array}$ \\
\hline Biswas ${ }^{37}$ & $\begin{array}{l}\text { Periarthritis } \\
\text { Humeroscapularis } \\
\text { Not specified }\end{array}$ & $\begin{array}{l}\text { i. Hydrocortisone injections }(18+1) \\
\text { ii Short-wave diathermia }(17+7) \\
\text { iii Aspirine } 700 \mathrm{mg} 3 \text { times daily }(12+?) \\
\text { - All groups: non painful active exercises and passive } \\
\text { mobilisation in all directions } \\
\text { - } 120 \text { Patients randomized }\end{array}$ \\
\hline Delacerda ${ }^{30}$ & $\begin{array}{l}\text { Shoulder girdle } \\
\text { myofascial syndrome }\end{array}$ & $\begin{array}{l}\text { i Analgesics and muscle relaxants, } 10 \text { days (7) } \\
\text { ii Ultrasound } 4 \text { minutes, } 1.25-1.5 \mathrm{Watt} / \mathrm{cm}^{2} \text { and } 20 \text { minutes } \\
\text { thermotherapy. } \\
\text { hydrocollator packs, } 1 \text { time daily, } 10 \text { days (8) } \\
\text { iii lontophorese: } 4 \% \text { dexamethasone sodium phosphate and } 4 \% \\
\text { lidocaine, } 5 \mathrm{~mA}, 15 \text { minutes daily, } 10 \text { days (8) }\end{array}$ \\
\hline Knorre" & $\begin{array}{l}\text { Rheumatoid conditions } \\
>6 \text { months }\end{array}$ & $\begin{array}{l}\text { i } 1 \times 40 \text { mg Intra-articular triamcinolone (30) } \\
\text { ii Ultrasound therapy (30) } \\
\text { ii Cryotherapy: icepacks (30) }\end{array}$ \\
\hline Lee & $\begin{array}{l}\text { Periarthritis } \\
\text { Humeroscapularis } \\
\text { Not specified }\end{array}$ & $\begin{array}{l}\text { i Hydrocortisone intra-articular } 1 \times 25 \text { mg plus exercise therapy (15) } \\
\text { ii Hydrocortisone } 1 \times 25 \text { mg in biceps tendon sheath plus exercise } \\
\text { therapy (18) } \\
\text { iii Infra-red thermotherapy plus exercise therapy (17) } \\
\text { iv Analgesics only (15) }\end{array}$ \\
\hline
\end{tabular}


Diflerences between groups

(95\% confidence interval)

Improvement for pain on movement:

4 weeks $62.7 \pm 0.8$ (ii) $1.2 \pm 0.9 ; 8$ weeks (i) $3.6 \pm 1.0$ (ii) $1.8+1.2$ Improvement for functional status:

4 weeks (i) $2.9 \pm 0.6$ (ii) $2.0 \pm 0.8 ; 4$ weeks (i) $3.6 \pm 0.9$ (ii) $2.9 \pm 0.7$

Improvement of ROM in all directions. Pain and ROM improvement: no significant differences.

Improvement scores $(0-10 \mathrm{~cm}$ scale $)$ at 2 weeks:

ivs ii: movement 2 ; pain 2.5 ; stiffiness 1 ; function 1.5 .

ivs ii: pain 2; differences for movement, stiffness and function not significant (no data)

iii vs ii: movement 1.3, function 1; differences for stiffness and pain not significant ino data)

Success rates (number of patients much better or free of symptoms): (i) 42 (ii) 18 .

Success rates 3 weeks (number of patients with goodvery good result): (i) 19 (iii) 21

Pain improvement (0-100 scale, $\bar{x}) 3$ weeks: 40 (i) 44 (ii)

Success rates 3 months ( $\%$ patients substantially improved): (i) $80 \%$ (ii) $47 \%$ Number of patients $290^{\circ}$ abduction improvement: 1 month (i) 2 (ii) 0 ; 3 months (i) 6 (ii) 2

Number of patients without night pain: 11 month (i) 1 (ii) $0 ; 3$ months (i) 4 (ii) 2 Number of patients without disability: 1 month (i) 2 (ii) $0 ; 3$ months (i) 7 (ii) 2

Succes rates: symptom duration $<3$ months after baseline (based on 47 out of 120 included patients) (i) $50 \%$ (ii) $47 \%$ (iii) $58 \%$

Success rates (number of patients with painless full ROM abduction): (i) 4 (ii) 6 (iii) 8

Success rates: perceived benefit 'very good' at 2 weeks

(i) $47 \%$ (ii) $50 \%$ (iii) $40 \%$; at 12 weeks (i) $40 \%$ (ii) $50 \%$ (iii) $37 \%$

Only graphical data presentation of pain: group i significantly better after. 12 weeks

ROM improvement significantly less in group iv No significant differences for pain and $\mathrm{ADL}$
Pain on movement (mean),

at 8 weeks: $1.8(1.1,2.5)$

Functional status (mean)

at 8 weeks: $0.7(0.0,1.4)$

Only graphical data presentation

Pain improvement (median):

i versus ii: $2.5(2,3)$

i versus iii: $2(1.0,3.5)$

Success rates:

$48 \%(31,65)$

Success rates:

$73,(-15,29)$

Success rates: $33 \%(1,65)$

> $90^{\circ}$ abduction: $27 \%(-3,57)$

Number of patients after randomization unclear

Success rates:

ii versus i: $18 \%(-29,65)$

iii versus i: $43 \%(6,80)$

iii versus ii: $25 \%(-5,55)$

Success rates at 2 weeks:

ii versus i: $3 \%(-22,28)$

ii versus iii: $10 \%(-15,35)$

Only graphical data presentation 
Efficacy research on physiotherapy for shoulder disorders appears to be very heterogeneous with respect to the compared treatments, the selection of study populations and the assessment of outcome. For instance, trials on the same modality (e.g. ultrasoundtherapy or low-level-lasertherapy) differ markedly with respect to [1] the way in which these therapies were administered, e.g. intensity, duration and frequency of administration, [2] type of control group, e.g. placebo, no or alternative treatment, [3] exclusion criteria, e.g. regarding specific soft-tissue disorders or symptom duration at baseline, and [4] follow-up measurements, e.g. timing of outcome assessment and choice of outcome measures. In addition, although sufficient duration of follow-up is important in the evaluation of the efficacy of physiotherapy for shoulder disorders, only 4 trials reported follow-up assessments at 2 months after randomization or later.

\section{Treatment efficacy}

Deficiencies in the data presentation frequently hampered calculation of $95 \%$ confidence intervals. Where confidence intervals could be calculated they proved to be wide and included zero. This also holds for trials with generally more acceptable methods ${ }^{19,23,26}$. The type of control treatment was not related to the study results. Few of the assessed trials favoured the efficacy of physiotherapy. Considering the large number of small negative trials, statistical pooling of the results of trials with acceptable methods would have been useful. However, pooling was impeded by the heterogeneity of trials on the interventions, the poor quality of methods and data presentation.

\section{Conclusion}

Given the generally higher validity of placebo-controlled trials on ultrasoundtherapy and their outcomes it does not appear that this modality is efficacious for shoulder disorders. One placebo-controlled trial with generally more valid methods showed that PEMF was efficacious. All the other trials that report significant results are small and have unsatisfactory trial methods. Therefore, there is insufficient evidence to draw conclusions on the efficacy of low-level-lasertherapy, thermotherapy, coldtherapy, electrotherapy, exercise therapy and mobilisations. Future trials should study whether these physiotherapy modalities for shoulder disorders are superior to a wait-and-see policy, steroid injections, analgesics or anti-inflammatory drugs. This should be particularly interesting for exercise therapy and mobilisations, which despite their frequent use for shoulder disorders rarely have been subjected to scientific scrutiny in randomized clinical trials.

Prevalent flaws, such as many withdrawals, many missing data and a lack of blinding during treatment and outcome assessment, should be avoided in future trials.

Furthermore, standards of reporting trials should prevent confusion about the validity of trial methods and ensure adequate data analysis and presentation of pertinent data.

\section{References}

1 Croft P. Soft-tissue rheumatism. in: Silman A), Hochberg MC (Eds). Epidemiology of the rheumatic diseases. Oxford: Oxford University Press; 1993: 375-421.

2 Windt DAWM van der, Koes BW, Jong BA de, Bouter LM. Shoulder disorders in general practice: incidence, patient characteristics, and management. Annals of Rheumatic Diseases 1995; 54: $959-64$. 
3 Lamberts $\mathrm{H}$, Brouwer H], Mohrs I. Reason for encounter, episode- and process-oriented standard output from Transition project. Part I. Amsterdam: Department of General Practiceffamily Medicine, University of Amsterdam; 1991.

4 Peters D, Davies P, Pietroni P. Musculoskeletal clinic in general practice: trial of 1 years referrals. British Journal of Ceneral Practice 1994; 44: $25-9$.

5 Grundemeijer HCLM, Brouwer HJ. De betekenis van fysiotherapie bij aandoeningen aan het bewegingsapparaat. Huisarts \& Wetenschap 1988; [Suppl 12]: 44-59.

6 Windt DAWM van der, Heijden GIMG van der, Scholten RJPM, Koes BW, Bouter LM. The efficacy of non-steroidal anti-inflammatory drugs for shoulder complaints. Journal of Clinical Epidemiology 1995; 48: 691-704 (Chapter 4).

7 Heijden GJMG van der, Windt DAWM van der, Kleijnen I, Koes BW, Bouter LM, Knipschild PG. Steroid injections for shoulder disorders. British lournal of Ceneral Practice 1996; 46: $309-16$ (Chapter 3).

8 Nitz AJ. Physical therapy management of the shoulder. Physical Therapy 1986; 66: 1912-9.

9 Rey B, Gerber NI. Shoulder pain trials. In: Schlapbach P, Gerber NJ (Eds). Rheumatology Physiotherapy: controlled trials and facts. Basel: Karger; 1991:91-8.

10 Dekker I, Baar M van, Curfs ChrE, Kerssens IJ. Diagnosis and treatment in physiotherapy: an investigation of their relationship. Physical Therapy 1993; 73: $371-6$.

11 Gentle PH, Herlihy PJ, Roxburgh IO. Controlled trial of open-access physiotherapy service. British Journal of Ceneral Practice 1994; 34: 371-6.

12 Miendema HS. Reuma-onderzoek meerdere echelons (ROME): basisrapport. Leiden: Nederlands. Instituut voor Praeventieve Gezondheidszorg TNO; 1994.

13 Dickersin K, Scherer R, Lefebvre C. Identifying relevant studies for systematic reviews. British Medical Journal 1994; 309: 1286-91.

14 Moher D, Jadad AJ. Nichol G, Penman M, Tugwell P, Walh S. Assessing the quality of randomized controlled trial: an annotated bibliography of scales and checklists. Controlled Clinical Trials 1995. 16: $62-73$.

15 Cho MK, Bero LA. Instruments for assessing the quality of drug studies published in medical literature. Journal of the American Medical Association 1994; $272: 101-4$.

16 The standards of reporting trials group. A proposal for structured reporting of randomized controlled trials Journal of the American Medical Association 1994; 272: 1926-31.

17 Chalmers TC, Smith HIr, Blackburn B, et al. A method for assessing the quality of a randomized control trial. Controlled Clinical Trials 1981; $2: 31-49$.

18 Eysenck HJ. Meta-analysis and its problems. British Medical Journal 1994; 309: 789-92.

19 Downing SD, Weinstein A. Ultrasound therapy of subacromial bursitis. A double blind trial. Physical Therapy 1986; 66: 194-9.

20 Binder A, Parr G, Hazleman B. Pulsed electromagnetic field therapy of persistent rotator cuff tendinitis. A double blind controlled assessment. Lancet 1984; i: 695-8.

21 Leclaire R, Bourgouin J. Electromagnetic treatment of shoulder periarthritis. A randomized controlled trial of the efficiency and tolerance of magnetotherapy. Archives of Physical Medicine and' Rehabilitation 1991; 72 : 284-7.

22 Saunders L. The efficacy of low-level laser therapy in supraspinatus tendinitis. Clinical Rehabilitation 1995; 9: 126-34.

23 Berry H. Fernandes L, Bloom B, et al. Clinical trial comparing acupuncture, physiotherapy, injection and oral anti-inflammatory therapy in shoulder-cuff lesions. Current Medical Research Opinion 1980; 7: 121-6.

24 Fernandes L, Berry H, Clark RJ, et al. Clinical trial comparing acupuncture, physiotherapy, injection and oral anti-inflammatory therapy in shoulder-cuff lesions. Lancet 1980; i: 208-9.

25 Brox II, Staff PH, Ljunggren AE, Brevik II. Arthroscopic surgery compared with supervised exercises in patients with rotator cuff disease (stage II impingement syndrome). British Medical fournal 1993; 307: 899-903.

26 Chard MD, Hazleman BL, Devereux MD. Controlled trial to investigate dose-response patterns to portable pulsed electromagnetic fields in the treatment of rotator cuff tendinitis. A review trial. Journal of Orthopaedic Rheumatology: 1988; 1: 33-40.

27 Dacre JE, Beeney N, Scott DL. Injections and physiotherapy for the painful stiff shoulder. Annals of Rheumatic Diseases 1989; 48: 322-5. 
28 Herrera-Lasso I, Mobarak L, Fernández-Domingeuz L, Cardiel MH, Alarcón-Segovia D. Comparative effectiveness of packages of treatment including ultrasound or transcutaneous electrical nerve stimulation in painful shoulder syndrome. Physiotherapy 1993; 79: 251-3.

29 Nykanen M. Pulsed ultrasound treatment of the painful shoulder. A randomized, double-blind, placebo-controlled trial. Scandinavian Journal of Rehabilitation Medicine 1995; 27: 105-8.

30 Vecchio P, Cave C, King V, Adebajo AO, Smith M, Hazleman BL. A double-blind trial of the effectiveness of low-level laser treatment of rotator-cuff tendonitis. British Journal of Rheumatology 1993; 32: 740-2.

31 Bulgen DY, Binder Al, Hazleman BL, Dutton J, Roberts S. Frozen shoulder: prospective clinical trial with an evaluation of three treatment regimens. Annals of Rheumatic Diseases 1984; 43: 353-60.

32 England S, Farrel AJ, Coppock JS, et al. Low power laser therapy of shoulder tendonitis. Scandinavian Journal of Rheumatology 1989; 18: 427-31.

33 Gudmundsen J., Vikne J. Lasertreatment for epicondilitis humeri and rotatorcuffsyndrome. Nordisk Tidsskrift for Idrettsmedicine 1987; $2: 6-15$.

34 Hartvig P, Vikne J, Gudmundsen J. Does lasertreatment work for tendinitis. Tidsskrift for Norske Laegeforning 1989; 109: 2184.

35 Knüsel O. Die transcutane elektrische Nervenstimulation beim Weichteilrheumatismus - Eine kontrollierte untersucherblinde Studie an 60 Patienten mit Levator-Scapulae-Syndrom. Zeitschrift fur Physikalische Medizin und Balneologie und Medische Klimatologie 1984; 13: 337-9.

36 Thomas D, Williams RA, Smith DS. The frozen shoulder: a review of manipulative treatment. Rheumatology and Rehabililitation 1980; 19: 173-9.

37 Biswas AK, Sur BN, Gupta CR. Treatment of periarthritis shoulder. Journal of the Indian Medical Association 1979; 72: 276-7.

38 Delacerda FG. A comparative trial of three methods of treatment for shoulder girdle myofascial syndrome. Journal of Orthopaedic and Sports Physical Therapy 1982; 4: 51-4.

39 Knorre B, Keitel W. Vergleichende Therapiestudie: Ultraschall, Kryotherapie und Intraartikuläre Kortisonoide bei Veränderungen des Schultergelenkes aus entzündlicher Ursach. Zeitschrift fur Physiotherapie 1990; 42: 221-5.

40 Lee M, Lee M, Haq AMMM, Longton EB, Wright V. Periarthritis of the shoulder. Trial of treatments investigated by multivariate analysis. Annals of Rheumatic Diseases $1974 ; 33: 116-9$.

41 Lee M, Haq AMMM, Wright V, Longton EB. Periarthritis of the shoulder: a controlled trial of physiotherapy. Physiotherapy 1973; 59: 312-5.

42 Schulz KF, Chalmers I, Hayes RJ, Altman DG. Emperical evidence of bias. Dimensions of methodological quality associated with estimates of treatment effects in controlled trials.Journal of the American Medical Association 1995; 273: 408-12.

43 Altman DG, Doré CJ. Randomisation and baseline comparisons in clinical trials. Lancet 1990; 335: 149-53.

44 Ederer $\mathrm{F}$. Patient bias, investigator bias and the double-masked procedures in clinical trials. American Journal of Medicine 1975; 58: 295-9. 


\section{Chapter 3}

\section{Steroid injections for shoulder disorders} A Systematic review of randomized clinical trials

GJMG van der Heijden', DAWM van der Windt', J Kleijnen', BW Koes², LM Bouter², PG Knipschild'

1 Department of Epidemiology, University of Limburg, Maastricht, the Netherlands.

2 Institute for Research in Extramural Medicine, Vrije Universiteit, Amsterdam, the Netherlands.

3 Department of Clinical Epidemiology and Biostatistics, Academic Medical Center, Amsterdam, the Netherlands. 


\section{Abstract}

Background Patients with shoulder disorders are believed to benefit considerably from steroid injections. However, the controversy on their efficacy persists.

Purpose The study was designed to assess the efficacy of steroid injections for shoulder disorders.

Method A systematic computerized literature search in MEDLINE (Index Medicus 1/1966-11/1995) and EMBASE (Excerpta Medica 1/1984-11/1995) was conducted, supplemented with citation tracking of all relevant publications. Studies publișhed before November 1995 were selected if steroid injections were randomly allocated to patients with shoulder disorders and when clinically relevant outcome measures were reported. Because the validity of study outcomes depends heavily on the strength of methodological quality, the methods were assessed systematically by two 'blinded' independent reviewers. This resulted in a method score (maximum 100 points) that was based on four categories: study population, interventions, measurement of effect and data presentation and analysis. Confidence intervals for the differences between groups in success rates were calculated in order to summarize the efficacy of steroid injections.

Results Only three out of the 16 studies scored more than 50 points, indicating a generally poor quality of methods. Most studies reported small sample sizes. The flaws most often found were incomparability of co-interventions and poor blinding of therapist. The methods assessment was frequently hampered by incomplete information about randomisation, prognostic comparability, compliance, outcome measures included, blinding of patients and blinding of outcome measurement.

Conclusions The evidence in favour of the efficacy of steroid injections for shoulder disorders is scarce. The methods of most studies appear to be of poor quality. The few studies that appear to be credible do not provide conclusive evidence about which patients at what time in the course of shoulder disorders benefit most from steroid injections. 


\section{Introduction}

\section{Shoulder disorders}

About $10 \%$ of the population suffer from one or more episodes of shoulder disorders in the course of their life'. Pain and stiffness in the deltoid region, which cause limitations of daily activities, are the commonest complaints of these patients. Pain is elicited or aggravated by movement and usually restricts the range of movement. Pain when lying on the impaired shoulder results in problems with sleeping ${ }^{1.3}$. Most often these shoulder complaints are caused by periarticular soft tissue impairment ${ }^{3,4}$. A minority of all complaints originate from neurological or generalized musculoskeletal conditions, neoplasms or referred pain from the neck or from internal organs ${ }^{4}$. Five per cent of all consultations in general practice relate to shoulder disorders ${ }^{1,5,6}$. Out of all newly presented episodes, $23 \%$ resolve within one month, $51 \%$ within six months, and $59 \%$ within a year [Van der Windt et al, submitted for publication].

\section{Injection}

Twelve per cent of all patient-physician contacts for shoulder disorders involve local steroid injections?. Steroid injections are commonly used in combination with analgesics, NSAIDS, rest, physical therapy or exercises. In the Netherlands, injection therapy is given in approximately $20 \%$ of all episodes of shoulder disorders ${ }^{\circ}$. Patients with shoulder disorders are believed to benefit considerably from steroid injections? However, controversy over their efficacy persists. Anti-inflammatory effects of steroid injections are to relieve pain, improve or maintain joint function and diminish disability ${ }^{7,10}$.

The postulated mechanisms for the effects of steroid injections have not been supported by sufficient clinical empirical evidence. Steroid injections should inhibit the synthesis of inflammation-mediating substances (e.g. prostaglandins), stabilize mast cells and inhibit cellular activity; pain-reducing effects have been reported ${ }^{12}$. In addition, a decrease of tissue calcification and iron deposition has been reported, logether with increased vascularization, permeability of the synovial membrane and viscosity of synovial fluid ${ }^{7,10-12}$. Regenerating effects on damaged articular cartilage ${ }^{13}$ or slowing of the progression of cartilage attrition ${ }^{7,12}$ have not been demonstrated.

Adverse clinical effects of steroid injections have not been systematically investigated. Dermal atrophy, bacterial arthritis, hemarthrosis and thrombophlebitis are attributed to technical artefacts ${ }^{7,12,14}$, while urticaria and facial flushing are ascribed to suspension preservatives ${ }^{7}$. Charcot arthropathy is reported in about $1 \%$ of all injections and systemic post-injection flare (i.e. acute steroid synovitis with fever), paresis and vertigo in about $2 \%$ of all injections. Ligamentous laxity, joint instability and calcification or rupture of tendons and joint capsules, caused by collagen necrosis and increased soft tissue degeneration, are associated with depot injections of long-acting steroids and repeated injections of the same joint ${ }^{12,13}$. Therefore, repeated injections in the same joint within a short period of time should be avoided. Zuckerman recommended injecting the same joint only once in every six weeks, with a maximum of three times a year $^{13}$.

In this systematic review we summarize the results of randomized clinical trials (RCTS), on the efficacy of steroid injections for shoulder disorders. While RCTs offer the best 
possibility for a valid evaluation of treatment efficacy ${ }^{15-17}$, many aspects of design, conduct and analysis require careful handling for conclusions to be valid. In order to minimize bias we assessed the methods of available trials according to generally accepted methodological requirements for intervention research ${ }^{15-20}$.

\section{Methods}

We identified relevant publications by means of computerized searches and citation tracking. The search strategy included MEDLINE (Index Medicus 1/1966-11/1995) and EMBASE (Excerpta Medica 1/1984-11/1995). Potentially relevant papers were harvested from a total of 105 records in Index Medicus and a total of 101 records in Excerpta Medica. In addition, relevant citations of available papers were traced.

For this systematic review, we included studies that met the following conditions:

- Patients had shoulder pain at the moment of inclusion;

- At least one of the treatment regimens included steroid injections;

- Treatment regimens were allocated by a random procedure;

- Clinically relevant outcome measures were included (e.g. treatment success, pain, mobility or functional status);

- Results were published as a full report before November 1995.

G)MGH selected the study reports. In order to minimize potential reviewer bias, he blinded papers for author(s), journal identification, results and conclusions. BWK and JK independently assessed the blinded reports with respect to the quality of study methods. Then, still blinded, they resolved disagreement in a consensus discussion. Our assessment of methods was based on four categories (Table 1): (1) study population, (2) interventions, (3) measurement of effect and (4) data presentation. We divided these four categories into 15 different criteria ( $A-O)$.

Table 1. Criteria list for a methods assessment of randomized clinical trials of steroid injections for shoulder disorders.

\section{Study population}

A Selection

B Adequate randomisation procedure

C Study size

D Comparability of relevant prognosis at baseline

E Drop-outs described for each treatment group separately

F Loss-to-follow-up described for each treatment group separately

\section{Interventions}

G Description of treatment(s)

H Co-interventions avoided (or comparable)

Measurement of effect

I Patients blinded

J Therapist blinded

K Observer blinded

L Relevant outcome measures

M Blinded outcome measurement

$\mathrm{N}$ Duration of follow-up

Analysis and results

O Adequate analysis and presentation 
A Two points if target population is defined by means of explicit selection criteria; 2 points if selection is restricted to a population homogenous for relevant prognostic markers (e.g. duration of complaints, painful arc, pain at night, radiating pain, prior treatment).

B Five points if number generation and concealed allocation is used for treatment allocation

C Five points if smallest group is bigger than 25 patients immediately after randomisation; 10 points if more than 50 patients; 15 points if more than 75 patients.

D Two points each if study groups are comparable at baseline for (1) duration of the complaint; (2) baseline scores for outcome measures; (3) age; (4) number of relapses; (5) radiating pain.

E Six points if no patients withdrew after randomisation (drop-outs). 2 points if the number of drop-outs. is presented for each study group separately; 4 additional points if reasons for withdrawal are specified for each study group separately.

F Loss-to-follow-up: ( 1 minus [the number of patients at the main moment of effect measurement for the main outcome measure (if not stated according to the reviewers), divided by all randomized patients]). times $100 \%$.

One point if loss-to-follow-up is less than $20 \%$ in each group; 4 points if it is less than $10 \%$ in each group.

G One point for every adequately described feature of injection and reference treatment: treatment type; steroid type or modality; needle placement or application technique; intensity or solution; treatment number and frequency; compliance. 2 additional points if both placebo and pragmatic control group are included.

$H$ One point if co-interventions are comparable between the groups; 3 points if co-interventions are standardized or avoided in study design.

I Two points if blinding of patients was attempted or only naive patients were enrolled, 2 additional points if blinding for treatment contrast proved successful.

I Two points if blinding of therapists was attempted, 2 additional points if blinding for treatment contrast proved successful.

$K$ Two points if blinding of observer was attempted, 2 additional points if blinding for treatment contrast proved successful.

L. Two points for every assessed outcome measure: (1) pain; (2) success rate or proportion for global measure of improvement or recovery; (3) functional status (activities of daily living); (4) mobility (range of motion); (5) medical consumption (e.g. medication, surgery).

$\mathrm{M}$ One point for every blindly assessed outcome measure (see L)

$N$ Two points if outcomes were assessed immediately after the last treatment; 2 additional points if this was done 3 months or longer after randomisation.

O Five points if data for most important outcome measure on the most important moment of effect measurement are adequately presented (frequencies or mean \& standard deviation or centifes). 3 additional points for an adequate analysis, with adjustment for drop-outs, loss-to-follow-up, missing, values, non-compliance and co-interventions if appropriate.

Similar criteria are used in peer review systems of journals $\mathrm{s}^{21-24}$ and have been used in other systematic reviews ${ }^{25-33}$. For this review, we adjusted the criteria for application to steroid injections, and shoulder disorders.

For each of the 15 criteria (A-O), we assigned a weight relative to its putative importance for validity, precision or clinical relevance. The information from the papers about each criterion was analysed. If sufficient information was reported the likelihood of potential bias was evaluated. If bias was unlikely, the criterion was rated as satisfied. For each study, we calculated a method score by summing the weights for all criteria satisfied. The studies were subsequently ranked according to this sumscore. The theoretical maximum sumscore of 100 points could be obtained when the design, conduct and results of a study were adequately reported and bias was considered to be unlikely in all criteria.

Incomplete information about study methods may hamper the assessment of the quality of methods. The sumscore of the weights for insufficiently reported criteria indicates the amount and magnitude of this incomplete information. 
Success-rates were determined for each intervention group, by dividing the number of documented successes at the end of the intervention period by the number of patients randomly allocated to the intervention. These calculations were made according to the intention-to-treat principle; drop-outs and loss-to-follow-up were assumed to represent failures. The differences between the success rates, and the corresponding $95 \%$ confidence intervals $(95 \% \mathrm{Cls}$ ) were calculated for all relevant comparisons.

\section{Results}

\section{Methodological quality}

We identified 23 papers reporting studies that met our five conditions for inclusion in the blinded method assessment. We excluded five studies: one ${ }^{34}$ because it was only published as an abstract; one ${ }^{35}$ because the results of patients who received injection could not be identified separately; and three studies ${ }^{36-38}$ without a contrast for injection between intervention groups. The quality of methods of studies that are reported in the remaining 16 papers and 2 theses ${ }^{39.56}$ was assessed.

Initial disagreement between the two independent reviewers was found mostly to result from reading errors. All discrepancies were easily resolved during a consensus discussion, the methods scores are based on the reviewers full agreement. For two studies that have been reported more than once ${ }^{48,49 ; 55,56}$, we calculated the method scores from the combined information. Hence, the results of 16 RCTS are presented. Table 2 presents, for each study, the points assigned to each criterion and the method scere:

Table 2. Results of the methods assessment of the randomized clinical trials of steroid injections for shoulder disorders

\begin{tabular}{|c|c|c|c|c|c|c|c|c|c|c|c|c|c|c|c|c|c|}
\hline First author ${ }^{\mathrm{nd}}$ & $\begin{array}{l}\text { A } \\
4\end{array}$ & $\begin{array}{l}8 \\
5\end{array}$ & $\begin{array}{l}\mathrm{C} \\
15\end{array}$ & $\begin{array}{l}D \\
10\end{array}$ & $\begin{array}{l}E \\
6\end{array}$ & $\begin{array}{l}F \\
5\end{array}$ & $\begin{array}{l}\mathrm{G} \\
12\end{array}$ & $\begin{array}{l}\mathrm{H} \\
4\end{array}$ & $\begin{array}{l}1 \\
4\end{array}$ & $\frac{1}{4}$ & $\begin{array}{l}K \\
4\end{array}$ & $\begin{array}{l}\mathrm{L} \\
10\end{array}$ & $\begin{array}{l}M \\
5\end{array}$ & $\begin{array}{l}N \\
4\end{array}$ & $\begin{array}{l}0 \\
8\end{array}$ & $\begin{array}{l}\text { Method } \\
\text { score }\end{array}$ & $\begin{array}{l}\text { Information } \\
\text { incomplete }\end{array}$ \\
\hline Petri ${ }^{39}$ & 2 & 5 & 5 & 2 & - & 5 & 12 & $=$ & 2 & 2 & 2 & 8 & 4 & 2 & 8 & 59 & 26 \\
\hline Adebajo ${ }^{* 0}$ & 4 & - & - & 6 & 6 & 5 & 12 & . & 2 & - & 2 & 6 & 3 & 2 & 8 & 56 & 16 \\
\hline Vecchio"1 & 4 & - & 5 & 6 & 6 & 5 & 10 & 3 & 2 & - & - & 6 & - & 2 & 5 & 54 & 36 \\
\hline De Jong ${ }^{42}$ & 2 & 5 & - & 6 & 6 & 1 & 8 & 3 & 2 & 2 & 2 & 6 & 2 & 2 & - & 47 & 31 \\
\hline Richardson ${ }^{43}$ & 2 & - & 5 & 6 & 2 & 1 & 8 & 3 & 2 & $=$ & 2 & 4 & 2 & 2 & 5 & 44 & 37 \\
\hline White ${ }^{4}$ & 4 & - & - & 8 & 2 & - & 8 & $\cdot$ & 2 & * & 2 & 6 & 2 & 2. & 5 & 41 & 45 \\
\hline Withrington ${ }^{45}$ & - & - & - & 4 & 6 & 5 & 8 & 3 & 2 & - & 2 & 4 & 2 & 2 & 3 & 41 & 34 \\
\hline Jonquière ${ }^{46}$ & 4 & 5 & 10 & 4 & 2 & - & 8 & - & - & $=$ & 2 & 6 & - & 4 & 5 & 40 & 44 \\
\hline Jacobs" & 2 & - & - & 4 & 6 & 1 & 8 & - & - & . & 2 & 6 & - & 4 & 5 & 38 & 35 \\
\hline Berry ${ }^{49}$ & 2 & - & - & 2 & 6 & 5 & 6 & - & - & - & 2 & 6 & 1 & 2 & 5 & 37 & 29 \\
\hline$R i z k^{50}$ & 4 & - & - & 6 & 2 & 1 & 8 & 3 & - & . & 2 & 4 & 1 & 4 & - & 35 & 40 \\
\hline Hollingworth" & 2 & - & 5 & 2 & - & $\cdot$ & 8 & - & 2 & $=$ & 2 & 2 & 1 & 2 & 5 & 31 & 53 \\
\hline Knorre" & - & - & 5 & 4 & - & - & 8 & - & - & - & - & 4 & - & 2. & 5 & 28 & 47 \\
\hline Dacres" & 4 & - & - & 4 & - & 1 & 2 & - & - & - & 2 & 4 & 1 & 4 & - & 22 & 49 \\
\hline Bulgen ${ }^{4}$ & 4 & - & - & $=$ & $=$ & - & 6 & - & - & - & 2 & 4 & - & 4 & $=$ & * 20 & 57 \\
\hline lee"s & 2 & - & - & $=$ & $=$ & - & 4 & - & - & - & - & 2 & - & 2 & - & 10 & 51 \\
\hline
\end{tabular}

The main features of the design of the sixteen RCTS and their results are given in Table 3. All studies scored less than 60 points. Only three studies ${ }^{3941}$ attained a method score of more than 50 points, indicating the overall poor methodological quality of most studies. 
In general, studies proved to be methodologically sound with respect to (A) patient selection, (E) reported drop-outs, $(\mathrm{G})$ intervention descriptions, and $(\mathrm{O})$ analysis and presentation of data. Nevertheless, the range of the method score is wide (average 37 points, range 10-59). The most prevalent flaws were in $(\mathrm{H})$ incomparability of cointerventions and $(0)$ poor blinding of therapist. In addition, most study sizes (C) were small.

The sumscore for insufficiently reported criteria varied widely (average 39 points, range 16-57). Methods assessment was often hampered by incomplete information about (B) the randomisation procedure, (D) prognostic comparability of study groups at baseline, (G) compliance with interventions, (L) outcome measures, and blinding (I) of patients, (K) of observer and (M) during effect measurement. In addition, reporting of long-term adverse effects was deficient.

\section{Efficacy of steroid injections}

Whereas reporting of data for treatment success and pain relief generally was informative enough to support the conclusions, several authors drew conclusions about additional outcome measures for which no data were presented. We used differences in proportions of treatment success in order to evaluate efficacy of steroid injections. Poor presentation of data impeded these calculations for five studies ${ }^{42,47.53 .55}$. In only one study ${ }^{50}$ did our intention-to-treat analysis result in slightly different success rates compared with the results reported in the original publication.

In Table 4, the 95\% confidence intervals are presented for comparisons between steroid injections and placebo interventions. The studies are ranked according to quality of methods. The two studies ${ }^{39,40}$ with the highest method scores reported a significantly higher success rate for steroid injection ( $95 \%$ Cls exclude zero), but in only one study ${ }^{40}$ did the lower limit of the $95 \%$. Cl exceed a difference in success rate of $20 \%$.

Table 5 shows the $95 \% \mathrm{Cls}$ for comparisons between steroid injections and competing treatment modalities (mainly physiotherapy or medication). In two of the three studies with method scores above 50 points ${ }^{39,40}$, the lower limit of the $95 \% \mathrm{Cl}$ exceeded a $10 \%$ difference in success rate in favour of steroid injection. Other studies reporting results in favour of steroid injection ${ }^{42,47,51}$ did not reach a method score of 50 points.

\section{Discussion}

Our search strategy in the medical literature identified 16 studies that met our inclusion criteria. It is not very likely that we have missed large RCTS by our rather extensive searches. Nevertheless, additional relevant studies might have remained unpublished or have been published in journals, that are difficult to retrieve.

Although the checklist used is not exhaustive, it represents a high standard for quality of methods. Therefore, the maximum score of 100 points is probably not easily reached. However, it is disappointing to find that the quality of methods. of the published RCTS is. so low. This indicates that serious bias was present in most of the available studies. In addition, incomplete information, about important features of design and conduct frequently hampered the assessment of the quality of methods. Incomplete information can indicate only poor reporting, but can also disguise additional flaws. Guidelines have been proposed to improve the reporting of RCTS ${ }^{57,58}$. It is hoped that better reporting of trials will also improve the informativeness of systematic reviews.. 
Table 3. Details of randomized clinical trials of steroid injections for shoulder disorders

\begin{tabular}{|c|c|c|c|}
\hline $\begin{array}{l}\text { First } \\
\text { authoret. }\end{array}$ & $\begin{array}{l}\text { Method } \\
\text { score }\end{array}$ & $\begin{array}{l}\text { Diagnostic group } \\
\text { symptom duration }\end{array}$ & $\begin{array}{l}\text { Steroid injections } \\
\text { (number of patients) }\end{array}$ \\
\hline Petri" & 59 & $\begin{array}{l}\text { Painful shoulder } \\
\leqslant 6 \text { months }\end{array}$ & $\begin{array}{l}\text { i } 1 \times 40 \mathrm{mg} \text { Intrabursal triamcinolone and lidocaine plus } \\
\text { placebo naproxen (25) } \\
\text { ii } 1 \times 40 \mathrm{mg} \text { Intrabursal triamcinolone and lidocaine plus } \\
\text { naproxen } 1000 \mathrm{mg} \text { daily (25) }\end{array}$ \\
\hline
\end{tabular}

\begin{tabular}{|c|c|c|c|c|}
\hline Adebajo $^{* 0}$ & 56 & $\begin{array}{l}\text { Rotator cuff tendinitis } \\
\leq 6 \text { months. }\end{array}$ & $\mathrm{i}$ & $\begin{array}{l}1 \times 80 \mathrm{mg} \text { Subacromial triamcinolone hexacetonic } \\
\text { lignocaine plus placebo diclofenac }(20)\end{array}$ \\
\hline Vecchio"1 & 54 & $\begin{array}{l}\text { Rotator cuff tendinitis } \\
\leq 3 \text { months }\end{array}$ & $i$ & $\begin{array}{l}\text { 1x. } 40 \text { mg Subacromia! methylprednisolone plus } \\
\text { lignocaine (28) }\end{array}$ \\
\hline
\end{tabular}

\begin{tabular}{|c|c|c|c|c|}
\hline De fong ${ }^{42}$ & 47 & $\begin{array}{l}\text { Capsulitis } \\
\text { No restiction }\end{array}$ & i & $\begin{array}{l}3 \times .40 \mathrm{mg} \text { Intra-articular triamcinolone (25) } \\
3 \times 10 \mathrm{mg} \text { Intra-articular triamcinolone (32) }\end{array}$ \\
\hline Richardson" & 44 & $\begin{array}{l}\text { Painful shoulder } \\
>6 \text { months }\end{array}$ & i & $\begin{array}{l}2 \times \text { Intra-articular and intrabursal } 25 \mathrm{mg} \text { prednisolone } \\
\text { acetate plus distalgic ( } 54 \text { ) }\end{array}$ \\
\hline White ${ }^{44}$ & 41 & $\begin{array}{l}\text { Rotator cuff tendinitis } \\
\text { No restiction }\end{array}$ & $\mathrm{i}$ & $\begin{array}{l}\text { 1x } 40 \mathrm{mg} \text { Intrabursal triamcinolone acetoride plus } \\
\text { placebo indomethacin (20) }\end{array}$ \\
\hline
\end{tabular}

Withrington ${ }^{45} \quad 41 \quad$ Supraspinatus tendinitis $\leqslant 3$ months.

i 1x Suprașpinatus tendon 80 mg methylprednisolone and lignocaine (12)

$\begin{array}{lll}\text { Jonquière } & 40 & \begin{array}{l}\text { Painful shoulder } \\ >6 \text { months }\end{array} \\ \text { Jacobs } & \text { 38. } & \begin{array}{l}\text { Capsulitis } \\ \text { No restriction }\end{array} \\ \text { Berry } & 37 & \begin{array}{l}\text { Shoulder cuff lesion } \\ \text { No restriction }\end{array}\end{array}$

i Cyriax treatment: local triamcinolone, local
anaesthesia, physiotherapy (22)

i. $3 \times 40 \mathrm{mg}$ Ințra-ạrticular triamcinolone (15)

ii $3 \times 40 \mathrm{mg}$ Intra-articular triamcinolone plus distension (18)

i $1 \times 40 \mathrm{mg}$ Intra-articular methyl-prednisolone and lignocaine plus placebo tolmetin sodium (12)

ii $1 \times 40 \mathrm{mg}$ Intra-articular methyl-prednisolone and lignocaine plus tolmetin sodium. $1200 \mathrm{mg}$ daily (12). 


\section{Reference treatmentis) (number of patients) \\ iii Ix Intrabursal lidocaine plus placebo naproxen tablets $(25)$ \\ iv $1 \times$ intrabursal lidocaine plus naproxen $1000 \mathrm{mg}$ daily (25) \\ ii $1 \times$ Subacromial lignocaine plus diclofenac 150 mg daily (20) \\ iii $1 \times$ Subacromial lignocaine plus placebo diclofenac (20)}

ii $1 \times$ Subacromial lignocaine $(27)$

ii $2 x$ intra-articular and intrabursal saline plus distalgic (47)

ii Ix Intrabursal saline plus indomethacin $100 \mathrm{mg}$ daily (20)

ii $1 \times$ Supraspinatus tendon saline (13) Success rates

ii Local anaesthesia, physiotherapy (36)

ii Distension only (14)

iii Acupuncture (12)

iv Ultrasound therapy (12)

$\checkmark$ Placebo ultrasound therapy (12)

(iii) $42 \%$ (iv) $50 \%$ (v) $75 \%$ after 2 weeks (i) $58 \%$ (ii) $31 \%$ after 8 weeks (i) $42 \%$ (ii) $23 \%$ Improvement pain scores $(\mathrm{g})$ : after 2 weeks (i) 3.7 (ii) 1.8 after 8 weeks (i) 2.7 (ii) 1.2

Success rates after 2 weeks:

(i) 83 (ii $20 \%$ (iii) $4 \%$ (iv) 123

Success rates after 4 weeks:

(i) $28 \%$ (ii) $28 \%$ (iii) $20 \%$ (iv) $8 \%$

improved pain scores $(\mathrm{R} \geq \mathrm{s})$ after 4 weeks: (i) $2.04 \pm 0.31$ (ii) $1.95 \pm 0.35$

(iii) $1.76 \pm 0.31$ (iv) $1.00 \pm 0.32$

Success rates after 4 weeks:

(i) $70 \%$ (ii) $30 \%$ (iii) $0 \%$

Improvement pain scores $(8 \pm 2)$ after 4 weeks: $(0) 4.95+0.74$ (10) $3.60 \pm 0.67$ (iii) $1.35 \pm 0.74$

Success rates after 12 weeks: (i) $32 \%$ (i) $26 \%$ Improvement pain scores (median): after 2 weeks (i) 10 (ii) 7.5 after 4 weeks (i) 10 (ii) 8 after 12 weeks (i) 8 (ii) 8

Improvement pain scores: $(x+1)$ after I week: (i) 225 (ii) $7 \mathrm{x}$ after 3 weeks; (i) $40 \%$ (ii) $19 \%$ after 6 weeks: (i) $54 \%$ (ii) $31 \%$

Success rates:

after 2 weeks (i) $33 \%$ (ii) $20 \%$ after 6 weeks (i) $53 \%$ (ii) $46 \%$

Success rates after 6 weeks:

(i) $45 \%$ (ii) $50 \%$

Improvement pain scores $(x \pm 5)$ :

(i) $4.3 \pm 5.2$ (iii) $5.5 \pm 8.3$

Success rates after 16 weeks:

(i) $64 \%$ (ii) $72 \%$

Improvement of abduction $(x \pm 5)$ :

(i) $3.4 \pm 2.2$ (ii) $4.3 \pm 2.2$ (iii) $1.0 \pm 3.8$

Success rates after 4 weeks:

(i) $50 \%$ (ii) $42 \%$ Improvement pain scores $(x)$ : (i) 12 (ii) 10 (iii) 7 (iv) 7 (v) 30
Authors' conclusions?

Significant differences for success rate, paing. ROM, and functional status in favour of triamcinolone (it and ii)

Significant difference for success rate in favour of triamcinolone (i). Significant difference for pain ROM, functional status in favour of $i$ and $i$.

No significant differences for success rate, pain and ROM

Significant differences for ROM. pain, functional status, sleep disturbance in favour of highe dose triamcinolone (1)

No significant differences for success rate, ROM, and pain.

No significant differences for success rate, pain and ROM.

No significant differences for success rate, pain and ROM

No significant differences for success rate and number of sick leave days

Significant differences for ROM in favour of $i$ and ii: no signficant cant differences between $i$ and $i i$.

No significant differences for success rates, pain and ROM. 
Table 3. Continued

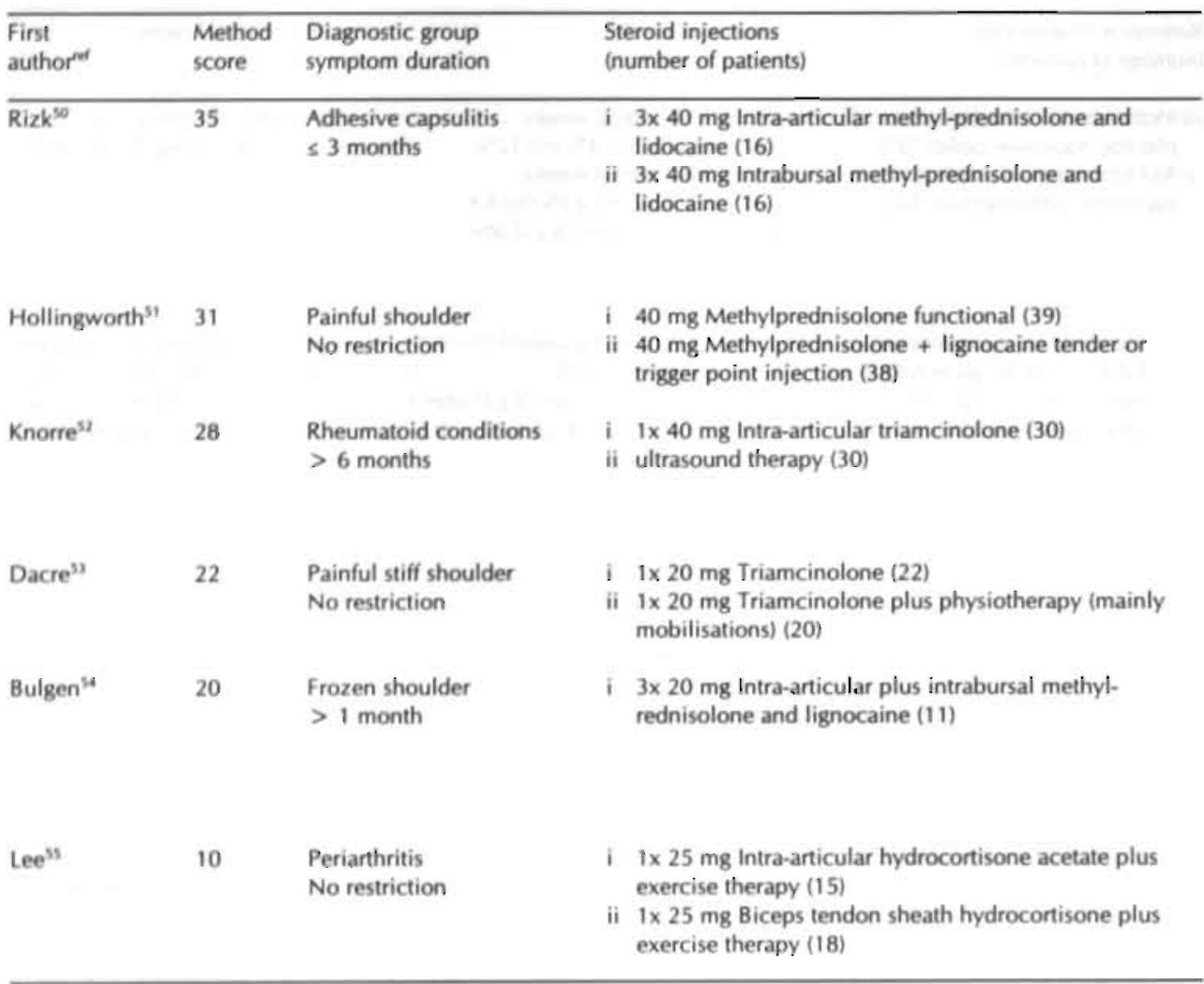

$8 \pm s$ - mean \pm standard deviation.

Table 4. Point estimates and $95 \%$ confidence intervals for the difference in success rates in studies comparing steroid injections with placebo treatment for shoulder disorders.

The studies are ranked according to methodological quality.

\begin{tabular}{|c|c|c|c|c|}
\hline First Authoret & Method score & Comparison & $\begin{array}{l}\text { Difference in } \\
\text { success rates }\end{array}$ & $\begin{array}{l}95 \% \text { Confidence } \\
\text { limits }\end{array}$ \\
\hline Petri ${ }^{39}$ & $59 !$ & $i+i i$ versus $i i i+i v$ & $14 \%$ & 1,27 \\
\hline Adebajo ${ }^{40}$ & 56 & i versus iii & $70 \%$ & 50,90 \\
\hline Vecchio ${ }^{41}$ & 54 & & $6 \%$ & $-18,30$ \\
\hline Richardson 4 & 44 & & $7 \%$ & $-13,27$ \\
\hline Withrington ${ }^{4 s}$ & 41 & & $27 \%$ & $-11,65$ \\
\hline Berry & 37 & i versus $\mathrm{v}$ & $-25 \%$ & $-62,12$ \\
\hline $\operatorname{Rizk}^{50}$ & 35 & $i+i i$ versus $i i+i v$ & $.9 \%$ & $-25,9$ \\
\hline
\end{tabular}




\begin{tabular}{ll}
\hline $\begin{array}{l}\text { Reference treatment(s) } \\
\text { inumber of patients) }\end{array}$ & Reported results'
\end{tabular}

iii $3 \mathbf{x}$ intranticular lidocaine (8) iv $3 \mathbf{x}$ Intrabursal lidocaine (6)

ii Ultrasound therapy

ii Cryotherapy: icepacks (30)

ii Ptysiotherapy only (20)

ii Maitland mobilisations (11)

ii Ice packs plus proprioceptive neuromuscular facilitation (12)

iv Pendular exercises, analgesics, diareparn (8)

iii Infra-red irradiation plus exercise therapy (17)

iv Analgesics only (15)

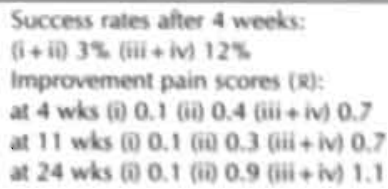

Success rates:

after 1 week (i) $60 \%$ (ii) $20 \%$

after 2 weeks (i) $59 \%$ (ii) $19 \%$

Perceived benefit "very good" according to patients at 2 wks (i) $47 \%$ (ii) $50 \%$ (iii) $40 \%$ at 12 whs (i) $40 \%$ (ii) $50 \%$ (iii) $37 \%$

Only graphical data presentation.

Only graphical data presentation.

Only graphical data presentation.

No significant differences, except for less improvement for $\mathrm{ROM}$ in group iv.

1 Reported data for improvement of pain or success rate (ratio of recovered/improved patients to those allocated to respective groups)

2. P-values $<5 \%$ were considered to be statistically significant, ROM - Range of motion.

Table 5. Point estimates and $95 \%$ confidence intervals for the difference in success rates in studies comparing steroid injections with currently applied treatment modalities for shoulder disorders.

The studies are ranked according to methodological quality. Five studies $2.07,50.55$ provided insufficient data for the calculation of confidence intervals.

\begin{tabular}{|c|c|c|c|c|}
\hline First Author & Method score & Comparison & $\begin{array}{l}\text { Difference in } \\
\text { success rates }\end{array}$ & $\begin{array}{l}95 \% \text { Confidence } \\
\text { limits }\end{array}$ \\
\hline Petri" & 59 & i versus iv & $20 \%$ & 13,27 \\
\hline Adebajo ${ }^{40}$ & 56 & i versus ii & $40 \%$ & 13,68 \\
\hline White ${ }^{4}$ & 41 & & $-5 \%$ & $-35,25$ \\
\hline Jonquière $e^{46}$ & 40 & & $-8 \%$ & $-33,17$ \\
\hline \multirow[t]{4}{*}{ Berry ${ }^{\text {an }}$} & 37 & i versus iii & $8 \%$ & $.32,48$ \\
\hline & & $i$ versus iv & $0 \%$ & $-40,40$ \\
\hline & & it versus iii & $0 \%$ & $-40,40$ \\
\hline & & ii versus iv & $8 \%$ & $-48,32$ \\
\hline Hollingworth" & 31 & & $40 \%$ & 20,60 \\
\hline \multirow[t]{2}{*}{ Knorre } & 28 & i versus ii & $-3 \%$ & $-28,22$ \\
\hline & & i versus iii & $7 \%$ & $-18,32$ \\
\hline
\end{tabular}


Our scoring system provides a quantitative index of the likelihood that the reported results of RCTS are free of bias. However, combining information from different study features in a sumscore for quality of methods may conceal variation between studies, thereby reducing informativeness. Hence, method scores must be interpreted as relative scores, and one must be cautious in comparing the scores between reviews with different research questions.

When the studies are ranked according to their method scores, however, the order of studies included in both our review on NSAIDS ${ }^{26}$ and the present one does not differ substantially ${ }^{39,40,44,48}$, despite slightly different criteria and different reviewers. The same holds for studies that were included in both our review about physiotherapy ${ }^{25}$ and the present one ${ }^{46,48,53-55}$. Only one study ${ }^{48}$ was ranked higher in both the other reviews.

The studies included in this review were aimed at a wide variety of conditions and disorders. Unfortunately, there is much confusion and lack of consensus regarding the classification of shoulder disorders. For disorders labelled seemingly straightforwardly as tendinitis or capsulitis, diagnostic criteria even differed between studies. In addition, the majority of the studies included heterogeneous populations with respect to the duration of the shoulder disorders. In order to identify any difference in efficacy of steroid injections between indications, we included diagnostic categories in Table 3; there was no strong evidence for such differences.

A valid randomization procedure, with adequate generation of random number sequence and concealed assignment, can prevent selection bias ${ }^{59}$. In addition, randomization in blocks can balance sample sizes between treatment groups. Although we excluded studies without random treatment allocation, biased results cannot be ruled out completely, since method assessment revealed that only a few papers gave a clear description of the randomization procedure. Reporting and interpretation of prognostic comparability of groups at baseline was deficient in many studies. An adequate randomisation procedure does not always guarantee equal distribution of confounding variables among the study groups, particularly when the study size is small ${ }^{60}$. Documentation of confounding variables and baseline rates of outcome measures gives some indication whether the randomization procedure has been successful for these (known and measured) variables. Only occasionally relevant prognostic variables were accounted for, such as recurrence status, prior treatment (e.g. steroid injections), involvement of both shoulders and antecedent trauma.

Blinding can prevent information bias during outcome measurement $t^{61}$. In a placebocontrolled study, blinding of both patient and therapist can be ensured when the milky colour of steroid injection fluid is masked, by covering the ampule. However, only a few studies reported on blinding of patients and therapists or blinded effect measurement, or attempts to do so. Clinical evidence on the importance of needling techniques is scarce. Although standardisation of injections seemed to be adequate, problems with placement of injections due to anatomical variations ${ }^{62}$ or inaccurate intra-articular needling techniques ${ }^{63}$, might contribute to poor clinical outcome. Hollingworth et al. ${ }^{51}$ reported higher success rates for injections aimed at the impaired soft tissue structure that was identified during physical assessment compared to tender or trigger point injection. 
Little information was provided about the scales and procedures employed during outcome measurement. Pain and recovery or general improvement were the most frequently reported outcome variables. Few studies provided data about other relevant outcome measures, such as range of motion, functional status and medical consumption. Moreover, although the statistical significance of results was always reported, the statistical tests on which the conclusions were based were reported only occasionally. Little attention was given to the clinical relevance of the results ${ }^{64}$. Different authors claim positive short-term effects of triamcinolone injection. However, no long-term effects have been reported. In addition, because the generally very short follow-up impeded detection of more serious long-term adverse effects, a valid benefitrisk estimation is not possible. Hence, its effect on long term prognosis remains unclear.

Although reporting of confidence intervals ${ }^{65}$ was deficient in most studies, only a few studies failed to provide sufficient data about pain and recovery essential for our calculations of $95 \%$ Cls. A sufficiently large study size is necessary in order to detect clinically relevant differences in outcome between interventions. Most $95 \%$ Cls proved to be wide owing to small study sizes. Statistical pooling can increase power, but we decided not to pool the data because of the widely varying quality of study methods and inadequate reporting. Pooling was further impeded by the heterogeneity of the studies included with respect to populations, interventions, outcome measures and duration of follow-up. For these reasons, and because of our fear that statistical pooling would yield a biased effect estimate, we preferred systematic methods assessment to study the evidence and to identify and present sources of disparity and conflict among clinical trials.

The evidence in favour of the efficacy of steroid injections for shoulder disorders is scant. Only a few of the available RCTs seem to be credible, but they do not provide conclusive evidence about the efficacy and safety of steroid injections for shoulder disorders, especially regarding long-term outcome. Because of the poor quality of methods of most available studies, it is not possible to formulate a strong and valid judgement for or against the use of steroid injections for shoulder disorders. There is more evidence for the short-term efficacy of periarticular triamcinolone injection ${ }^{39,40}$ than for prednisolone injection. Future studies into the efficacy of steroid injection should focus on the comparison of periarticular triamcinolone injection with no intervention or a placebo injection. In addition, studies comparing steroid injections with competing treatment modalities should focus on long-term (cost-)effectiveness and benefit-risk ratios. Methodological flaws presented in this review should be avoided. During the design and conduct of studies, more attention should be given to recruitment of a sufficient sample size, a valid randomization procedure, determination of prognostic comparability at baseline, compliance with interventions, restriction or standardisation of co-interventions, blinding of therapists, patients and effect measurement, sufficient duration of follow-up, and documentation of adverse effects. In addition, more attention should be given to adequate reporting of design, conduct and results of such studies. 


\section{References}

1 Croft P. Soft Tissue rheumatism. In: Epidemiology of the rheumatic diseases. Silman Al, Hochberg MC (eds). Oxford University Press, Oxford, 1993: 375-421.

2 Jayson MIV. Frozen shoulder: adhesive capsulitis. British Medical Journal 1981; 283: 1005-6.

3 Bland JH, Merit JA, Boushey, DR. The painful shoulder. Seminars in Arthritis and Rheumatism 1977; 7: $21-47$.

4 Uthoff HK, Sarkar K. An algorithm for shoulder pain caused by soft-tissue disorders. Clinical Orthopaedics and Related Research 1990; 254: 121-7.

5 Grundemeijer HGLM, Brouwer HJ. De betekenis van fysiotherapie bij aandoeningen aan het bewegingsapparaat. Huisarts en Wetenschap 1988; 31 [suppl 12]: 44-59.

6 Peters D, Davies P, Pietroni P. Musculoskeletal clinic in general practice: study of one year's referrals. British fournal of General Practice 1994; 44: 25-9.

7 Gray RG, Gottlieb NL. Intra-articular corticosteroids. An update assessment. Clinical Orthoppaedics 1983; 177: 235-63.

8 Miedema HS. Reuma-onderzoek meerdere echelons, (ROME): basisrapport. Leiden, Nederlands Instituut voor Praeventieve Gezondheidszorg TNO; 1994.

9 Anonymous. Injecting the painful shoulder. [Editorial] Lancet 1976; i: 27.

10 Goldie I. Local steroid therapy in painful orthopaedic conditions. Scottish Medical Journal 1972; 17:176-83.

11 Bakker JF, Jongh $\mathrm{L}$ de, Jonquière $\mathrm{M}$, Mens J, Oosterhuis JJ, Poppelaars A, Schoonheim FL, Winters JC. Schouderklachten Standaard M08 Nederlands Huisartsen Genootschap. Huisarts en Wetenschap 1990; 33: 196-202.

12 Putte LBA van de, Joosten LAB, Berg WB van den. Corticosteroids: immediate and delayed risks of intra-articular administration. In: Mummenthaler M, Zwieten PA van, Farcor JM (Eds). Treatment of chronic pain. Possibilities, limitations and long term follow up. Chur, Harwood Academic Publishers; 1990: $72-5$.

13 Zuckerman JD, Meislin RJ, Rothberg M. Injections for joint and soft tissue disorders: when and how to use them. Geriatrics 1990; 45: 45-55.

14 Hollander $\mathrm{K}$. Intra-articular hydrocortisone in the treatment of arthritis. Annals of Internal Medicine 1953; 39: 735-46.

15 Pocock SJ. Clinical trials. Chichester, J.Wiley \& Sons, 1991.

16 Meinert CL. Clinical trials: design, conduct and analysis. New York, Oxford University Press, 1986.

17 Feinstein AR. Clinical epidemiology: the architecture of clinical research. Philadelphia, WB Saunders, 1985.

18 Cha MK, Bero LA. Instruments for assessing the quality of drug studies published in medical literature. Journal of the American Medical Association 1994; 272: 101-4.

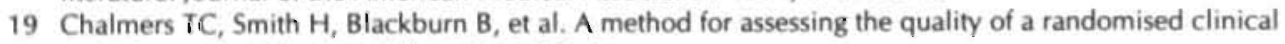
trial. Controlled Clinical Trials $1981 ; 2: 31-49$.

20 Linden Sj van der, Bouter LM, Tugwell P. What are the minimal methodological and statistical requirements for a good trial? I. The clinician's view. In: Rheumatology Physiotherapy: controlled trials and facts. Schlapbach P, Gerber NJ (Eds). Basel, Karger, 1991; 14: 1-8.

21 Anonymous. Instructions to authors. British Medical Journal. 1994; 308: 39-42

22 Boissel IP. Standards for reporting clinical trials. Clinical trials and meta-analysis. 1993; 28: 195-7.

23 Nachemson AL, Larocca H. Editorial. Spine 1989; 12: 427-9.

24 Mosteller F, Gilbert JP, McPeek B. Reporting standards and research strategies for controlled trials: agenda for the editor. Controlled Clinical Trials 1980; 1:37-58.

25 Heijden GJMG van der, Bouter LM, Beckerman H, Bie RA de, Oostendorp RAB. Effectiviteit van fysiotherapie bij schouderklachten. Nederlands Tijdschrift voor Fysiotherapie 1992; 102: 38-46.

26 Windt DAWM van der, Heijden GJMG van der, Scholten RJPM, Koes BW, Bouter LM. The efficacy of non-steroidal anti-inflammatory drugs for shoulder complaints. Journal of Clinical Epidemiology 1995; 48: 691-704.

27 Riet ter G, Kleijnen J, Knipschild P. Acupuncture and chronic pain: a criteria based meta-analysis. Journal of Clinical Epidemiology 1990; 43: 1191-9.

28 Kleijnen J, Knipschild P. Riet G ter. Clinical trials of homoeopathy. British Medical Journal 1991; 302: 316-23. 
29 Koes BW, Assendelit WII, Heijden GJMC van der, Bouter LM, Knipschild PG. Spinal manipulation and mobilisation for neck and back pain. British Medical lournal 1991: 303: 1298-303.

30 Koes BW, Bouter LM, Beckerman H, Heijden GIMG van der, Knipschild PG. Physiotherapy exercises and back pain. British Medical lournal 1991; 302: $1572-6$.

31 Beckerman H, Bouter LM, Heijden G]MG van der, Bie RA de, Koes BW. Eificacy of physiotherapy for musculoskeletal disorders. What can we learn from research? British lournal of General Practice 1993; 43: $73-7$.

32 Koes BW, Tulder MW, Windt DAWM van der, Bouter LM. The efficacy of back schools: a review of randomised clinical trials. Journal of Clinical Epidemiology 1994; 47: 851-62.

33 Koes BW, Hoogen HMM van den. Efficacy of bed rest and orthoses of low-back pain. A review of randomised clinical trials. European of Journal Physical Medicine and Rehabilitation 1994; 4: 86-93.

34 Williams NE, Seifen MH, Cuddigan JH, Wize RA. Treatment of capsulitis of the shoulder. Rheumatology and Rehabilitation 1975; 14: 236.

35 Arias M, Alcala T. Frozen shoulder: a new approach to its treatment with local anaesthesia. European of Journal Physical Medicine and Rehabilitation 1992; 2: 11-14.

36 Friis J, Jarner D, Toft B, Christensen K, Christophersen I, Ibfeldt HH, Korsgaard I, Skinhoj A, Andersen F. Comparison of two ibuprofen formulations in the treatment of shoulder tendonitis. Clinical Rheumatology 1992; 11: 105-8.

37 Corbeil V, Duissault RG, Leduc BE, Fleury J. Capsulite rétractile de l'épaule: étude comparative de l'arthrographie avec corticotherrapie intraarticulaire avec ou sans distension capsulaire. Canadian Association Radiology lournal 1992; 43: 127-30.

38 Thomas D, Williams RA, Smith DS. The frozen shoulder: a review of manipulative treatment. Rheumatology and Rehabilitation 1980; 19: 173-9.

39 Petri M, Dobrow R, Neiman R, Whiting-O'Keefe Q, Seaman WE. Randomised, double-blind, placebo-controlled study of the treatment of the painful shoulder. Arthritis and Rheumatology 1987 30: $1040-5$.

40 Abedajo OA, Nash P, Hazleman BL. A prospective double blind dummy placebo controlled study comparing triamcinolone hexacetonide injection with oral diclofenac $50 \mathrm{mg}$ TDS in patients with rotator cuff tendinitis. Journal of Rheumatology 1990; 17: 121-6.

41 Vecchio PC, Hazleman BL, King RH. A double-blind trial comparing subacromial methylprednisolone and lignocaine in acute rotator cuff tendinitis. British Journal of Rheumatology 1993; 32: 743-5.

42 Jong BA de. The painful stiff shoulder. University of Amsterdam [Thesis]. Amsterdam, Rodopi, 1991.

43 Richardson T. The painful shoulder. Proceedings of the Royal Society of Medicine 1975; 68: 731-6.

44 White $\mathrm{RH}$, Paull DM, Fleming KW. Rotator cuff tendinitis: comparison of subacromial injection of a long acting corticosteroid versus oral indomethacin therapy. J ournal of Rheumatology 1986; 13: 608-13.

45 Withrington RH, Girgis FL, Seifert MH. A placebo-controlled trial of steroid injections in the treatment of supraspinatus tendonitis. Scandinavian Journal of Rheumatology 1985; 14: 76-8.

46 Jonquière $M$. De behandeling van schouder- en elleboogklachten volgens de richtlijnen van Cyriax. Een vergelijkend onderzoek in de huisartsenpraktijk. Erasmus University [Thesis]. Rotterdam, 1986.

47 Jacobs LG, Barton MA, Wallace WA, Ferrousis J, Dunn NA, Bossingham DH. Intra-articular distension and corticosteroids in the management of capsulitis of the shoulder. British Medical Journal 1991; 302: 1498-501.

48 Berry H, Fernandes L, Bloom B, Clark RJ, Hamilton EB. Clinical study comparing acupuncture, physiotherapy, injection and oral anti inflammatory therapy in shoulder-cuff lesions. Current Medical Research and Opinion 1980; 7:121-6.

49 Fernandes L, Berry H, Clark RJ, Bloom B, Hamilton EBD. Clinical study comparing acupuncture, physiotherapy, injection and oral anti inflammatory therapy in shoulder-cuff lesions. Lancet 1980; i: 208-9.

50 Rizk TE, Pinals RS, Talaiver AS. Corticosteroid injections in adhesive capsulitis: investigation of their value and site. Archives of Physcial Medine and Rehabilitation 1991; 72: 20-2.

51 Hollingworth GR, Ellis RM, Hattersley TS. Comparison of injection techniques for shoulder pain: results of a double blind, randomised study. British Medical Journal 1983; 287: 1339-41.

52 Knorre B, Keitel W. Vergleichende Therapiestudie: Ultraschall, Kryotherapie und intraartikuläre Kortisonoide bei Veränderungen des Schultergelenkes aus entzündlicher Ursach. Zeitschrift für Physiotherapie 1990; 42: 221-5. 
53 Dacre JE, Beeney N, Scott DL. Injections and physiotherapy for the painful' stiff shoulder. Annals of Rheumatic Diseases 1989; 48: 322-5.

54 Bulgen DY, Binder Al, Hazleman BL, Dutton J, Roberts S. Frozen shoulder: prospective clinical study with an evaluation of three treatment regimens. Annals of the Rheumatic Diseases 1984; 43: 353-60.

55 Lee PN, Lee M, Haq AMMM, Wright V, Longton EB. Periarthritis of the shoulder. Trial of treatments investigated by multivariate analysis. Annals of the Rheumatic Diseases $1974 ; 33: 116-9$.

56 Lee M, Haq AM, Wright V, Longton EB. Periarthritis of the shoulder: a controlled trial of physiotherapy. Physiotherapy 1973; 59: 312-5.

57 The Standards of Reporting Trials Group. A proposal for structured reporting of randomised controlled trials. Journal of the American Medical Association 1994; 272: 1926-31.

58 Working Group. Call for comments on a proposal to improve reporting of clinical trials in the biomedical literature. Annals of Internal Medicine 1994; 121: 894-5.

59 Schulz KF, Chalmers I, Grimes DA, Altman DG. Assessing the quality of randomisation from reports: of controlled trials published in obstetrics and gynaecology journals. Journal of the American Medical Association 1994; 272: 125-8.

60 Altman DG, Doré CJ. Randomisation and baseline comparisons in clinical trials. Lancet 1990; 335: 149-53.

61 Ederer $\mathrm{F}$. Patient bias, investigator bias and the double-masked procedures in clinical trials. American Journal of Medicine 1975; 58: 295-9.

62 Strizah AM, Danzig L, Jackson DW, Reznick D, Staple T. Subacromial bursography. An anatomica! clinical study. Journal of Bone and Joint Surgery (Am) 1982; 64: 196-201.

63 Jones A, Regan M, Ledingham !, Pattrick M, Mauhire H, Doherty M. Importance of placement of intra-articulat steroid injections. British Medical Journal 1993; 307: 1329-30.

64 Moher D, Dulberg CS, Wells GA. Statistical power, sample size, and their reporting in randomised controlled trials. Journal of the American Medical Association 1994; 272: 122-4.

65 Gardner MJ, Altman DG. Statistics with confidence. Confidence interval's and statistical guidelines. London, British Medical lournal Publishers, 1989. 


\section{Chapter 4}

\section{Non-steroidal anti-inflammatory drugs (NSAIDS) for shoulder complaints A systematic review}

DAWM van der Windt', GJMG van der Heijden², RJPM Scholten', BW Koes', LM Bouter ${ }^{1,3}$

1 Institute for Research in Extramural Medicine, Faculty of Medicine, Vrije Universiteit, Amsterdam, the Netherlands

2 Department of Epidemiology, Faculty of Medicine and Health Sciences, University of Limburg, Maastricht, the Netherlands

3 Department of Epidemiology and Biostatistics, Faculty of Medicine, Vrije Universiteit, Amsterdam, the Netherlands 


\begin{abstract}
The medical literature was evaluated with respect to the efficacy of NSAIDS for shoulder complaints. Nineteen randomized clinical trials (RCTS) met the selection criteria and were included in this review. Each publication was independently scored by two blinded reviewers, according to a standardized set of 17 methodological criteria. The RCTS were ranked according to their total methods score (maximum 100 points). The methodological quality of the majority of the RCTS was rather disappointing; only 5 RCTS received a methods score exceeding 50 points. Furthermore, methodologica! criteria were often inadequately described, particularly those regarding the randomization procedure, co-interventions and control of compliance. The three RCTS with the highest methods scores demonstrated superior short-term efficacy of NSAIDS in comparison with placebo intervention. Fourteen RCTS comparing two types of NSAIDS showed no conclusive evidence in favour of a particular NSAID with respect to efficacy or tolerability.

Future RCTS should compare the benefit-risk ratios of NSAIDS and analgesics for shoulder complaints in order to establish whether the use of NSAIDS is more favourable than analgesics, despite the higher risk of adverse reactions from NSAIDS.
\end{abstract}




\section{Introduction}

A painful or stiff shoulder may be the result of a variety of diseases and conditions. Shoulder complaints occur frequently: epidemiological studies have reported pointprevalences ranging from $7 \%$ to $25 \%$ in western general populations ${ }^{1,2,3}$. The annual incidence is estimated at 10 per 1000 , peaking at 25 per 1000 in the age-category of $42-46$ years'. Approximately $50 \%$ of these patients consult a physician for their shoulder complaints. The incidence of shoulder complaints in Dutch general practice is estimated at 13 per 1000 registered patients per yeart.

Shoulder complaints are usually a self-limiting condition of relatively short duration. In $48 \%$ of the patients, pain or stiffness will disappear or substantially improve within 1 month after consulting their general practitioner (GP) [unpublished observations]. Unfortunately, the long-term outcome is not always this favourable. Persisting pain or restriction of movement, due to more chronic conditions, may last for several years 5,6 ? A painful shoulder may be caused by articular or peri-articular rheumatic conditions, or may be the result of neurological or vascular disorders, neoplasms, or referred pain from internal organs. Because of the complex functional anatomy of the shoulder girdle, even intrinsic complaints which emanate from the shoulder joint may constitute a diagnostic challenge. To date, there is no conclusive evidence on either the pathogenesis of shoulder disorders or the accuracy of diagnostic procedures such as Xray, magnetic resonance imaging, computed tomography or ultrasonography ${ }^{n, 9}$. A wide variety of treatment modalities has been introduced, including medication, physical therapy modalities, exercise therapy, corticosteroid injections and surgery. In primary health care, therapy is frequently initiated with the prescription of a nonsteroidal anti-inflammatory drug (NSAID) ${ }^{4}$. A variety of NSAIDS is available to the GP, and new drugs are being introduced on a regular basis. NSAIDS are assumed to act by inhibiting prostaglandin synthesis, resulting in relief of pain and suppression of inflammatory processes in articular or peri-articular structures ${ }^{10}$. Adverse reactions include mild gastrointestinal symptoms, which occur frequently, as well as more serious complications, such as gastrointestinal bleeding, renal insufficiency, hepatitis and bronchospasm. The efficacy of NSAIDS should be studied in terms of benefit-risk ratios, in order to determine whether the advantages of NSAIDS outweigh the risk of adverse reactions.

The efficacy of NSAIDS has been studied extensively, but most randomized clinical trials (RCTS) have included rheumatic conditions affecting various joints. The purpose of this paper was to evaluate the medical literature with respect to the efficacy of NSAIDS for patients with shoulder complaints only. There is still much confusion and corresponding lack of consensus regarding the classification of shoulder disorders. Periarthritis humeroscapularis or a painful stiff shoulder do not constitute clearly defined clinical entities. Diagnostic criteria may even differ between studies for disorders seemingly straightforward labelled as tendinitis or bursitis. We therefore prefer to present one overview of the use of NSAIDS for all indications. In this systematic review, conclusions with respect to the efficacy of NSAIDS were made after blinded assessment of the methodological quality of the RCTS according to standardized methodological criteria. 


\section{Methods}

\section{Study selection}

A Medline literature search of the period (1966-1993) was conducted, using the keywords shoulder, analgesics, anti-inflammatory drugs, bursitis, tendinitis, periarthritis, capsulitis, comparative study and evaluation study. All Medline citations referring to review articles or RCTS were retrieved and examined. The references of all retrieved articles were screened for additional relevant publications.

Studies had to meet the following criteria to be included in this review: (1) The study population included patients with intrinsic shoulder complaints; (2) At least one of the interventions under study included NSAIDS; (3) Patients were randomly allocated to the interventions under study; (4) The publication was a full report. Letters and abstracts were excluded; (5) In publications concerning various rheumatic disorders, the results of patients with shoulder complaints were presented separately, or at least $90 \%$ of the study population had to be composed of patients with shoulder complaints; (6) The publication was written in English, German, French or Dutch.

\section{Methods assessment}

The selected publications were blinded for author(s), source and results by removing sections of the text, tables and figures. GIMGH and RJPMS independently scored each publication according to a standardized set of 17 methodological criteria (A-Q), referring to the selection of the study population, description of interventions, outcome measurements, analysis and presentation of data (Table 1).

Table 1. Criteria list for a methodological assessment of RCTS for shoulder complaints.

\begin{tabular}{|c|c|c|c|}
\hline \multicolumn{2}{|c|}{ Study population } & \multicolumn{2}{|l|}{35} \\
\hline A & selection and restriction: homogenous study population & & 4 \\
\hline B & adequate randomization procedure & & 3 \\
\hline C & prognostic comparability at baseline & & 7 \\
\hline D & drop-outs & & 3 \\
\hline E & loss to follow-up $<20 \%$ or & & 1 \\
\hline & loss to follow-up $<10 \%$ & & 3 \\
\hline $\mathrm{F}$ & smallest study group $\geq 25$ subjects or & & 6 \\
\hline & smallest study group $\geq 50$ subjects or & & 9 \\
\hline & smallest study group 275 subjects & & 15 \\
\hline \multicolumn{2}{|c|}{ Interventions } & 25 & \\
\hline G & informative description of each intervention & & 10 \\
\hline$H$ & placebo-controlled study & & 5 \\
\hline 1 & pragmatic study & & 5 \\
\hline 1 & co-interventions avoided & & 5 \\
\hline \multicolumn{2}{|c|}{ Measurement of outcome } & 25 & \\
\hline K & blinding of patient and physician & & 7 \\
\hline $\mathrm{i}$ & relevant outcome measures & & 8 \\
\hline M & blinded assessment of outcome measures & & 5 \\
\hline $\mathrm{N}$ & adequate follow-up period & & 5 \\
\hline \multicolumn{2}{|c|}{ Analysis and presentation of data } & 15 & \\
\hline $\mathrm{O}$ & analysis according to intention-to-treat principle & & 5 \\
\hline $\mathbf{P}$ & adequate presentation of data & & 5 \\
\hline Q & adjustment for confounding variables and/or differences & ine. & 5 \\
\hline
\end{tabular}


A Clearly described criteria for selection (1 pt). Restriction to a homogenous population with respect to diagnosis, duration of complaint, previous treatments, contra-indications for treatment with NSADS (3 pts).

B Randomization procedure is described and is a procedure which excludes bias (e.g. sealed envelopes, allocation by telephone, pre-coded packaged medication ( 3 pts)).

C Comparability for duration of complaints (2 pts), baseline scores for outcome measures (2 pts), age (1 pt), recurrence status ( 1 pt), previous treatment of complaint (1 pt).

D No drop-outs ( 3 pts). If there are drop-outs: the number of drop-outs (1 pt and the reason for withdrawal (1 pt) is presented for each study group.

E Loss to follow-up: $\{1$ - inumber of patients at main moment of effect measurement/number of patients at randomization) $\} \times 100 \%$.

F Smallest study group immediately after randomization.

C Description of type of intervention (4 pts), dosage schedule or intensity of treatment ( 2 pts), duration of treatment or number of injections (2 pts), control of compliance (2 pts).

$\mathrm{H}$ A comparison is made with a study group receiving a placebo treatment only.

1 A comparison is made between two or more existing interventions, medication or otherwise. (No addition of any placebo to the other study group.)

J All other interventions are avoided (5 pts) or comparable co-interventions between study groups ( 3 pts).

$\mathrm{K}$ Double-dummy system ( 5 pts) or some other attempt at blinding of the patient ( $2 \mathrm{pts}$ ) and the physician (1 pt). Blinding of patient (1 pt) or physician (1 pt) is evaluated and successful.

L. Results are presented of: pain (2 pts), global measure of improvement ( 2 pts), functional status (11 pt), range of movement (1 pt), adverse reactions (2 pts).

$M$ Blinded assessment of the outcome measures mentioned under $L$ ( $1 \mathrm{pt}$ each).

N Timing of effect measurement is identical for all study groups (3 pts). Final effect measurement at least three months after randomization ( 2 pts).

O When loss to follow-up $\leq 10 \%$ : analysis according to intention-to-treat principle: results on all randomized patients are presented for most outcome measures, and on the most important moments of effect measurement, irrespective of drop-outs or missing values.

When loss to follow-up $>10 \%$ : intention-to-treat-analysis plus alternative analysis that accounts for drop-outs and missing values.

P Presentation of frequencies or means and SD of the most important outcome measures for each study group at most important moments of effect measurement.

Q Adjustment of the results for confounding variables (e.g. differences of prognostic indicators at baseline, compliance, additional medication) by using multivariate analysis.

The reviewers rated each methodological criterion according to the following rules: + : Informative description of the criterion at issue; adequate design and conduct (prevention of bias).

-: Informative description, but inadequate design or conduct.

?: Lacking or insufficient information, assigning either ' +' or '-' was not possible.

Disagreements between the reviewers were identified and subsequently discussed during a consensus, meeting. If disagreements were not resolved during this meeting BWK was consulted for a finall judgement. Next, all methodological criteria rated 'plus' were scored using the weighting factors listed in Table 1. Each RCT was assigned a total methods score by summing up all weighted criteria. This evaluation finally resulted in a hierarchical order, ranking the RCTS according to methodological quality. The methodological criteria and matching weights are based on the criteria used by Koes et al. ${ }^{11,12}$, but were adjusted to fit the disorders and interventions. included in this review. 


\section{Data abstraction}

The success rate in each intervention group was determined by using information from text and tables of the original publications. Whenever possible, success was defined as recovery or substantial improvement from baseline, according to the patient. The exact definition of success may somewhat differ between RCTS, and will be presented in tables summarizing the details and results of the RCTS. Success rates were calculated according to the intention-to-treat principle, dividing the number of documented successes at the end of the intervention period by the number of patients allocated to the intervention by randomization (irrespective of drop-outs and loss to follow-up during the study). There will probably be a number of successfully recovered patients among the dropouts, but the reasons for drop-out are not always clearly described. Consequently, for some RCTS our calculations will be an underestimation of the real success rate and produce somewhat lower success rates than the results reported in the original publications. The differences between the success rates in groups treated with NSAIDS and reference groups were calculated, along with the corresponding $95 \%$ confidence intervals $(95 \% \mathrm{Cls})^{13}$.

In order to estimate the ability to detect a clinically relevant difference, the power of each study was determined ${ }^{13}$. For these calculations a difference in success rate of $25 \%$ between intervention groups was considered to be clinically relevant.

The conclusions of the RCTS regarding the efficacy of NSAIDS were marked as being "positive" or "negative". A RCT was marked "positive" if NSAIDS proved to be significantly ( $p<0.05$ ) more effective than a reference treatment with respect to at least two relevant outcome measures (e.g. severity of pain or functional limitation) or with respect to our calculations of differences in success rates $(95 \%$ confidence interval excludes a difference of ' 0 '). Conclusions were marked "negative" if treatment with NSAIDS was less effective than a reference treatment, or if there were no statistically significant differences.

\section{Results}

The literature search resulted in the identification of 63 publications on the efficacy of NSAIDS for shoulder complaints. Fourty four publications were excluded, being either non-randomized trials, abstracts, or RCTS concerning several joints or disorders without a separate presentation of the outcome for intrinsic shoulder complaints. Eighteen publications met the selection criteria and were included in this review ${ }^{14-31}$, one of which reported on two different RCTS which have been reviewed separately ${ }^{23}$. GJMGH and RJPMS initially agreed on 840 of the 931 items scored $(90 \%)$. Nearly al! disagreements were due to reading errors or a difference in interpretation of the methodological criteria. Since all disagreements were resolved during the consensus meeting, BWK did not have to be consulted.

\section{Methodologica! quality}

In Table 2, scores assigned to each methodological criterion, together with the final methods score, are presented for each $\mathrm{RCT}$. Only $5 \mathrm{RCTS}^{14-18}$ received a methods score exceeding 50 points, indicating a rather poor methodological quality of most of the evaluated publications. Design or conduct was often inadequate (rated '- ') with respect to loss to follow-up (E), sample size $(F)$ and analysis according to the intention-to-treat principle $(\mathrm{O})$. 
A considerable amount of relevant information on methodological criteria was lacking or inadequate, representing a total of $12^{26}$ to 43 points ${ }^{29}$ (Table 2). Description of the following criteria was often considered to be inadequate: selection criteria and restriction to a homogeneous study population (A), randomization procedure (B), cointerventions $(0)$, prognostic comparability at baseline (C), control of compliance (G4) and adjustment for confounding variables (Q).

Table 2. Methodological quality of ecrs on the eflicacy of Nuos for shoulder complaints.

\begin{tabular}{|c|c|c|c|c|c|c|c|c|c|c|c|c|c|c|c|c|c|c|c|c|c|}
\hline $\begin{array}{l}\text { First } \\
\text { whoret }\end{array}$ & $\begin{array}{l}\mathrm{M} \\
\mathrm{A} \\
4\end{array}$ & $\begin{array}{l}\text { Bo } \\
3\end{array}$ & $\begin{array}{l}\text { Jolic } \\
\text { C } \\
7\end{array}$ & $\begin{array}{l}\text { gical } \\
\text { D } \\
3\end{array}$ & $\begin{array}{l}\mathrm{cri} \\
\mathbf{f} \\
\mathbf{3}\end{array}$ & $\begin{array}{l}\text { eria* } \\
\text { f } \\
15\end{array}$ & $\begin{array}{l}\mathrm{G} \\
10\end{array}$ & $\begin{array}{l}H \\
5\end{array}$ & $\begin{array}{l}1 \\
5\end{array}$ & $\frac{1}{5}$ & $\frac{K}{7}$ & $\frac{1}{8}$ & $\begin{array}{l}M \\
5\end{array}$ & $\begin{array}{l}N \\
5\end{array}$ & $\begin{array}{l}0 \\
5\end{array}$ & $\begin{array}{l}p \\
5\end{array}$ & $\begin{array}{l}Q \\
5\end{array}$ & $\begin{array}{l}\text { Methods } \\
\text { score } \\
100\end{array}$ & $\begin{array}{l}\text { Inade } \\
\text { quate } \\
\text { info! }\end{array}$ & Indication & $\begin{array}{l}\text { Conclus: } \\
\text { sion' }\end{array}$ \\
\hline Petri" & 4 & 3 & 2 & - & 3 & 6 & 8. & 5 & - & - & 3 & a & 5 & 3 & * & 5 & = & 57 & 24 & painful shoulder & $\begin{array}{l}2 \text { wi pos. } \\
4 \text { wi nes. }\end{array}$ \\
\hline Adebajo" & 4 & 3 & 5 & 3 & 3 & $*$ & 8 & 5 & - & $=$ & 5 & 4 & 3 & 3 & 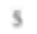 & 5 & $=$ & 56 & 20 & Iendinitis $<3 m$ & pos. \\
\hline Mena & 4 & - & 3 & 2 & 3 & 6 & 10 & 5 & - & $\cdot$ & 3 & 7 & 3 & 3 & . & 5 & . & 54 & 23 & fendinaisbunitis $<4 \mathrm{c}$ & 4d pos \\
\hline Zuinen" & 4 & - & 6 & $\cdot$ & 1 & 15 & 6 & - & 5 & $=$ & 3. & 7 & 2 & 3 & * & 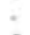 & . & 54 & 23 & tendinitisbunitis $<3 d$ & Id neg. \\
\hline Berny" & 1 & - & 5 & 3 & 3 & $*$ & 6 & 5 & 5 & - & 2 & 5 & 4 & 3 & 5 & 5 & - & 52 & 24 & rotator cuff lesions & neg. \\
\hline Menkes is & 1 & - & 3 & 1 & 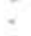 & 9 & 8 & - & - & - & 5 & 6 & 3 & 3 & 5 & 5 & $=$ & 49 & 28 & periarthritis & neg. \\
\hline Friis" & * & - & 3 & 2. & 3 & 9 & 10 & - & - & 3 & 5 & 4 & 2 & 3 & * & 5 & . & 49 & 19 & tendinitis & neg. \\
\hline Duben" & 1 & - & 3 & 2 & - & 6 & 6 & - & - & $=$ & 5. & 8 & 4 & 3 & - & 5 & . & 45 & 18 & varioun conditions & neg. \\
\hline Thumb" & - & $*$ & 5 & 2 & 1 & * & 8. & - & 5 & $=$ & $\mathbf{3}$ & 7 & 4 & 3 & - & 5 & . & 43 & 21 & perianthritis & nes. \\
\hline Cinsberg"rt & - & - & 3 & 1 & 1 & - & 6 & - & - & 5. & 5 & 7 & 4 & $\mathbf{3}$ & * & 5 & . & 42 & 23 & tendinitimbursitis & nes. \\
\hline Cinsbere"t" & 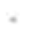 & - & 3 & 1 & 1 & - & 6 & - & - & 5 & 5. & 7 & 4 & 3 & - & 5 & - & 42 & 23 & tendinitivbursitis & neg. \\
\hline Fanaey" & - & - & 3 & 2 & 3 & 6 & 6 & - & 5 & 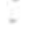 & 3 & 7 & 1 & $\mathbf{3}$ & - & . & = & 41 & 23 & various conditions & neg. \\
\hline White'li & 4 & - & 6 & 1 & - & - & B & - & - & - & 5 & 7 & 4 & * & * & 5 & - & 40 & 17 & tendinitis $<3 m$ & neg. \\
\hline Huskisson" & 1 & - & 3 & 2 & 3 & - & 8 & - & - & 5. & 5 & 7 & 3 & 3 & $*$ & - & $*$ & 40 & 12 & painful stif shoulder & nes. \\
\hline Wielandts & - & - & 3 & 1 & - & * & 8 & 5 & - & 3 & 7 & 3 & 3 & . & 5 & $=$ & - & 38 & 22 & tendinitis & nes: \\
\hline Smith" & h & * & 3 & 2. & 1 & $\cdot$ & 10 & - & - & . & 5 & 5 & 1 & $\mathbf{3}$ & - & 5 & . & 36 & 24 & chronic pain shoulder & y neg \\
\hline Yamamoto" & 8 & - & * & 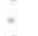 & $=$ & 9 & 8 & - & - & . & 5 & 2 & 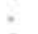 & 3 & $\cdot$ & 5 & $=$ & 33 & 43 & periarthritis & nell. \\
\hline Rhind" & - & - & 1 & 2 & . & - & 6 & - & $=$ & . & 5 & 7 & 3 & 3 & - & 5 & . & 32 & 23 & periarthritis & neg. \\
\hline Valtonen" & - & $\cdot$ & $\cdot$ & $\overline{1}$ & 3. & - & 8 & - & $\cdot$ & $\cdot$ & 5 & 4 & 2 & 3 & - & 5 & . & 31 & 36 & various conditions & $\begin{array}{l}1 \text { w: pos. } \\
2 \text { w: neg. }\end{array}$ \\
\hline
\end{tabular}

" Points are assigned to criteria rated '+ ' (no points for ' 7 ' or "

1 Amount of points assigned to criteria rated ' $P$ '

Pos: "Positive" if treatment with NSAIOS (treatment i) in Table 4 or 5 is significantly (p < 0.05 ) more effective than a reference treatment with respect to success rate or at least two other relevant outcome measures

Neg: "Negative" if treatment with NSADS is less effective than a reference treatment or if there are no significant differences.

Table 3 presents the ranking of the RCTS according to their methods score, as well as the ranking under the assumption that the RCT was in fact adequately performed with respect to insufficiently described methodological criteria. The maximum attainable scores would range from $52^{26}$ to 81 points ${ }^{14}$, provided that more informative description of design and conduce did not reveal any bias. This assumption did not result in dramatic changes in the ranking of the RCTS according to methodological quality. Exceptions are the RCT by Valtonen" and, in particular, the RCT by Yamamoto et al. ${ }^{29}$, which would be ranked among the first 6 RCTS. Both publications report on rheumatic conditions affecting several joints, including only a limited amount of information on shoulder complaints.

Table 3 also presents the ranking of RCTS under the assumption that all methodological criteria are equally important. Calculation of unweighted methods scores resulted in some minor changes in the hierarchical order. However, the hierarchical order of the 5 RCTS with the highest methods scores remains the same when using a scoring system without weighting factors. 
Table 3. Methods scores and ranking " of the RCTs according to their methodological quality under three different assumptions.

\begin{tabular}{|c|c|c|c|}
\hline $\begin{array}{l}\text { First } \\
\text { authoret }\end{array}$ & $\begin{array}{l}\text { Weighted scores ' } \\
\text { (ranking I) }\end{array}$ & $\begin{array}{l}\text { Maximal attainable } \\
\text { scores }^{2} \text { (ranking II) }\end{array}$ & $\begin{array}{l}\text { Unweighted scores }{ }^{3} \\
\text { (ranking III) }\end{array}$ \\
\hline Petri ${ }^{14}$ & $57(1)$ & $81(1)$ & $24(1)$ \\
\hline Adebajo's & $56(2)$ & 76 (5) & $23(2)$ \\
\hline Mena $^{16}$ & $54(3)$ & $77 \quad(2)$ & $23(2)$ \\
\hline Zuinen 17 & $54(3)$ & $77 \quad(2)$ & $22(4)$ \\
\hline Berry ${ }^{18}$ & 52 ( 5$)$ & $76(5)$ & $22(4)$ \\
\hline Menkes ${ }^{19}$ & $49(6)$ & $77 \quad(2)$ & $20(6)$ \\
\hline Friis $^{20}$ & 49 ( 6$)$ & $68(8)$ & 19. (10) \\
\hline Duke $^{21}$ & $45 \quad(8)$ & 63 (13) & $20(6)$ \\
\hline Thumb ${ }^{22}$ & $43(9)$ & 64 (11) & $20 \quad(6)$ \\
\hline Ginsberg $^{23}$ & $42 \quad(10)$ & 65 (10) & 19: (10) \\
\hline Famaey $y^{24}$ & 41 (11) & 64 (11) & $17 \quad(13)$ \\
\hline White ${ }^{25}$ & $40 \quad(12)$ & $57 \quad(16)$ & $20 \quad(6)$ \\
\hline Huskisson ${ }^{26}$ & $40 \quad(12)$ & 52. (18) & $191 \quad(10)$ \\
\hline Wielandts ${ }^{27}$ & $38 \quad(14)$ & $60 \quad(14)$ & $17 \quad(13)$ \\
\hline Smith ${ }^{28}$ & $36 \quad(15)$ & $60 \quad(14)$ & $16 \quad(15)$ \\
\hline Yamamoto ${ }^{29}$ & 33 (16) & $76(5)$ & $10 \quad(18)$ \\
\hline Rhind $^{30}$ & 32 (17) & $55 \quad(17)$ & 13. (16) \\
\hline Valtonen" & $31 \quad(18)$ & 67 (9) & 13. (16) \\
\hline
\end{tabular}

- RCIS with equal scores are given the same ranking in the hierarchy.

1 Weighted methods scores as presented in (Table 2).

2 Methods scores under the assumption that all criteria assigned a question-mark would have received points if relevant information had been available. Points reflecting, "insufficient information" (Table 2) have been added to the weighted methods score.

3 Methods scores under the assumption that all methodological criteria are equally important: methods scores are calculated without the use of weighting factors.

\section{Comparison of NSAIDS with placebo intervention or other treatment modalities}

Table 4 summarizes the design and results of 5 RCTS which have included a placebo treatment and/or other treatment modalities for shoulder complaints. The RCTS varied considerably with respect to the type of NSAID used, dosage schedule, diagnosis or indication, duration of complaints and the exact definition of success. These differences may account for some of the variation in success rates between RCTS, which ranged from $20 \%{ }^{14}$ to $86 \%^{16}$ in groups taking NSAIDS.

Four of these 5 RCTS scored more than 50 points ${ }^{14-16,18}$. The RCT described by Petri et al. ${ }^{14}$ was assigned the highest methods score (57 points). In this RCT, naproxen was compared with triamcinolone injections in 100 patients with a painful shoulder, using a double-dummy technique to ensure blinding of both patient and physician. All 4 intervention groups received an injection (triamcinolone or lidocaine) as well as tablets (naproxen or placebo). After 2 weeks, improvement in functional status and range of movement was significantly larger when using naproxen than placebo tablets (group i versus iv in Table 4). This difference was not statistically significant after conclusion of the intervention period at 4 weeks. 
Mena et al. ${ }^{16}$ conducted the only RCT in this review which compared a NSAID (flurbiprofen) with placebo tablets in patients with acute tendinitis or bursitis of the shoulder. The results show a significant difference in favour of flurbiprofen. This publication received a relatively high methods score ( 54 points). In all, only 4 RCTS compared the efficacy of NSAIDS with a placebo intervention, using placebo tablets alone $^{16}$ or in combination with local infiltration of an anaesthetic or corticosteroid ${ }^{14,15,15}$. Three of these RCTS, all of relatively high methodological quality, demonstrated superior short-term efficacy of NSAIDS ${ }^{1416}$.

In 2 out of 4 RCIS comparing NSAIDS with other treatment modalities, corticosteroid injections appeared to be significantly more effective than NSAIOS ${ }^{14,15}$.

\section{Comparison between two types of NSAIDS}

The majority of the RCTS included in this review were designed to study the differences between NSAIDS, with respect to efficacy or tolerability, and have not included a placebo intervention. Details of the design and results of 14 comparative RCTS are presented in Table 5.

Success rates in the intervention groups varied between $10 \% 26$ and $79 \%^{22,29}$, As mentioned earlier, this variation may partly be the result of differences with respect to intervention protocol, characteristics of the study population and the exact definition of success. Due to the intention-to-treat analysis, in some RCTS our calculations produced lower success rates than the results reported in the original publications ${ }^{19,21,27,31}$. Menkes ${ }^{19}$ presented success rates of $62 \%$ (etodolac) and $43 \%$ (piroxicam) for patients who did not deviate from the protocol, whereas we calculated success rates of $46 \%$ and $33 \%$, respectively (Table 5 ).

The RCTS revealed few differences between the various types of NSAIDS. With the exception of the study by Valtonen ", the conclusions of all RCTS were rated 'negative'. Valtonen demonstrated a significantly larger improvement of a combined symptom score in patients receiving diclofenac than in patients receiving naproxen. This difference was only statistically significant after 1 week, halfway through the intervention period. According to Yamamoto et al. ${ }^{29}$, indomethacin was more effective than piroxicam with respect to relief of pain, but these differences were not reflected by differences in success rates. Smith et al. ${ }^{28}$ reported a significantly larger reduction of pain at night for piroxicam, compared with naproxen. However, it must be noted that the intervention groups were not comparable with respect to severity of nocturnal pain at baseline. There was no adiustment for this difference in the analysis of the results. Methods scores of these 3 RCTS ${ }^{28,29,31}$ were low (31, 33 and 36 points, respectively). Only one of the RCTs listed in Table 5 was assigned more than 50 points ${ }^{17}$. In this RCT the efficacy and tolerability of diclofenac (187 patients) was compared with a combination of diclofenac and misoprostol (185 patients). The two formulations proved to be of equal efficacy, showing similar success rates and improvement in tenderness, pain and range of movement.

In Table 6 the results of power calculations are presented for each RCT. Only 3 RCTS were designed with sufficient power $(1-B>0.80)$, to demonstrate a difference in success rate of $25 \%{ }^{17,20,29}$. 
Table 4. Details of RCTS studying the efficacy of NSADS for shoulder complaints: comparison with placebo treatment or other treatment modalities.

\begin{tabular}{lll}
\hline First authoret. & $\begin{array}{l}\text { Treatment with NSAD* } \\
\text { (no. of patients) }\end{array}$ & $\begin{array}{l}\text { Reference treatment (s) } \\
\text { (no. of patients) }\end{array}$
\end{tabular}

\begin{tabular}{|c|c|c|c|c|}
\hline Petri ${ }^{14}$ & ii & $\begin{array}{l}\text { Naproxen } 1000 \mathrm{mg} \text { daily for } 4 \text { weeks plus } 1 \mathrm{x} \\
\text { intrabursal injection of lidocaine (25) } \\
\text { Naproxen } 1000 \mathrm{mg} \text { daily for } 4 \text { weeks plus } 1 \mathrm{x} \\
\text { intrabursal injection of lidocaine and } \\
\text { triamcinolone (25) } \\
\text { double-dummy }\end{array}$ & iv & $\begin{array}{l}\text { Naproxen matched placebo tablets plus } 1 \mathrm{x} \\
\text { intrabursal injection of triamcinolone and } \\
\text { lidocaine (25) } \\
\text { Naproxen matched placebo tablets plus ix } \\
\text { intrabursal injection of lidocaine (25) }\end{array}$ \\
\hline Adebajo's & ; & $\begin{array}{l}\text { Diclofenac } 150 \text { mg daily for } 4 \text { weeks plus } 1 \mathrm{x} \\
\text { subacromial injection of lignocaine }(20) \\
\text { double-dummy }\end{array}$ & iii & $\begin{array}{l}\text { Diclofenac matched placebo tablets plus } 1 \times \\
\text { subacromial injection of lignocaine and } \\
\text { triamcinolone (20) } \\
\text { Diclofenac placebo tablets plus } 1 \times \text { subacromial } \\
\text { injection of lignocaine }(20)\end{array}$ \\
\hline Mena $^{16}$ & i & $\begin{array}{l}\text { Flurbiprofen, dosage decreasing from } 300 \mathrm{mg} \\
\text { to } 200 \mathrm{mg} \text { daily for a maximum period of } \\
14 \text { days (35) }\end{array}$ & ii & Flurbiprofen matched placebo tablets (34) \\
\hline Berry ${ }^{18}$ & $i$ & $\begin{array}{l}\text { Tolmetin sodium } 1200 \mathrm{mg} \text { daily for } 4 \text { weeks } \\
\text { plus ix intra-articular injection of } \\
\text { prednisolone and lignocaine (12) }\end{array}$ & $\begin{array}{l}\text { ii } \\
\text { iii } \\
\text { iv } \\
\text { v }\end{array}$ & $\begin{array}{l}\text { Tolmetin matched placebo tablets plus } 1 \times \\
\text { injection of prednisolone + lignocaine (12) } \\
\text { Ultrasound therapy (12) } \\
\text { Tolmetin matched placebo tablets plus placebo } \\
\text { ultrasound therapy (12) } \\
\text { Acupuncture }\end{array}$ \\
\hline White ${ }^{\text {s }}$ & i & $\begin{array}{l}\text { Indomethacin } 100 \text { mg daily for } 25 \text { days } \\
\text { plus } 1 \mathrm{x} \text { intrabursal injection of saline (20) } \\
\text { double-dummy }\end{array}$ & ii & $\begin{array}{l}\text { Indomethacin placebo matched tablets plus Ix } \\
\text { intrabursal injection of triamcinolone }(20)\end{array}$ \\
\hline
\end{tabular}

SR - Success Rate

ROM - Range Of Movement

$95 \% \mathrm{Cl}-95 \%$ Confidence interval

- Some RCTS have used a double-dummy system in order to maintain the double-blind nature of the trial. Additional placebo tablets or injections are provided for each intervention group, matched to the reference medication.

\section{Adverse reactions}

Adverse reactions were reported by $8 \%^{14}$ to $76 \%^{30}$ of the patients, receiving NSAIDS (Tables 4 and 5). Side-effects were mainly of gastrointestinal nature or included skin rash, headache or dizziness. Adverse reactions were usually considered to be of a moderate or mild nature, and were the reason for withdrawal in less than $10 \%$ of all participants in most RCTS. However, Rhind et al. ${ }^{30}$, Friis et al. ${ }^{20}$ and Famaey and Ginsberg $^{24}$ reported higher drop-out rates due to side-effects: 20,19 and $12 \%$, respectively. In RCTS comparing 2 different types of NSAIDS, the incidence of adverse reactions was approximately similar, except for the RCTS conducted by Friis et al. ${ }^{20}$, Huskisson et al. ${ }^{26}$ and Zuinen ${ }^{17}$ (Table 5). 


\begin{tabular}{|c|c|c|}
\hline $\begin{array}{l}\text { Methods } \\
\text { score }\end{array}$ & $\begin{array}{l}\text { Results } \\
\text { (p-values }<0.05 \text { were considered significant) }\end{array}$ & $\begin{array}{l}\text { \% Patients with } \\
\text { adverse reactions }\end{array}$ \\
\hline 57 & $\begin{array}{l}\text { Improvements of ROM and limitation of function were significantly larger when using } \\
\text { naprosen than placebo at } 2 \text { weeks. At } 4 \text { weeks naproxen was not significantly better } \\
\text { than placebo. } \\
\text { Triamcinolone was superior to naproxen in relief of pain and global clinical index. } \\
\text { SRs (perfect score of global index after } 4 \text { weeks: } 20 \%(0,28 \%(i i), 28 \% \text { (iii), } 8 \% \text { (iv). } \\
\text { Difference i vs iv: } 12 \%, 95 \% \mathrm{Cl}(-6,31) \text {. }\end{array}$ & $\begin{array}{l}8 \% \text { (i) } \\
16 \% \text { (ii) } \\
12 \% \text { (iii) } \\
12 \% \text { (iv) }\end{array}$ \\
\hline 56 & $\begin{array}{l}\text { Groups } i \text { and ii showed significant benefit over those taking placebo in improvement of } \\
\text { pain, ROM and functional limitation. SRs (improvement in all three outcome measures) } \\
\text { was significantly higher in group ii than in i and iii (SRs: } 70 \%, 30 \%, 0 \% \text {, respectively). } \\
\text { Difference i vs iii: } 30 \%, 95 \% \mathrm{Cl}(10,50) \text {. }\end{array}$ & $?$ \\
\hline 54 & $\begin{array}{l}\text { The pattern of dose reduction during treatment was evident in group i, not in ii. } \\
\text { Group i showed a larger proportion of patients with improvements in pain, tenderness, } \\
\text { swelling, and ROM. SRs (better according to investigator) were: } 86 \% \text { (i) and } 56 \% \text { (ii). } \\
\text { Difference: } 30 \%, 95 \% \mathrm{Cl}(10,50) \text {. }\end{array}$ & $\begin{array}{l}238 \text { (i) } \\
9 \% \text { (ii) }\end{array}$ \\
\hline 52 & $\begin{array}{l}\text { There were no significant differences in pain score, ROM and SR between the five } \\
\text { groups. SRs (success according to the investigator) were } 50 \% \text { (i), } 50 \% \text { (ii), } 50 \% \text { (iii), } \\
75 \% \text { (iv), } 42 \% \text { (v). } \\
\text { Difference ivs ii: }-8 \%, 95 \% \mathrm{Cl}(-48,32) \text {. }\end{array}$ & $\begin{array}{l}\text { active tolmetin: } \\
33 \%(i) \\
\text { placebo: } \\
25 \%(i i+\mathrm{M})\end{array}$ \\
\hline 40 & $\begin{array}{l}\text { In each group pain and ROM improved significantly, but there were no significant } \\
\text { differences between the groups. SRs (global assessment score s } 4 \text { ) were: } 50 \% \text { (i) } \\
\text { and } 45 \% \text { (ii). Difference: } 5 \%, 95 \% \mathrm{Cl}(-26,36) \text {. }\end{array}$ & $?$ \\
\hline
\end{tabular}

- Success rates (SR) were calculated according to the intention-to-treat principle, using data presented in the original publications. Unless stated otherwise, results are presented for success rates according to the patient. For each RCT the definition of success rate is given in the last column. Differences between success rates were calculated together with the $95 \%$ confidence intervals, using the following equation:

$$
\begin{aligned}
& \left(p_{i}-p_{c}\right) \pm z_{\alpha} x \sqrt{p_{i}\left(1-p_{i}\right) / n_{i}+p_{c}\left(1-p_{c}\right) / n_{c}} \\
& p_{i}-\text { success rate in group } i \text { (NSAIDS) } \\
& p_{c}=\text { success rate in the reference group } \\
& z_{\alpha}=1.96
\end{aligned}
$$

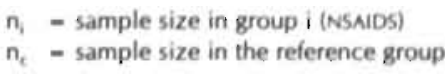

Notwithstanding a higher incidence of gastrointestina! side-effects in his RCT, Zuinen recommends use of the combined formulation diclofenac/misoprostol, referring to previous studies in rheumatoid arthritis and osteoarthritis in which misoprostol was ascribed a gastroprotective benefit.

The issue of benefit-risk ratio was only addressed by Menkes ${ }^{19}$, who calculated the ratio of opinions on efficacy and safety of both patient and investigator, with very similar results for the two NSAIDS under study, etodolac and piroxicam. 
Table 5. Details of RCTS studying the efficacy of NSAD shoulder complaints: comparison between two NSAIDS.

\begin{tabular}{lll}
\hline First author"d & $\begin{array}{l}\text { Treatment with NSAIO* } \\
\text { (no, of patients) }\end{array}$ & $\begin{array}{l}\text { Alternative treatment with NSADS } \\
\text { (no, of patients) }\end{array}$ \\
\hline Zuinen $^{17}$ & $\begin{array}{l}\text { i Diclofenac/misoprostol for } 2 \text { weeks (185) } \\
100-150 \mathrm{mg} / 400-600 \mu \mathrm{g} \text { daily }\end{array}$ & ii Diclofenac, 100-150 mg daily for 2 weeks (187)
\end{tabular}

Menkes's i Etodolac $400 \mathrm{mg}$ daily for 2 weeks (52)
double-dummy

Friis ${ }^{20}$

Duke" $\quad$ i Naproxen 825 mg daily for 4 weeks (30) double-dummy

Thumbn 27 Fentiazac $400 \mathrm{mg}$ daily for 3 weeks (19)

Ginsberg $^{23}$ i Slow release fentiazac $300 \mathrm{mg}$ daily: $1 \mathrm{x}$ daily 1 tablet for 2 weeks (17) double-dummy

Ginsberg 2 i Slow release fentiazac $300 \mathrm{mg}$ daily; 1x daily i tablet for 2 weeks (17) double-dummy

Famaey ${ }^{24}$ i Ibuprofen 1600 mg daily for 2 weeks (25)

Huskisson $^{26}$ i Diclofenac 150 mg daily for 2 weeks (20) double-dummy

Wielandts $^{27}$ i Fentiazac $400 \mathrm{mg}$ daily for 1 week (14) (one patient with tendinitis of the elbow was included in the RCT)

Smith $^{20} \quad$ i Piroxicam $20 \mathrm{mg}$ daily for 21 days (20) double-dummy

Yamamoto's i Indomethacin $25 \mathrm{mg}$ daily for 2 weeks (148, 67 with PHS) double-dummy

Rhind $^{10} \quad$ i Naproxen 750 mg daily for 4 weeks (20) double-dummy ii Piroxicam $40 \mathrm{mg}$ daily for 2 days, followed by $20 \mathrm{mg}$ daily for 12 . days (52)

ii Conventional ibuprofen $2400 \mathrm{mg}$ daily: $2 x$ daily 1 tablet for 3 weeks (74)

ii Indomethacin $100 \mathrm{mg}$ daily for 4 weeks (29)

ii Diclofenac $50 \mathrm{mg}$ daily for 3 weeks (19)

ii Conventional f́entiazac $400 \mathrm{mg}$ daily: $4 \mathrm{x}$ daily 1 tablet for 2 weeks (15)

ii Conventional fentiazac $200 \mathrm{mg}$ daily: $2 \times$ daily 1 tablet for 2 weeks (16)

ii Diclofenac. $100 \mathrm{mg}$ daily for 2 weeks (25)

ii Ibuprofen $1200 \mathrm{mg}$ daily for 2 weeks (20)

ii Phenylbutazone $400 \mathrm{mg}$ daily (12)

ii Naproxen $250 \mathrm{mg}$ daily for 21 days (20)

ii Piroxicam $20 \mathrm{mg}$ daily for 2 weeks (147, 79 with PHS)

ii Indomethacin $50 \mathrm{mg}$ daily for 4 weeks (21)

Vạttonen" i Diclofenac sodium 25 mg daily for two weeks (60, 16 with shoulder complaints) double-dummy 
Consult table 4 for legend

\begin{tabular}{|c|c|}
\hline $\begin{array}{l}\text { Methods } \\
\text { score }\end{array}$ & $\begin{array}{l}\text { Results * } \\
\text { (p-values }<0.05 \text { were considered significant) }\end{array}$ \\
\hline 54 & $\begin{array}{l}\text { Both groups showed steady improvements in pain, limitation of movement and } \\
\text { tenderness, but there were no significant differences between the groups, } \\
\text { SRs (maximal or moderate improvement from baseline) are } 48 \% \text { (i) and } 478 \text { (ii). } \\
\text { Difference: } 18,95 \% \mathrm{CI}(-4,6) \text {. }\end{array}$ \\
\hline
\end{tabular}

49 Both groups improved significantly within 1 week, but there were no significant differences with regard to spontaneous pain, pain on movement, functional score, and use of acetaminophen. SRs (better compared to initial state): $46 \%$ (0) and $33 \%$ (ii). Difference: $13 \%, 95 \% \mathrm{Cl}(-6,32)$.

49 A significantly larger proportion showed complete relief of pain in group it $21 \%$ versus $7 \%$. SR (better or complete relief) was not significantly different between the groups: $66 \%$ (i) and $76 \%$ (ii). Difference: $-10 \%, 95 \% \mathrm{Cl}(-25,5)$.

Difference: $4 \%, 95 \% \mathrm{CI}(-24,32)$.

Difference: $5 \%, 95 \% \mathrm{Cl}(-15,25)$.

There were no significant differences with respect to tenderness, pain, function loss or ROM. SRs (improved compared to initial state) were $50 \%$ (i) and $42 \%$ (ii).

Difference: $8 \%, 95 \% \mathrm{Cl}(-30,46)$.

Piroxicam was significantly more successful in relieving pain at night. No drug was superior for treatment of pain on movement or ROM. No data have been given on any measure of global benefit.

Patients' perceptions of improvement slightly favoured indomethacin. SRs (improvement according to the physician) were $79 \%$ (i) and $73 \%$ (ii).

Difference: $6 \%, 95 \% \mathrm{Cl}(-8,19)$.

Results of total symptom score (pain, swelling, tenderness, functional impairment, ROM, disfurbed sleep) were significantly better in group it than in group ii after the 
Table 6. Power calculations for each RCT: the ability of the RCTS to detect a clinically relevant difference* between intervention groups.

\begin{tabular}{|c|c|c|c|c|}
\hline $\begin{array}{l}\text { First } \\
\text { author [ref.] }\end{array}$ & $\begin{array}{l}\text { Mean number of } \\
\text { patients per group }\end{array}$ & $\begin{array}{l}\text { Success rate in least } \\
\text { successful group }\end{array}$ & $\begin{array}{l}\text { Power } \\
(1-\beta)\end{array}$ & Conclusion \\
\hline Petri! ${ }^{14}$ & 25 & $8 \%$ & 0.59 & $\begin{array}{l}\text { positive at } 2 \text { weeks } \\
\text { negative at } 4 \text { weeks }\end{array}$ \\
\hline Adebajo $^{13}$ & 20 & $0 \%$ & 0.68 & positive \\
\hline Mena ${ }^{16}$ & 35 & $59 \%$ & 0.64 & positive \\
\hline Zuinen $^{17}$ & 186 & $47 \%$ & 0.99 & negative \\
\hline Berry' & 12 & $42 \%$ & 0.23 & negative \\
\hline Menkes ${ }^{19}$ & 52 & $43 \%$ & 0.74 & negative \\
\hline Friis $^{20}$ & 74 & $67 \%$ & 0.97 & negative \\
\hline Duke ${ }^{21}$ & 30 & $50 \%$ & 0.52 & negative \\
\hline Thumb ${ }^{22}$ & 19 & $68 \%$ & 0.49 & negative \\
\hline Ginsberg $^{23}$ & 16 & $53 \%$ & 0.31 & negative \\
\hline Ginsberg $^{23}$ & 17 & $47 \%$ & 0.31 & negative \\
\hline Famaey ${ }^{24}$ & 25 & $48 \%$ & 0.44 & negative \\
\hline White ${ }^{25}$ & 20 & $45 \%$ & 0.36 & negative \\
\hline Huskisson 26 & 20 & $11 \%$ & 0.46 & negative \\
\hline Wielandts ${ }^{27}$ & 13 & $50 \%$ & 0.25 & negative \\
\hline Smith ${ }^{28 t}$ & 20 & - & - & negative \\
\hline Yamamoto ${ }^{29}$ & 73 & $73 \%$ & 0.99 & negative \\
\hline Rhind $^{30}$ & 21 & $40 \%$ & 0.36 & negative \\
\hline Valtonen" & 16 & $63 \%$ & 0.37 & $\begin{array}{l}\text { positive at } 1 \text { week } \\
\text { negative at } 2 \text { weeks }\end{array}$ \\
\hline
\end{tabular}

- A difference in success rate of $25 \%$ between intervention groups was considered to be clinically relevart. Power (1- $\beta$ ) was calculated according to the formula described by Friedman et al. [13]:

$z_{\beta}=\frac{-z_{a} \sqrt{2 p(1-p)}+\sqrt{N}\left(p_{c}-p_{i}\right)}{\sqrt{p_{c}\left(1-p_{e}\right)+p_{i}\left(1-p_{i}\right)}}$

$p_{i}=$ success rate in group i $\left(p_{c}+25 \%\right)$

$P_{c}-$ success rate in the reference group

$p=$ mean success rate

$\mathrm{N}$ - mear sample size

Values of $z_{8}$ were converted to $B$ using statistical tables of standard normal distributions.

† Smith et al. have not presented data on success rate or any other measure of perceived benefit. Therefore, it was not possible to make a power calculation for this RCT.

\section{Discussion}

Studies of low methodological quality may introduce bias and may consequently result in different effect sizes. Therefore, we assessed the efficacy of NSAIDS for shoulder complaints after evaluation of the methodological quality of the RCTS, in order to avoid conclusions based on RCTS of inferior methodologica! quality. Blinding of the publications enabled us to evaluate the methods of the RCTS objectively. Each methodological criterion was assigned a weighting factor which reflected our assessment of the relative importance of the criteria. These weighted criteria were summated into a final score, reflecting the methodological quality of a RCT. The resulting hierarchical order of RCTS, according to methodological quality, was not severely affected when the methods scores were recalculated under different assumptions. The 6. RCTS with the highest methods scores remained in the first 6 
positions when points were assigned for inadequately described methodological criteria or when weighting factors were totally discarded (Table 3). This means that our scoring system could discriminate between studies of higher and lower methodological quality, regardless of weighting factors. Conclusions on the efficacy of NSAIDs for shoulder complaints were therefore based on RCTS which are listed in the top of our ranking. When weighting factors are used, the quality of the RCTS is measured on a numerical scale, rather than a ranking scale. This may have consequences for concluding statements if final conclusions are based on RCTS with, for example, at least 50 points or a minimum of 60 points for methodological quality.

The methodological quality of the majority of RCTS was disappointingly low; only 5 RCTS received a methods score exceeding 50 points. Furthermore, a considerable amount of information, relevant for the evaluation of the methodological quality, seemed to be missing. An adequate description of the randomization procedure is very important, as valid randomization is the only way to prevent selection bias. A brief description of the randomization procedure was only provided by two RCTS ${ }^{14,15}$. Even when an adequate randomization procedure has been carried out, it does not guarantee equal distribution of prognostic factors and confounding variables among the study groups, particularly when a study size is small. Documentation of relevant prognostic indicators and baseline rates of outcome measures gives some indication whether the randomization procedure has been successful for these variables. However, in a considerable number of RCTS, baseline characteristics were not presented, or only partly presented (Table 2). In addition, only 4 RCTS received points for description of co-interventions ${ }^{20,21,26,27}$ or control of compliance ${ }^{16,20,28}$. Interpretation of the efficacy of NSAIDS is difficult when information on the use of co-interventions is limited and no information is presented with respect to the adherence of the participants to the treatment regimen. A complete and more informative report may have revealed additional flaws in the design or conduct of the RCTs included in this review.

In our scoring system no category for the quality of outcome measure is included, although this is a very relevant aspect of a clinical trial. Apart from the frequently applied visual analog scales for pain, a wide variety of outcome measures was used for the assessment of global improvement, functional limitation, swelling and tenderness. Most of these measures have probably been designed on the basis of face validity, and may have proved useful in clinical practice. A thorough assessment of the quality of outcome measures for shoulder complaints requires a detailed study of their applicability, reliability, validity and responsiveness. Unfortunately, this was not feasible within the scope of this review.

The efficacy of NSAIDS was compared with a placebo intervention in 4 RCTS 14,15,16,18. Three of these RCTS, all highly positioned in our methodological hierarchy, demonstrated the superior short-term efficacy of NSAIDS. Corticosteroid injections showed even better results in 2 of these RCTS ${ }^{14,15}$, but NSAIDS may be considered useful in the short-term management of shoulder complaints. We hoped to find out whether NSAIDS are useful for shoulder disorders in general and, if possible, for which type of patient. In order to detect these differences, RCTS should have a relatively homogeneous study population with respect to prognosis and susceptibility to treatment. However, selection criteria varied over the RCTS and were often inadequately described, or a wide 
variety of patients were included within one RCT. Consequently, there was no strong evidence for any differences in efficacy of NSAIDS between the various indications and diagnoses in this review.

The intention-to-treat analysis for the calculation of success rates may have underestimated true effect rates, but it might also be possible that the review has overestimated effect rates. Publication bias, for example, may have resulted in an over representation in the literature of RCTS with positive results. Definite answers on the efficacy of NSAIDS can only be provided after conducting RCTS of adequate methodological quality and power.

If studies do not recruit a sufficiently large study population, they are a priori only able to detect very large, improbable differences between groups. An adequate sample size enhances the precision of an estimated effect size and enables the detection of more subtle though clinically relevant differences. However, the results of power calculations vary depending on a number of factors, including the goal of the RCT, the choice of outcome measure, the variability of the results of the outcome measure, the size of a clinically relevant difference and the level of significance. We considered a $25 \%$ difference between groups in success rate (on a dichotomous scale) to be clinically relevant. Power calculations showed that only 3 RCTS had sufficient power to detect this rather large difference. These 3 RCTS ${ }^{17,20,29}$ compared different types of NSAIDS and detected only minor differences between intervention groups. The methodological quality of 2 of these powerful RCTS ${ }^{20,29}$ was disappointing. Nevertheless, other RCTS studying the efficacy of NSAIDS in reumatoid arthritis, osteoarthitis, soft tissue rheumatism and sports injuries have also demonstrated that not many differences should be expected between the various types of NSAIDS ${ }^{10,32,33,34}$. Any preference for a particular NSAID will probably be influenced by differences in tolerability, cost or convenience of dosage schedule. The less frequent administration of slow-release formulations may offer advantages in terms of patient compliance, although this issue could not be studied by Friis et al. ${ }^{20}$ or Ginsberg and Famaey ${ }^{23}$. The use of a doubledummy system in these RCTS hindered the assessment of differences in compliance, as all participants received the same number of tablets.

Despite the lack of power of most RCTS, the results of the RCTS were not pooled in order to avoid pooling data from RCTS of widely varying methodological quality. As mentioned earlier, the outcome of studies of low quality may be biased. Furthermore, pooling was impeded by the fact that most RCTS differed considerably with respect to the intervention under study (type of NSAID and dosage schedule), the selection criteria for the study population and the choice of outcome measures. The possibilities of pooling were further restricted by incomplete reporting in some publications with respect to selection criteria and outcome measures.

The tolerability of ṆSAIDS varies considerably between patients, but the use of NSAIDS is quite frequently accompanied by adverse reactions, mostly of gastrointestinal nature. More serious adverse reactions, such as bronchospasm, renal insufficiency, gastrointestinal bleeding, hepatitis and allergic reactions are less often reported and may be prevented by careful prescription ${ }^{35}$. The RCTS in this review reported few differences between NSAIDS with respect to the incidence of adverse reactions. Fries et al. ${ }^{36}$ studied the comparative toxicity of NSAIDS by constructing a summary index of 
symptoms, laboratory abnormalities and hospitization in a large number of patients with rheumatoid arthritis. The most toxic drugs appeared to be indomethacin, tolmetin and meclofenamate, whereas coated aspirin, salsalate and ibuprofen were the least toxic drugs.

Although side-effects were often considered to be moderate or mild in the evaluated RCTS, a substantial number of participants discontinued medication because of adverse reactions. Moreover, it is uncertain whether the NSAIDS were merely effective as an analgesic or also because of their anti-inflammatory properties. It would be interesting to know whether simple analgesics, such as paracetamol, are as effective as NSAIDS without producing the accompanying adverse reactions. Bradley et al. ${ }^{37}$ demonstrated a similar short-term efficacy of acetaminophen and ibuprofen in patients with osteoarthritis, whether ibuprofen was administered in an analgesic or in a higher, antiinflammatory dose. Unfortunately, we could not find any reports of RCTS comparing the efficacy of NSAIDS with simple analgesics for soft-tissue theumatic conditions of the shoulder. Studies comparing the benefit-risk ratios of NSAIDS and analgesics should indicate whether the benefit of NSAIDS outweighs the risk of adverse reactions, which may be avoided by prescribing more simple analgesics. This is particularly relevant for the treatment of musculoskeletal disorders in elderly people, who are at an increased risk of NSAID-induced toxicity ${ }^{36}$.

In conclusion, the RCTS with the highest methods scores seemed to demonstrate a superior short-term efficacy of NSAIDS, compared with a placebo intervention. However, the methodological quality of the majority of RCTS studying the efficacy of NSAIDS for shoulder complaints was rather disappointing. When designing and conducting RCTS studying the efficacy of NSAIDS for shoulder complaints, more attention should be given to recruiting a sufficient sample size, limitation of the number of drop-outs, adequate data analysis and the writing of a more informative report of the RCT. There was no conclusive evidence in favour of any particular type of NSAID. for the treatment of shoulder complaints. Future RCTS should compare the benefit-risk ratios of NSAIDS and analgesics for shoulder complaints, in order to establish whether the use of NSAIDS is more favourable than analgesics, despite the higher risk of adverse reactions from NSAIDS.

\section{References}

1 Bjelle A. Epidemiology of shoulder problems. Bailliere's Clinical Rheumatology 1989; 3: 437-451.

2. Bergenudd H, Lindgărde F, Nilsson B, Petersson Cl. Shoulder pain in middle age. A study of prevalence and relation to occupational work load and psychosocial factors. Clinical Orthopaedics 1988; $231: 234-238$.

3 Chakravarty KK, Webley M. Disorders of the shoulder: an often unrecognised cause of disability in elderly people. British Medical Journal 1990; 300: 848-849.

4 Miedema HS. Reuma-onderzoek meerdere echelons (ROME): basisrapport. Leiden: Nederlands Instituut voor Praeventieve Gezondheidszorg TNO; 1994.

5 Reeves B. The natural history of the frozen shoulder syndrome. Scandinavian Journal of Rheumatology 1975; 4: 193-196.

6 Binder AI, Bulgen. DY, Hazleman BL, Roberts S. Frozen shoulder: A long-term prospective study. Annals of Rheumatic Diseases 1984; $43: 361-364$.

7 Chard MD, Satelle LM, Hazieman BL. The long-term outcome of rotator cuff tendinitis - A review study. British lournal of Rheumatology 1988; 27: 385-389. 
8 Chandnani V, Ho C, Gerharter J, Neumann C, Kursunoglu-Brahme S, Sartoris DJ, Resnick D. MR findings in asymptomatic shoulders: A blind analysis using symptomatic shoulders as controls. Clinical Imaging 1992; 16: 25-30.

9 Stiles RG, Otte MT. Imaging of the shoulder. Radiology 1993; 188: 603-613.

10 Todd PA, Clissold SP. Tenoxicam. An update of its pharmacology and therapeutic efficacy in rheumatic diseases. Drugs 1991; 41: 625-646.

11 Koes BW, Bouter LM, Beckerman H, Van der Heijden GJMG, Knipschild PG. Physiotherapy exercises and back pain: a blinded review. British Medical Journal 1991; 302: 1572-1576.

12 Koes BW, Assendelft WIJ, Van der Heijden GJMG, Bouter LM, Knipschild PG. Spinal manipulation and mobilization for back and neck pain: a blinded review. British Medical Journal 1991; 303: 12981303.

13 Friedman, LM, Furberg CD, Demets DL. Fundamentals of clinical trials. Littleton MA: PSG Publishing Company Inc; 1985.

14 Petri M, Dobrow R, Neiman R, Whiting-O'Keefe Q, Seaman WE. Randomized, double-blind, placebo-controlled study of the treatment of the painful shoulder. Arthritis and Rheumatism 1987; 30: 1040-1045.

15 Adebajo AO, Nash P, Hazleman BL. A prospective double blind dummy placebo controlled study comparing triamcinolone hexacetonide injection with oral diclofenac $50 \mathrm{mg}$ TDS in patients with rotator cuff tendinitis. The Journal of Rheumatology 1990; 17: 1207-1210.

16 Mena HR, Lomen PL, Turner LF, Lamborn KR, Brinn EL. Treatment of acute shoulder syndrome with flurbiprofen. American Journal of Medicine 1986; 80: 141-144.

17 Zuinen C. Dicfofenac/misoprostol vs diclofenac/placebo in treating acute episodes of tendinitis/bursitis of the shoulder. Drugs 1993; 45 suppl 1: 17-23.

18 Berry H, Fernandes L, Bloom B, Clark RJ, Hamilton EBD. Clinical study comparing acupuncture, physiotherapy, injection and oral anti-inflammatory therapy in shoulder-cuff lesions. Current Medical Research and Opinion 1980; 7: 121-126.

19 Menkes Cl. Périarthrite scapulo-humérale: efficacité, tolérance et bénéfice thérapeutique compare de. l'étodolac (600 mg/j) et du piroxicam (40/20 mg/j). Rhumatologie 1990; 42: 195-200.

20 Friis J, Jarner D, Toft B, Christensen K, Christophersen I, Ibfeldt HH, Korsgaard J, Skinhoj A, Andersen F. Comparison of two ibuprofen formulations in the treatment of shoulder tendonitis. Clinical Rheumatology 1992; 11: 105-108.

21 Duke O, Zecler E, Grahame R. Anti-inflammatory drugs in periarthritis of the shoulder: a doubleblind, between-patient study of naproxen versus indomethacin. Rheumatology and Rehabilitation 1981; 20: 54-59.

22 Thumb N, Kolarz G, Scherak O, Mayrhofer F. The efficacy and safety of fentiazac and diclofenac sodium in periarthritis of the shoulder: a multi-centre, double-blind comparison. The lournal of International Medical Research 1987; 15: 327-334.

23 Ginsberg F, Famaey JP. A double-blind comparison of șlow-release and ștandard tablet formulations of fentiazac in the treatment of patients with tendinitis and bursitis. Current Medical Research and Opinion 1985: 9: 442-448.

24 Famaey JP, Ginsberg F. Treatment of periarthritis of the shoulder: a comparison of ibuprofen and diclofenac, Journal of International Medical' Research 1984; 12: 238-243.

25 White RH; Paull DM, Fleming KW. Rotator cuff tendinitis: Comparison of subacromiali injection of a long acting corticosteroid versus oral indomethacin therapy. Journal of Rheumatology 1986; 13: 608613.

26 Huskisson EC, Bryans R. Diclofenac sodium in the treatment of painful stiff shoulder. Current Medical' Research and Opinion 1983; 8; 350-353.

27 Wielandts L, Dequecker D. Double-blind trial comparing fentiazac with phenylbutazone in patients with tendinitis. Current Medical Research and Opinion 1979; 6 suppl 2: 85-89.

28 Smith MD', Thomas D, McCredie M, Brooks PM. Piroxicam versus, naproxen in the treatment of the painful shoulder. Pharmatherapeutica 1986; 4: 585-589.

29 Yamamoto M, Sugano T, Kashiwazaki S, Kageyama T, Mizushima Y, Kameyama M. Double-blind comparison of piroxicam and indomethacin in the treatment of cervico-brachial syndrome and periarthritis scapulohumeralis (stiff shoulder). European fournal of Rheumatology and Inflammation $1983 ; 6: 266-273$.

30 Rhind V, Downie WW, Bird HA, Wright V, Engler C. Naproxen and indomethacin in periarthritis of the shoulder. Rheumatology and Rehabilitation 1982; 21: 51-53. 
31 Valtonen E]. A comparative short-term trial with Voltaren (diclofenac sodium) and naproxen in softtissue theumatism. Scandinavion lournal of Rheumatology 1978; suppl 22: 69-73.

32 Moser $\mathrm{U}$, Walburger $\mathrm{H}$, Schwarz $\mathrm{HA}$, Gobelet $\mathrm{CA}$. A double-blind randomised multicentre study with tenoxicam, piroxicam and diclofenac sodium retard in the treatment of ambulant patients with osteoarthritis and extra-articular rheumatism. Scandinavian loumal of Rheumatology 1989; suppl 80 : $71-80$.

33 Pena M. Etodolac: analgesic effects in musculoskeletal and postoperative pain. Rheumatology International 1990; 10 (suppl): 9-16.

34 Weiler JM. Medical modifiers of sports injury. The use of non-steroidal anti-inflammatory drugs (NSAIDs) in sports soth-tissue injury. Clinical Sports Medicine 1992; 11: 625-644.

35 Avouac B. Adverse effects of long-term treatment with non-steroid anti-inflammatory drugs. In: Munderthaler M, Van Zwieten PA, Farcot JM, editors. Treatment of chronic pain possibilities, Harvard Academic Publications, 1990:47-62.

36 Fries JF, Williams CA, Bloch DA. The relative toxicity of non-steroidal anti-inflammatory drugs. Arthritis and Rheumatism 1991; 34: 1353-1360.

37 Bradley JD, Brandt KD, Katz BP, Kalasinski LA, Ryan SI. Comparison of an anti-inflammatory dose of ibuprofen, an analgesic dose of ibuprofen, and acetaminophen in the treatment of patients with osteoarthritis of the knee. New England fournal of Medicine 1991; 325: 87-91.

38 Afable RF, Ettinger WH. Musculoskeletal disease in the aged. Diagnosis and management. Drugs Aging 1993; 3: 49-59. 



\section{Chapter 5}

\section{The efficacy of ultrasoundtherapy and electrotherapy for shoulder disorders} Results of a randomized placebo-controlled clinical trial

GJMG van der Heijden ${ }^{1,2}$, P Leffers ${ }^{2}$, PJMC Wolters', JJD Verheijden², H van Mameren ${ }^{4}$, IP Houben ${ }^{3}$, LM Bouter ${ }^{5}$, PG Knipschild ${ }^{2}$

1 Institute for Rehabilitation Research, Hoensbroek, The Netherlands

2 Department of Epidemiology, University Maastricht, The Netherlands

3 Hogeschool Heerlen, Health Care sector, Department of Physiotherapy, Heerlen, The Netherlands.

4. Department of Anatomy and Embryology, University Maastricht, The Netherlands.

5 Institute for Research in Extramural medicine, Vrije Universiteit, Amsterdam, The Netherlands 


\section{Abstract}

Purpose The study was designed to assess the efficacy of electrotherapy (ET) and ultrasoundtherapy (US) as adjuvants to exercise therapy for shoulder disorders.

Design Randomized placebo-controlled trial with a 2 by 2 factorial design plus an additional control group without adjuvants.

Setting Seventeen primary care physiotherapy practices in the south of the Netherlands.

Patients Patients with shoulder pain and/or restricted shoulder mobility without underlying generalized disorder were enrolled if they had not recovered with 6 sessions of exercise therapy in 2 weeks.

Interventions Patients received a maximum of 12 sessions of exercise therapy in 6 weeks. Additionally, they were randomized to receive (1) active ET plus active US;

(2) active ET plus dummy US; (3) dummy ET plus active US; (4) dummy ET plus dummy US; or (5) no adjuvants.

Follow-up Outcome measures: recovery, functional status, main complaint, pain, symptoms and restriction of mobility. Measurement at baseline, 6 weeks and 3,6, 9 and 12 months later was blinded for treatment.

Results After written informed consent 180 patients were randomized. Both active and dummy treatments were given to 73 and 72 patients respectively; 35 patients received no adjuvants. The prognosis of groups appeared similar at baseline. Blinding was successfully maintained. At 6 weeks $20 \%$ of the patients without adjuvants reported complete recovery or substantial improvement, $23 \%$ and $22 \%$ with active and dummy ET, and $26 \%$ and $19 \%$ with active and dummy US. These proportions increased up to 3 months, but remained virtually stable thereafter. Up to 12 months follow-up the $95 \% \mathrm{Cl}$ for differences between groups for all outcomes include zero.

Conclusion ET and US, either active or dummy, are inefficacious as adjuvants to exercise therapy for shoulder disorders. 


\section{Introduction}

About $10 \%$ of the population suffer from one or more episodes of shoulder disorders in the course of their life'. Pain and stiffness in the deltoid region are prevalent symptoms. When pain is elicited or aggravated by movement, it usually limits daily activities and restricts the range of motion. Pain when lying on the impaired shoulder commonly causes problems with sleeping ${ }^{1-3}$. Soft-tissue impairment is reported to be the most common source of these symptoms ${ }^{1 / 4}$. A minority of all cases originate from generalized conditions, such as a stroke, polyneuropathy, multiple sclerosis, rheumatoid arthritis, polymyalgia, ankylosing spondylitis, or from malignancies or referred pain from the neck or internal organs ${ }^{4}$.

Of all newly presented episodes of shoulder disorders, in general practice about $50 \%$ resolve within 6 months, but some last over a year 5 . Shoulder disorders make up $10 \%$ of all referrals to physiotherapists ${ }^{6-9}$. Exercise therapy is considered to be the comerstone of physiotherapy for shoulder disorders ${ }^{10}$. However, frequent use of electrotherapy (ET) and ultrasoundtherapy (US), mainly as adjuvants to exercise therapy, has been reported for several countries ${ }^{11-15}$. ET and US are supposed to be effective for soft-tissue shoulder impairment such as bursitis, tendinitis or capsulitis, regardless of its anatomical site. They are both believed. to promote recovery from shoulder disorders by elevation of the pain threshold and promotion of muscle relaxation ${ }^{16-18}$. Furthermore, ET is supposed to support recovery by inhibition of activity of the sympathetic nerve system $^{16}$, and US by enhancement of soft-tissue flexibility, acceleration of tissue repair, promotion of cellular metabolic rate and reduction. of inflammatory reactions of softtissue $\mathrm{e}^{17,18}$.

To date, 7 randomized clinical trials studying the efficacy of US for shoulder disorders ${ }^{19-26}$, and 6 randomized clinical trials studying the efficiacy of ET for shoulder disorders ${ }^{27-31}$ have been published. None of these studies showed a statistically. significant effect in favour of either ET or US. The studies were remarkably different with respect to the type of patients included, the way outcomes were measured and the way ET and US were administered. The validity of their results is jeopardized by insufficient blinding of treatment and outcome assessment, dissimilarities of prognosis. of groups at baseline, too short follow-up, withdrawal from treatment and loss to followup and missing data ${ }^{32}$. In addition, the studies lack statistical power due to small sample sizes $^{32}$. Therefore, doubt persists about the efficacy of ET and US for shoulder disorders, applied either separately or as an adjuvant to exercise therapy ${ }^{32,33}$. In the present randomized placebo-controlled trial we studied the efficacy of ET and US as adiuvants to exercise therapy for patients with shoulder disorders.

\section{Methods}

\section{Enrolment}

Potential participants, were patients of 18 years and older, who had been referred to cooperating private physiotherapy practices in primary care $(n-17 ; 2$ therapists per practice) by general practitioners or hospital physicians. Patients with either or both [1] pain in the deltoid region that could be elicited or aggravated by active or passive 
glenohumeral movement and [2] a restricted passive range of glenohumeral motion were selected if the therapist considered [3] US and ET to be indicated.

Patients with a stroke; polyneuropathy; multiple sclerosis; rheumatoid arthritis; polymyalgia; ankylosing spondylitis; referred pain from the neck or from internal organs; prior fractures or prior surgery of the shoulder, upper limb, neck or thorax were excluded. Also excluded were patients with contra-indications for the study treatments, i.e. malignancy; haemophilia; motor and sensory deficits in the shoulder, upper limb, neck or thorax.

Patients willing to take part entered a 2 -week qualification period ${ }^{34}$ with a maximum of 6 sessions of at least 20 minutes of exercise therapy. In addition, they received a booklet containing advice on continuation and adaptation of shoulder activities, and protection of the shoulder from overuse. At the end of the qualification period the research physiotherapist (JJDV) excluded patients who were completely or nearly completely free of symptoms; who indicated reluctance to adhere to the allocated treatment or to complete follow-up and who had already received ET or US during the current episode. Next, she excluded patients on the basis of information obtained from referring physicians about exclusion criteria and contraindications or after identifying shoulder hypermobility; complete rotator cuff tears; referred pain in the shoulder; glenohumeral joint inflammation; wounds and defects of the skin in the shoulder, upper limb, neck or thorax during a standardized clinical assessment (consult legend of Table 1 for elements included in the clinical assessment).

Subsequentiy, the research physiotherapist excluded patients with substantial improvement, who fulfilled 3 or 4 of the following putative indicators of a favourable prognosis: [1] only dominant side impaired, [2] first episode ever, [3] no pain radiating below the elbow, [4] no co-existent cervical or elbow disorder. She also excluded patients without any improvement, who fulfilled 3 or 4 of the following putative indicators of a poor prognosis: [1] non-dominant side or bilaterally impaired, [2] prior episodes, [3] pain radiating below the elbow, [4] co-existent cervical or elbow disorder. Written consent was provided by patients who qualified for participation. Finally, the research physiotherapist documented putative prognostic indicators and baseline values of outcome measures.

\section{Treatment assignment}

After stratification for physiotherapy practice and involvement of the dominant side, treatment was assigned. In order to balance treatment groups within the strata, randomized permuted blocks were generated per stratum. With equal weights within the blocks patients were randomized to receive [1] active ET plus active US; [2] active ET plus dummy US; [3] dummy ET plus active US; [4] dummy ET plus dummy US; or [5] no adjuvants. Sealed opaque envelopes were prepared and numbered accordingly. These contained specific instructions for the therapist concerning the use of the treatment device. The research physiotherapist labelled the appropriate envelope with the patient's name and identification number in accordance with the order in which patients enrolled. The envelope was sent to the appropriate therapist, who opened it at the first treatment session. 


\section{Interventions}

After randomization, 12 treatment sessions were given over 6 weeks. Treatment could be stopped before the $12^{\text {th }}$ session if a patient was free of symptoms. We asked the patients and therapists to refrain from non-study treatments (e.g. stroking and kneading massage, deep friction, orthopaedic manipulation and steroid injections) until 3 months after randomization. Analgesics and NSAIDS taken during the qualification period could be continued after randomization.

The 17 physiotherapy practices were provided with identical devices, with a $5 \%$ range for output calibration. In each session the same, fixed sequence of treatments was applied: [1] ET, [2] US and [3] exercise therapy.

\section{Electrotherapy}

A $4 \mathrm{KHz}$ sinusoidal bi-phasic electric current with a modulated amplitude was administered. The frequency of the amplitude modulation varied between 60 and 100 $\mathrm{Hz}$ with constant phases of 2 seconds and a fade in and fade out of 1 second each. This electric current had no resulting galvanic charge. With a non-painful intensity it has been reported to selectively excite large diameter nerve fibres ${ }^{36}$. According to the gate control principle, this excitation is considered to temporarily inhibit transmission of nociceptive signals in the spinal dorsal horn from pain mediating small diameter nerve fibres $^{16}$. An intensity sufficient to evoke electric paraesthesia would be a precondition for this effect ${ }^{37}$. Postponement of stimulus habituation by frequency modulation and an increase of the intensity of the current should lengthen the episodes of electroanalgesia ${ }^{37}$.

For each patient 2 reusable hypoallergic self-adhering electrodes $(5 \times 9 \mathrm{~cm})$ were used; one was placed in the deltoid region, the other over the homolateral erector trunci, parallel to the spine between the processus spinosus of the $4^{\text {th }}$ and $9^{\text {th }}$ thoracic vertebrae. Stimulation with the deltoid electrode should produce electroanalgesia in the shoulder by inhibition of signal transmission in the dorsal horn of the $4^{\text {th }}$ and $5^{\text {th }}$ cervical spinal segments. It has been postulated that sympathetic outflow from the lateral horn of the $4^{\text {th }}$ to the $9^{\text {th }}$ thoracic spinal segments, through the stellate ganglion, sensitizes for shoulder pain as a result of which can cause, amplify and maintain pain ${ }^{36}$. Stimulation of large diameter cutaneous nerve fibres of the ramus dorsalis of the $4^{\text {th }}$ to the $9^{\text {th }}$ thoracic spinal segments with the thoracic electrode should diminish this sympathetic outflow to the shoulder and thus contribute to alleviation of shoulder pain. This electrotherapeutical concept is commonly recommended and used ${ }^{16,35}$. The position of both electrodes was kept fixed during all treatment sessions.

The therapist administered either active or dummy ET according to the instructions from the randomization envelope. Active ET: the therapist quantified the intensity for the perception-threshold of electric paraesthesia at the start of each session. Subsequently, the therapist raised the intensity so that the patient felt intense non-painful electric paraesthesia under both electrodes, without continuous muscle contractions. When after a while stimulus habituation occurred, i.e. the electric paraesthesia diminished, the therapist raised the intensity until paraesthesia was felt again. Active ET treatment took 15 minutes at the most, or was stopped earlier after the third habituation. Dummy ET: the therapist quantified the intensity for the perception-threshold of electric. 
paraesthesia at the start of each session and repeated this 5, 10 and 15 minutes later. After each threshold determination, the therapist immediately set the intensity to zero. Hence, there was no electric output between subsequent determinations of the threshold. The duration of dummy ET treatment was fixed at 15 minutes.

\section{Ultrasoundtherapy}

The frequency of the US beam was $0.8 \mathrm{MHz}$, and the effective radiating transducer area was $4 \mathrm{~cm}^{2}$. In order to reduce the risk of hot spots and subsequent tissue damage due to reflection and interferential phenomena over superficial bone structures, intermittent US with a duty cycle of $20 \%$ (i.e. on-off ratio of 2:8) and slow circular transducer movements was applied. The transmission of US was enhanced by the use of inert aquasonic hypo-allergic coupling-gel. The therapist set the treatment device to a code included in the instructions from the randomization envelope. Only the manufacturer knew the identity of the 10 codes for active US and the 10 codes for dummy US.

The US beam was directed at the impaired soft-tissue structure identified by the therapist during a clinical assessment at the start of the first session. Sonation time was fixed at $2 \mathrm{~min} / \mathrm{cm}^{2}$ of the tender area over this structure. The spatial average temporal average (SATA) transducer output to which the device was to be set was calculated by' adding the estimated energy absorption between the transducer and the identified lesion to a fixed minimum penetration of $0.25 \mathrm{Watt} / \mathrm{cm}^{2}$.

With the fixed sonation time and a beam non-uniformity ratio ranging from 4 to 6 , sonation resulted in an exposure far above 50 Joules $/ \mathrm{cm}^{2}$ that is reported to be the threshold for biostimulation in mammalian tissue ${ }^{35}$. At the first session, the therapist calculated the SATA transducer intensity and the total sonation time. These values were kept constant during all subsequent sessions.

\section{Exercise therapy}

Exercise therapy during the qualification period and after randomization was adjusted to individual symptoms. Each session the treatment goals had to include pain reduction and mobility improvement. Muscle relaxation and strengthening were additional treatment goals. Exercise methods comprised active and passive abduction, flexion, internal and external rotation, extension, and adduction, as well as stretching, functional training and proprioceptive neuromuscular facilitation techniques.

\section{Blinding}

US and ET without output were used as dummy treatments. The display of the treatment device was identical for active and dummy treatments. During all treatments the device beeped every 15 seconds and its cooling fan was constantly running. In order to keep the patient and the therapists blinded for the identity of US, the transducer automatically heated to $30^{\circ} \mathrm{Celsius}$ before the codes from the randomization envelope could be set. The therapist knew which patient received active or dummy ET. In order to keep patients masked, therapists were asked not to talk about the identity of ET with patients. Blinding of therapists or patients for adjuvant treatment is obviously impossible due to the very nature of adjuvant treatment. Blinding of patients for active and dummy treatments was verified 6 weeks after randomization. In order to keep the research physiotherapist blinded during outcome assessment, patients were asked not to talk about treatments with her. 


\section{Outcome assessment}

Patients were asked not to take analgesics or NSAIDS 24 hours before each outcome assessment. At baseline and at 6 weeks, 3, 6, 9 and 12 months patients were asked to rate recovery and functional status by completing a questionnaire. During outcome assessments up to 3 months, patients rated the severity of restriction of daily activities, various dimensions of shoulder pain and their main complaint, after reviewing their previous scores. Based on a standardized clinical assessment at baseline and 6 weeks and 3 months thereafter, the research physiotherapist than rated restriction of functional shoulder mobility and symptom severity (consult legend of Table 1 for elements included in the clinical assessment). She also checked for side effects.

\section{Data analysis}

Data analysis was performed with SPSS ${ }^{39}$ and Minitab ${ }^{40}$, according to the intention-totreat principle. Blinding was broken after completion of the data analysis. We calculated proportions of patients indicating complete recovery or substantial improvement. The calculated $95 \%$ confidence intervals $(\mathrm{Cl})$ of differences between groups for these proportions are based on a Chi-square test. For all other outcome measures we calculated changes in severity scores for each patient by subtracting the baseline values from the respective follow-up values. For all groups these change scores had a non-Gaussian distribution. Therefore, the calculated $95 \% \mathrm{Cl}$ for median differences between groups were based on the rank-sumtest ${ }^{41}$. Interaction between US and ET and the influence of prognostic indicators and baseline values of outcome measures on recovery was examined by means of a linear multivariable regression analysis.

\section{Results}

\section{Enrolment and baseline similarity}

Figure 1 summarizes the routing of patients through the study. In total 855 patients were screened in participating practices. Of the 343 patients who entered the qualification period 180 were finally randomized. Table 1 shows that the groups were similar with respect to the prognostic indicators and baseline values of outcome measures.

The mean number of patients recruited per practice was 11 (range: 4-27). In 8 practices less than 10 patients were recruited, 7 practices recruited befween 10 and 20 patients, while 1 practice recruited 22 and another one 27 patients. Ten practices together filled. up 20 blocks (twice 4 blocks, and each four times 1 block and 2 blocks), while 7 practices recruited insufficient numbers of patients to fill up at least one block.

\section{Interventions}

\section{Electrotherapy}

For dummy. ET the median intensity for the perception-threshold of electric paraesthesia was 15. milli-Amperes (interquartile range [IQR]: 9, 28). The median intensity of this threshold for active ET, determined at the start of each session, was 14 milli-Amperes (IQR: 10, 26). There was virtually no within-subject change during subsequent freatment sessions for this threshold. The 3 subsequent stimulus habituations during active ET occurred after 3. minutes (median, range 1-5), with a median intensity of 29, 34 and 39 milli-Amperes, respectively. 


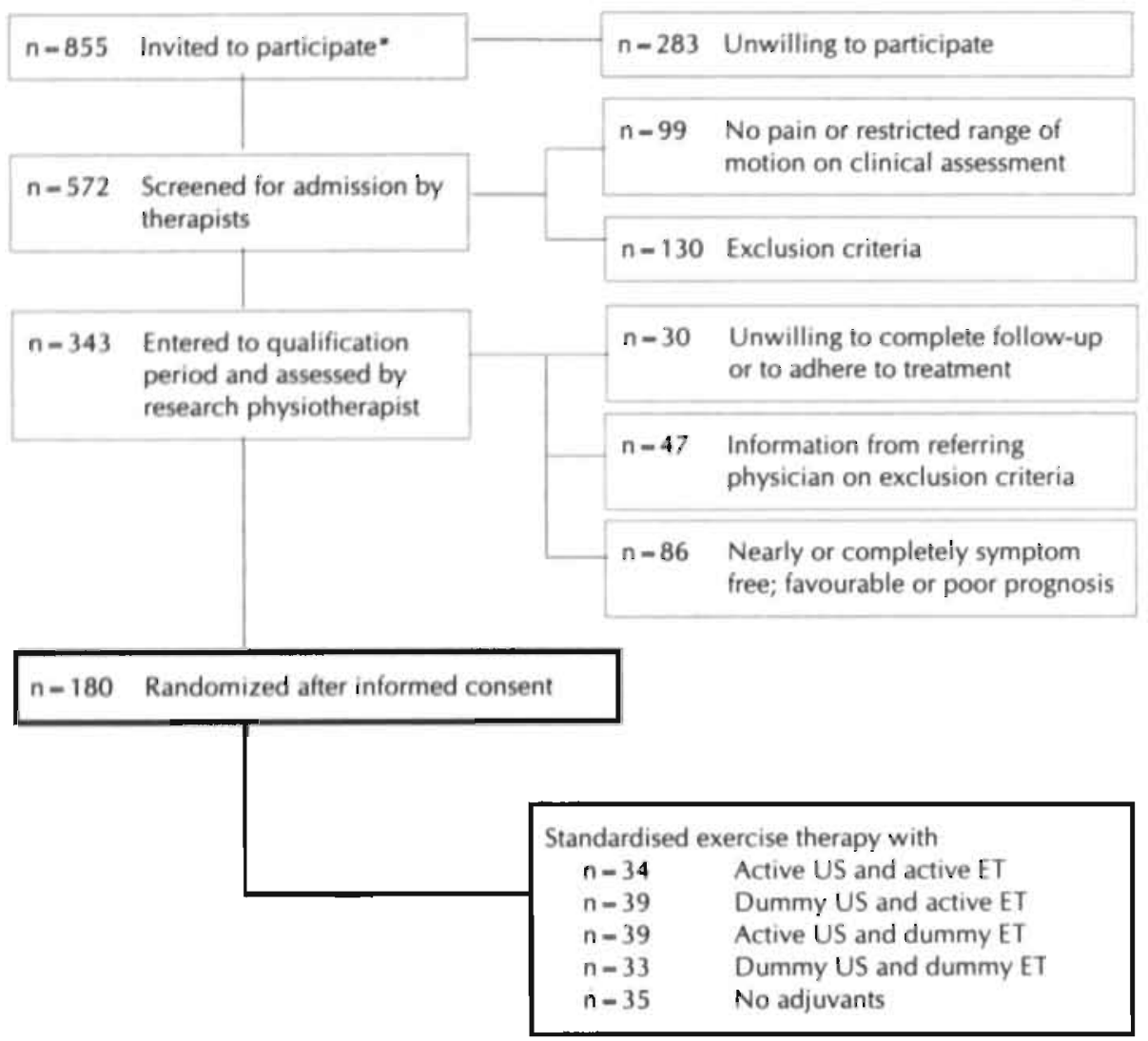

* Between 1 May 1992 and 1 November 1994

Figure 1. Routing of patients.

\section{Ultrasoundtherapy}

For active US, the median SATA transducer was $0.6 \mathrm{Watt} / \mathrm{cm}^{2}$ and the exposure through the identified impaired soft-tissue structure was $107 \mathrm{Joules} / \mathrm{cm}^{2}$ (median; IQR: 85,124 ). Although there was no output for dummy US, according to the device setting the transducer output would have been $0.6 \mathrm{Watt} / \mathrm{cm}^{2}$, while the exposure would have been 104 Joules $/ \mathrm{cm}^{2}$ (median; IQR: 87,124 ). The median session duration for active US was 5 minutes (IQR: 4,6 ) and 4.5 minutes (IQR: 3,6 ) for dummy US. 
Table 1. Prognostic similarity of groups at baseline.

\begin{tabular}{|c|c|c|c|c|c|}
\hline & $\begin{array}{l}\text { Active ET } \\
n=73\end{array}$ & $\begin{array}{l}\text { Dummy ET } \\
n=72\end{array}$ & $\begin{array}{l}\text { No ET/no US } \\
n=35\end{array}$ & $\begin{array}{l}\text { Active US } \\
n=73\end{array}$ & $\begin{array}{l}\text { Dummy US } \\
n=72\end{array}$ \\
\hline Age $\left(\bar{x}_{z}=1\right)$ & $51=14$ & $50 \pm 13$ & $54+13$ & $50 \div 13$ & $51 \div 14$ \\
\hline Females $(\%)$ & 46 & 56 & 51 & 52 & 50 \\
\hline \multicolumn{6}{|l|}{ Previous episodes $(\%)$} \\
\hline 0 & 56 & so & 60 & 49 & 57 \\
\hline $1-5$ & 33 & 40 & 26 & 36 & 37 \\
\hline$>5$ & 11 & 10 & 14 & 14 & 7 \\
\hline \multicolumn{6}{|l|}{ Co-existent disorders } \\
\hline cervical & 88 & 78 & 77 & 88 & 78 \\
\hline homolateral elbow & 25 & 32 & 31 & 25 & 32 \\
\hline \multicolumn{6}{|l|}{ Impaired shoulder } \\
\hline dominant & 51 & 47 & 54 & 45. & 53 \\
\hline left & 44 & 42 & 34 & 49 & 35 \\
\hline \multicolumn{6}{|l|}{ Duration ( $\%$ ) } \\
\hline $0 \leq 3 \mathrm{~m}$ & 41 & 37 & 37 & 38 & 39 \\
\hline $3 \leqslant 6 m$ & 21 & 33 & 26 & 22 & 22 \\
\hline $6 \leq 12 \mathrm{~m}$ & 22 & 15 & 20 & 18 & 19 \\
\hline$>12 \mathrm{~m}$ & 17 & 15 & 17 & 22 & 10 \\
\hline Pain radiating below elbow ( $\%$ ) & 75 & 76 & 60 & 67 & 85 \\
\hline Caused by trauma $(\%)$ & 8 & 12 & 17 & 8 & 13 \\
\hline Gradual onset $(\%)$ & 68 & 71 & 63 & 66 & 74 \\
\hline \multicolumn{6}{|l|}{ Symptoms $(\%)$} \\
\hline increased & 67 & 73 & 71 & 68 & 72 \\
\hline stable & 8 & 10 & 14 & 7 & 11 \\
\hline decreased & 25 & 17 & 15 & 25 & 17 \\
\hline Prognostic grading ${ }^{\text {* }}$ & $51(27,68)$ & $48(30,70)$ & $39(25,72)$ & $50(25,70)$ & $50(24,68)$ \\
\hline Main complaint ${ }^{\prime \prime}$ & $73(53,84)$ & $73(59,86)$ & $70(52,79)$ & $73(55,84)$ & $75(59,90)$ \\
\hline \multicolumn{5}{|l|}{ Shoulder pain } & $75(63,87)$ \\
\hline after assessment ${ }^{1 *}$ & $39(11,59)$ & $45(15,64)$ & $33(13,61)$ & $34(8,52)$ & $48(22,65)$ \\
\hline yesterday ${ }^{2}$ & $46(28,59)$ & $50(30,63)$ & $46(32,61)$ & $46(25,55)$ & $51(31,67)$ \\
\hline last night $=$ & $43(20,67)$ & $50(20,76)$ & $49(24,65)$ & $44(20,71)$ & $48(20,72)$ \\
\hline Physical impairment". & $43(17.75)$ & $50(24,69)$ & $43(26,65)$ & $49(19,67)$ & $49(20.77)$ \\
\hline Symptom score' * & $48(28,61)$ & $47(30,63)$ & $50(31,67)$ & $49(27,60)$ & $47(32,65)$ \\
\hline Mobility ${ }^{*}$ & $48(16,67)$ & $37(22,68)$ & $44(27,75)$ & $44(17,68)$ & $39(19,64)$ \\
\hline
\end{tabular}

Due to the factorial trial design the ET groups and the US groups represent the same patients.

$n$ number of patients

$m$ months

sd standard deviation

w weeks

- Median (interquartile range)

+ Severity rating of research physiotherapist on a 100-millimeter visual analogue scale (0/100:

best/worst), based on a standardized clinical assessment. This assessment involved a standardized. history; inspection of contour, muscle wasting and swelling; active and passive evaluation of range of motion and pain on abduction, flexion, internal and external rotation, extension and adduction; evaluation of the functional mobility and active glenohumeral-scapulo-thoracic rhythm; evaluation of joint play and pain on accessory movements; evaluation of muscle weakness and pain on isometric muscle testing; and palpatory assessment of pain and tissue condition.

* Patient rating for severity during the previous week on a 100 -millimeter visual analogue scale $10 / 100$ : best/worst). The main complaint was logged at baseline, and was defined as an unavoidable painful and/or limited functional activity in which the shoulder is involved. Physical impairment was defined as restriction of daily activities.

5. Patient rating for severity of functional' status limitation during the last 24 hours on the 16-item Shoulder Disability Questionnaire (0/100: best/worst).

I Rating of research physiotherapist on a 100-millimeter visual analogue scale (0/100: best/worst), based on a standardized assessment of active functional mobility: [1] glenohumeral-scapulo-thoracic rhythm; reaching with the index finger to [2] the heterolateral scapular angulus inferior and [3] the second thoracic processus spinosus; [4], flexion and [5] abduction. 


\section{Exercise therapy}

No differences were found between the groups with respect to employed methods and goals of exercise therapy. During the qualification period, exercise therapy was aimed at pain reduction and mobility improvement in 5 (median; IQR 3,6) of the 6 sessions. During the 12 sessions after randomization, it was aimed at pain reduction in 10 sessions (median; IQR 6, 12) and at improvement of mobility in 11 sessions (median; IQR 6, 12). Muscle relaxation was a treatment goal in half of all sessions.

\section{Protocol violations and missing data}

In all, 171 patients completed all 12 sessions with the assigned treatment. One patient with active US plus dummy ET withdrew from treatment due to complete recovery, and 8 patients did so due to symptom deterioration: 2 without adjuvant treatment, 2 with both active treatments, 1 with both placebo treatments, 2 with dummy ET plus active US, and 1 with active ET plus dummy US. Up to 3 months, 7 patients received nonstudy treatments; all steroid injections: 1 without adjuvant treatment, 1 with both active treatments, 2 with dummy ET plus active US, 3 with active ET plus dummy US. Patients did not report any side-effects. All randomized patients were present at the 6 weeks follow-up visit. Ratings from the research physiotherapist were missing for 3 patients who were unable to attend the 3 months follow-up visit. Two of these patients completed and returned questionnaires by post. By telephone, the third patient reported being completely recovered. After 3 months, 1 patient was lost-to-follow-up. Sporadically, details of other outcome measures were missing.

\section{Verification of blinding}

At 6 weeks after randomization 67 patients $(92 \%)$ with active ET and $51(71 \%)$ with dummy ET believed that they were being treated with active ET. The difference in recovery rates between patients who believed to be treated with active and dummy US was $5 \%[95 \% \mathrm{Cl}:-14 \%, 23 \%]$.

Furthermore, 42 patients ( $58 \%$ ) with active US and $43(60 \%)$ with dummy US believed that they were being treated with active US. The difference in recovery rates between patients who believed to be treated with active and dummy US was $-1 \%$ [95\% CI: $15 \%, 13 \%]$.

\section{Outcome measures}

Much or very much deterioration of symptoms was reported by 6 patients at 6 weeks: 1 with both active treatments, 1 with both dummy treatments, and 4 with active ET and dummy US; and by 4 patients at 3 months: 1 without and 1 with both active treatments and 2 with dummy ET and active US. Up to 12 months there were virtually no differences between groups for the proportions of patients reporting complete recovery or substantial improvement, while the $95 \%$ Cls (Table 2) generally rule out large effects. At 6 weeks and 3 months there were virtually no differences between groups for median changes in severity scores since baseline of all other outcome measures, and the $95 \%$ Cis (Table 3 and 4 ) rule out large effects.

When restricted to the filled blocks only, the analysis revealed similar outcomes. The linear regression analysis revealed that at 6 weeks the effect of the combination of ET and US on the recovery rate was $10 \%$ higher $[95 \% \mathrm{Cl}:-18 \%, 37 \%]$ than for $\mathrm{ET}$ or US alone. The interaction effect became even weaker with wider $\mathrm{Cls}$ during later follow-up. 
Table 2. Recovery rates and differences between groups.

\begin{tabular}{|c|c|c|c|c|c|}
\hline & $\begin{array}{l}n=73 \\
(\$)\end{array}$ & $\begin{array}{l}n=72 \\
\text { (\%) }\end{array}$ & $\begin{array}{l}n=35 \\
(\$)\end{array}$ & $\Delta(95 \% C l)$ & $\Delta(95 \times C)$ \\
\hline Electrotherapy & Active & Dummy & None & Active-dummy & No-dummy \\
\hline 6 weeks & 23 & 22 & 20 & $1(-13,15)$ & $.2(-19,15)$ \\
\hline Adjusted & & & & $-1(-15,13)$ & $=0(-18,18)$ \\
\hline 3 months & 41 & 39 & 40 & $2(-14,18)$ & $1(-19,21)$ \\
\hline Adjusted & & & & $-3(-19,13)$ & $=4(-24,17)$ \\
\hline 6 months & 32 & 46 & 34 & $-14(-30,2)$ & $-12(-32,9)$ \\
\hline Adjusted & & & & $-20(-35,-4)$ & $-8(-28,12)$ \\
\hline 9 months & 40 & 49 & 31 & $-9(-25,7)$ & $-18(-37,3)$ \\
\hline Adjusted & & & & $-11(-28,7)$ & $-19(-41,3)$ \\
\hline 12 months & 37 & 53 & 37 & $-16(-32,0)$ & $-16(-36,5)$ \\
\hline Adjusted & & & & $-13(-30,4)$ & $-19(-41,3)$ \\
\hline Ultrasoundtherapy & Active & Dummy & None & Active-dummy & No-dummy \\
\hline 6 weeks & 26 & 19 & 20 & $7(-7,20)$ & $1(-16,17)$ \\
\hline Adjusted & & & & $8(-6,23)$ & $1(-16,19)$ \\
\hline 3 months & 42 & 38 & 40 & $5(-11,21)$ & $3(-18,23)$ \\
\hline Adjusted & & & & $4(-13,20)$ & $=1(-23,21)$ \\
\hline 6 months & 40. & 38 & 34 & $2(-14,18)$ & $-4(-23,17)$ \\
\hline Adjusted & & & & $1(-15,17)$ & $3(-16,21)$ \\
\hline 9 months & 41 & 47 & 31 & $-6(-23,10)$ & $-16(-36,4)$ \\
\hline Adjusted & & & & $-7(-25,10)$ & $-16(-38,6)$ \\
\hline 12 months & 42 & 47 & 37 & $-5(-21,12)$ & $-10(-30,10)$ \\
\hline Adjusted & & & & $-9(-26,8)$ & $-14(-35,7)$ \\
\hline
\end{tabular}

Recovery was rated by patient on an 8-point Likert scale. Presented is the proportion of patients indicating complete recovery or substantial improvement. The complementary proportion reported being much improved, little improved, unchanged, little worse, much worse, very much worse.

US Ultrasoundtherapy

ET Electrotherapy

Adjusted Recovery adjusted for prognostic indicators (dominant status of the impaired shoulder, duration of current episode, number or previous episodes, pain radiating below the elbow and prognostic grading).

$\Delta \quad$ Differences between groups; negative values denote a difference in favour of the dummy treatment.

Cl Confidence interval.

In a multivariable linear regression analysis, putative prognostic indicators (dominant status of the impaired shoulder, duration of current episode, number or previous episodes, pain radiating below the elbow and prognostic grading) did not show any influence on differences in recovery between active and dummy treatment or between dummy treatment and no adjuvants (Table 2). Neither did these prognostic indicators alter the results for any other outcome measure. 
Table 3. Electrotherapy (ET): Medians and interquartile ranges for changes in scores since baseline and median differences between groups with $95 \%$ confidence intervals.

\begin{tabular}{|c|c|c|c|c|c|}
\hline & $\begin{array}{l}\text { Active ET } \\
n=73\end{array}$ & $\begin{array}{l}\text { Dummy ET } \\
n=72\end{array}$ & $\begin{array}{l}\text { NoET } \\
n-35\end{array}$ & $\begin{array}{l}\text { Active-dummy ET } \\
\Delta(95 \% \mathrm{Cl})\end{array}$ & $\begin{array}{l}\text { No-dummy ET } \\
\Delta(95 \% \mathrm{Cl})\end{array}$ \\
\hline \multicolumn{6}{|l|}{ Main complaint } \\
\hline 6 weeks & $24(3,48)$ & $20(0,45)$ & $27(2,42)$ & $-3(-13,6)$ & $4(-7,16)$ \\
\hline 3 months & $36(9,61)$ & $39(18,64)$ & $35(20,57)$ & $4(-6,15)$ & $-3(-15,8)$ \\
\hline \multicolumn{6}{|c|}{ Functional status } \\
\hline 6 weeks & $8(0,25)$ & $8(-3,31)$ & $9(-6,38)$ & $0(-6,8)$ & $0(-10,10)$ \\
\hline 3 months & $13(0,38)$ & $21(9.55)$ & $18(7,45)$ & $11(0,19)$ & $-2(-13,8)$ \\
\hline 6 months & $21(-13,56)$ & $31(8,49)$ & $10(-8,60)$ & $7(-6,21)$ & $-10(-26,8)$ \\
\hline 9 months & $34(-2,58)$ & $36(9,57)$ & $24(-3,56)$ & $0(-11,13)$ & $-7(-22,9)$ \\
\hline 12 months & $44(13,63)$ & $44(18,66)$ & $30(-11,44)$ & $3(-9,14)$ & $-19(-37,5)$ \\
\hline \multicolumn{6}{|c|}{ Pain after assessment } \\
\hline 6 weeks & $12(0,34)$ & $7(0,29)$ & $7(-1,28)$ & $-3(-10,2)$ & $-1(-9,6)$ \\
\hline 3 months & $7(-1,36)$ & $14(4,36)$ & $11(0,28)$ & $5(-2,12)$ & $-6(-16,2)$ \\
\hline \multicolumn{6}{|l|}{ Pain yesterday } \\
\hline 6 weeks & $21(3,39)$ & $9(-1,30)$ & $13(2,21)$ & $-5(-13,2)$ & $2(-6,9)$ \\
\hline 3 months & $15(1,45)$ & $23(11,45)$ & $19(5,33)$ & $6(-2,15)$ & $-3(-13,6)$ \\
\hline \multicolumn{6}{|l|}{ Pain last night } \\
\hline 6 weeks & $19(2,42)$ & $10(0,30)$ & $15(1,29)$ & $-7(-16,1)$ & $3(-6,13)$ \\
\hline 3 months & $19(0,46)$ & $24(6,46)$ & $18(9,53)$ & $4(-6,14)$ & $0(-10,11)$ \\
\hline \multicolumn{6}{|c|}{ Physical impairment } \\
\hline 6 weeks & $15(1,29)$ & $13(0,29)$ & $11(0,23)$ & $-1(-8,4)$ & $-1(-8,8)$ \\
\hline 3 months & $18(2,39)$ & $23(8,39)$ & $19(4,34)$ & $5(-2,13)$ & $-4(-15,5)$ \\
\hline \multicolumn{6}{|l|}{ Symptorn score } \\
\hline 6 weeks & $20(4,45)$ & $16(4,31)$ & $21(10,29)$ & $-4(-13,4)$ & $3(-5,12)$ \\
\hline 3 months & $21(6,45)$ & $25(10,36)$ & $27(14,32)$ & ? $(-8,9)$ & $1(-8,7)$ \\
\hline \multicolumn{6}{|l|}{ Mobility } \\
\hline 6 weeks & $10(1,39)$ & $10(-3,27)$ & $14(2,30)$ & $-3(-11,49)$ & $3(-6,13)$ \\
\hline 3 months & $10(0,44)$ & $13(2,31)$ & $15(3,32)$ & $-1(-9,7)$ & $1(-8,9)$ \\
\hline
\end{tabular}

Consult legend for Table 1 for outcome measures.

Negative values for medians or interquartile ranges denote deterioration.

Negative values for differences between groups $(\Delta)$ and $95 \%$ confidence interval $(\mathrm{Cl})$ denote a difference in favour of the dummy group.

\section{Discussion}

The primary goal of our study was to assess whether US and ET add to the effect of exercise therapy for shoulder disorders. A secondary goal was to examine the magnitude of a potential placebo effect of US and ET. We used a factorial study design because of its statistical efficiency. Interaction between US and ET was considered unlikely and could indeed, not be shown by our data. Most patients improved over time, irrespective of the treatment allocated. The recovery rate for the whole population was $22 \%$ at 6 weeks and increased to $40 \%$ at 3 months. The absence of differences in improvement between groups is consistent for all outcome measures. At 6 weeks, the statistical power $(1-B, 2$-sided: $\alpha-5 \%)$ to detect a difference in recovery rates of at least $25 \%$ between active and dummy ET is $90 \%$ and $92 \%$ for such differences between active and dummy US. After 3 months this power was $88 \%$ for both treatments. Therefore, it is unlikely that we have missed a large effect of ET and US. 
Table 4 Ultrasoundtherapy (US): Medians and interquartile ranges for changes in scores since baseline and median differences between groups with $95 \%$ confidence intervals

\begin{tabular}{|c|c|c|c|c|c|}
\hline & $\begin{array}{l}\text { Active US } \\
n=73\end{array}$ & $\begin{array}{l}\text { Dummy US } \\
n-72\end{array}$ & $\begin{array}{l}\text { No US } \\
n-35\end{array}$ & $\begin{array}{l}\text { Active-dummy US } \\
\Delta(95 \%(1)\end{array}$ & $\begin{array}{l}\text { No-dummy US } \\
\Delta \text { (95\%Cl) }\end{array}$ \\
\hline \multicolumn{6}{|c|}{ Main complaint } \\
\hline 6 weeks & $22(2,55)$ & $22(1,44)$ & $27(2,42)$ & $-3(-12,6)$ & $-4(-15,7)$ \\
\hline 3 months & $31(14,61)$ & $41(16,62)$ & $35(20,5 n$ & $3(-6,15)$ & $3(-2,16)$ \\
\hline \multicolumn{6}{|c|}{ Functional status. } \\
\hline 6 weeks & $11(0,31)$ & $7+3,201$ & $9+6,38$ & $-6(-13,2)$ & $-2(-13,7)$ \\
\hline 3 months & $23(0,47)$ & $15(0,51)$ & $18(7,45)$ & $-3(-13,7)$ & $-4(-16,7)$ \\
\hline 6 months & $36(6,52)$ & $25+3,500$ & $10+8,60$ & $-3(-16,9)$ & $3(-13,21)$ \\
\hline 9 months & $33(1,56)$ & $38(9,60)$ & $24+3,56$ & $2(-10,14)$ & $7(-9,23)$ \\
\hline 12 months & $38(8,63)$ & $49(25,65)$ & $30(-11,44)$ & $9(-2,20)$ & $23(7,39)$ \\
\hline \multicolumn{6}{|c|}{ Pain after assessment } \\
\hline 6 weeks & $9(0,32)$ & $7(0,31)$ & $7+1,260$ & $-1(-6,5)$ & $3(-4,12)$ \\
\hline 3 months & $11(0,35)$ & $14(2,39)$ & $11(0,28)$ & $2(-5,9)$ & $4(-4,15)$ \\
\hline \multicolumn{6}{|l|}{ Pain yesterday } \\
\hline 6 weeks & $12(0,32)$ & $13(1,34)$ & $13(2,21)$ & $1(-7,8)$ & $1(-7,10)$ \\
\hline 3 months & $19(0,34)$ & $22(8.47)$ & $19(5,33)$ & $4(-5,13)$ & $2(-8,13)$ \\
\hline \multicolumn{6}{|l|}{ Pain last night } \\
\hline 6 weeks & $12(0,49)$ & $15(0,30)$ & $15(1,29)$ & $-4(-14,4)$ & $-1(-10,8)$ \\
\hline 3 months & $25(1,51)$ & $19(1,45)$ & $18(9,53)$ & $-2(-12,8)$ & $=3(-14,7)$ \\
\hline \multicolumn{6}{|c|}{ Physical impairment } \\
\hline 6 weeks & $15(0,29)$ & $13(1,30)$ & $11(0.23)$ & $0(-6,6)$ & $1(-7,9)$ \\
\hline 3 months & $20(2,39)$ & $22(4,39)$ & $19(4,34)$ & $1(-7,9)$ & $2(-7,13)$ \\
\hline \multicolumn{6}{|l|}{ Symptom score } \\
\hline 6 weeks & $18(4,34)$ & $13(4,37)$ & $21(10,29)$ & $-2(-10,7)$ & $=2(-12,8)$ \\
\hline 3 months & $23(8,40)$ & $23(8,42)$ & $27(14,32)$ & $0(-7,9)$ & $0(-8,10)$ \\
\hline \multicolumn{6}{|l|}{ Mobility } \\
\hline 6 weeks & $9(1,30)$ & $10(-4,32)$ & $14(2,30)$ & $-1(-7,8)$ & . $1(-12,10)$ \\
\hline 3 months & $13(1,37)$ & $12(1,38)$ & $15(3,32)$ & $1(-8,7)$ & $0(-10,10)$ \\
\hline
\end{tabular}

Legend see Table 3 .

\section{Similarity of groups}

After randomization baseline values of outcome measures appeared to be balanced between groups. In a multivariable regression analysis, the few differences regarding prognostic status at baseline did not alter the results, for US and ET. Furthermore, it does not seem likely that the few protocol violations (i.e. treatment withdrawal, loss-tofollow-up and non-study treatment) have resulted in bias of any importance. Their negligible number can be explained by the restriction of enrolment to patients willing to adhere to the allocated treatment and to complete follow-up.

\section{Treatment contrasts and blinding}

ET and US without output were used in order to control for potential placebo effects. Therapists could be blinded for the identity of US, but not for the identity of ET. The patients and the research physiotherapist were kept blinded for the identity of active and dummy treatments. Blinding of patients for treatment identity was considered to be successful, since active and dummy treatments appeared equally convincing to patients. Identification of the true nature of treatments at 6 weeks did not appear to be related to their effect. Therefore, it is not likely that unmasking resulted in bias of any importance. 
ET was administered according to the concept of non-painful transcutaneous stimulus induced analgesia. This concept is based on assumptions about generation and maintenance of pain and related sympathetic involvement. Although according to this concept ET was expected to support recovery, we could not demonstrate a beneficial effect in favour of active ET. To date, there is no evidence from randomizedi clinical trials to substantiate the efficacy of any other form of $\mathrm{ET}^{33}$.

While intermittent US and slow circular transducer movements reduce the risk of tissue damage, a $0.8 \mathrm{MHz}$ US beam possesses sufficient penetration for the glenohumeral region. The administered exposure was higher than the 50 Joules $/ \mathrm{cm}^{2}$ threshold for biostimulation and was therefore expected to promote recovery. Nevertheless, we have not been able to demonstrate beneficial effects in favour of active US. It is not likely that the benefit of an increased dose of ultrasound exposure, if any, would outweigh the potential risk of tissue damage. To date, there is no evidence from randomized clinical trials to substantiate the efficacy of US ${ }^{33}$.

An effect of exercise therapy could have masked a possible difference between the active and dummy treatments, but it is not likely that such a difference, if it exists at all, will be large enough to be clinically relevant. Hence, it must be concluded that US and ET, adjuvant to exercise therapy, have no treatment-specific beneficial effect for shoulder disorders.

In order to study the magnitude of a potential placebo effect we included a control group without adjuvant treatment. This treatment comparison could not be blinded for therapists and patients, but the groups were similar as far as exercise therapy was concerned. Although outcome assessment by the research physiotherapist was blinded, we could not demonstrate a difference in favour of dummy-ET and dummy-US. Therefore, a placebo effect of US and ET is also considered to be unlikely.

\section{Study population}

US and ET are supposed to be effective for soft-tissue disorders of the shoulder, regardless of the anatomical site of the soft-tissue involved. Hence, enrolment was not limited to a specific type of soft-tissue shoulder disorder, such as bursitis, tendinitis or capsulitis. For reasons of efficiency enrolment was restricted to a study population that was as homogeneous as possible with respect to putative prognostic indicators. In addition, participation was confined to patients who were considered most likely to respond favourably to US and ET and who were highly motivated to adhere to treatment and to complete follow-up. Since no benefit could be demonstrated, less susceptible and less motivated patients with soft-tissue shoulder disorders are even less likely to benefit from US and ET.

\section{Outcome measures}

Patient-tailored outcome measures are clinically relevant and have been reported to be sensitive to change ${ }^{42}$. We therefore used ratings of patients for recovery and the change in severity of the main complaint, pain, functional status impairment as outcome measures. All severity scores were rated on visual analogue scales, while recovery was evaluated on a Likert scale. These scales are reported to be valid and reproducible for measurement of pain and functional capacity $y^{43-46}$, especially for serial measurements when previous scores are made available ${ }^{47,48}$. The Shoulder Disability Questionnaire is 
considered to be sensitive to change in the evaluation of functional status limitation of patients with shoulder disorders ${ }^{49}$.

\section{Conclusion}

During the design and conduct of our study, we have been able to overcome the most important potential threats to validity. Consequently, the results allow a clear conclusion: neither US nor ET prove to be effective as adjuvants to exercise therapy for shoulder disorders.

So far, few studies on the efficacy of exercise therapy shoulder disorders have been reported $^{32}$. There are indications that NSAIDS and steroid injections may be effective as primary care treatment for shoulder disorders ${ }^{50.51}$. Therefore, future studies on the efficacy and cost effectiveness of physiotherapy for shoulder disorders should compare exercise therapy with NSAIDS and steroid injections, but also with analgesics, advice and no treatment (e.g. rest, waiting list). In addition, creative effort could be invested in the development of a credible dummy for exercise therapy that controls, for the effects of hands-on therapy and therapeutic attention (e.g. reassurance, support, transfer of knowledge).

\section{References}

1 Croft P. Soft-tissue rheurnatism. In: Epidemiology of the rheumatic diseases. Silman A, Hochberg MC (eds). Oxford University Press, Oxford, 1993: 375-421.

2. Jayson MIV. Frozen shoulder: adhesive capsulitis. British Medical Journal 1981; 283: 1005-6.

3 Bland JH, Merit JA, Boushey, DR. The painful shoulder. Seminars in Arthritis and Rheumatism 1977; 7: $21-47$.

4 Uthoff HK, Sarkar K. An algorithm for shoulder pain caused by soft-tissue disorders. Clinical Orthopaedics and Related Research 1990; 254:121-7.

5 Windt DAWM van der, Koes BW, Boeke AJP, Devillé W, Jong BA de, Bouter LM. Shoulder disorders in general practice. Prognostic indicators of outcome. British Journal of Ceneral Practice 1996; 54: 959-64.

6. Grundemeijer HGLM, Brouwer HJ. De betekenis van fysiotherapie bij aandoeningen aan het bewegingsapparaat. Huisarts en wetenschap 1983; 31 [suppl. 12]: 44-59.

7 Peters D, Davies P, Pietroni P. Musculoskeletal clinic in general practice: study of one year's referrals. British Journal of General Practice 1994; $44: 25-9$.

8. Hackett GI, Bundred P. Hutton JL, O'Brien J, Stanley IM. Management of joint and soft-tissue injuries in three general practices: value of on-site physiotherapy. British lournal of Ceneral Practice 1993; 43: $61-4$.

9 Gentle PH, Herlihy PJ, Roxburgh IO. Controlled trial of an open-access physiotherapy service. British Journal of General Practice 1994; 34: 371-6.

10 Rush PJ. Shore A. Physician perceptions of the value of physical modalities in the treatment of musculoskeletal disease. British Journal of Rheumatology 1994; 33: 566-8.

11 Lindsay DM, Dearness J, McGinley CC. Electrotherapy usage trends in private practice in Alberta. Physiotherapy Canada 1995; 47: 30-4.

12. Pope GD, Mocket SP, Wright JP. A survey of electrotherapeutic modalities: Ownership and use in the NHS in England. Physiotherapy 1995; 81: 82-91.

13. Robinson A, Snyder-Mackler L. Clinical' application of electrotherapeutic modalities. Physical Therapy 1988; 68: 1235-38.

14. Haar G ter, Dyson M, Oakley EM. The use of ultrasoundtherapy by physiotherapists in Britain, 1985. Ultrasoundtherapy in Medicine and Biology 1987; 13:659-63.

15. Health Insurance Council. Annua! Report. Klomp and Bosman, Amstelveen, the Netherlands 1990

16. Sjolund $\mathrm{BH}$, Eriksson $\mathrm{M}$, Loeser JD. Transcutaneous and implanted electric stimulation of pheripheral nerves. In: The management of pain. Bonica JJ (ed). Lea and Febiger, Philadelphia, 1990. 
17 Hayes KW. The use of ultrasoundtherapy to decrease pain and improve mobility. Critical Reviews in Physical and Rehabilitation Medicine 1992; 3: 271-87.

18 Sweitzer RW. Ultrasound. In: Physical agents. Hecox B, Weisberg J, Tsega AM (eds). Appleton and Lange, Connecticut, 1994: 163-92.

19 Nykànen M. Pulsed ultrasoundtherapy treatment of the painful shoulder. A randomised, double blind, placebo-controlled study. Scandinavian Journal of Rehabilitation 1995; 27: 105-8.

20 Inaba MK, Piorkowski M. Ultrasoundtherapy in treatment of painful shoulders in patients, with hemiplegia. Physical Therapy 1972; 52: 737-41.

21 Reginiussen T. Effekt av ultralydbehandling. En klinisk kontrollert studie. Fysioterapeuten 1990; 57: 58.

22 Swan-Downing D, Weinstein A. Ultrasoundtherapy of subacromial bursitis. A double blind trial. Physical Therapy 1986; 66: 194-9.

23 Berry H, Fernandes L, Bloom B, Clark RJ, Hamilton EBD. Clinical study comparing acupuncture, physiotherapy, injection and oral anti-inflammatory therapy in shoulder-cuff lesions. Current Medical Research Opinion 1980; 7: 121-6.

24 Fernandes L, Berry H, Clark RJ, Bloom B, Hamilton EBD. Clinical study comparing acupuncture, physiotherapy, injection and oral anti-inflammatory therapy in shoulder-cuff lesions. Lancet $1980_{i}^{;}$(26 Jan): 208-9.

25 Herrera-Lasso I, Mobarak L, Fernández-Domínguez L, Cardiel MH, Alarcón-Segovia D. Comparative effectiveness of packages of treatment including ultrasoundtherapy or transcutaneous electrical nerve stimulation in painful shoulder syndrome. Physiotherapy 1993; 79: 251-3.

26 Knorre B von, Keitel W. Vergeleigende therapiestudie. Ultrashall, kryotherapie und intraartikuläre: kortisonoide bei veränderungen des schultergelenkes aus entzündlicher urșache. Zeitschrift für Physiotherapie 1990; 42: 221-5.

27 Chee EK, Walton $\mathrm{H}$. Treatment of triggerpoints with microamperage transcutaneous electric nerve stimulation (TENS) - The electro-acuscope 80. Journal of Manipulative Physiological Therapeutics 1986; 9: 131-4.

28 Knüsel O. Die transkutane elektrische nervenstimulation beim weichteilrheumatismus. Ein kontrolierte utersucherblinde studie an 60 patienten mit levator-scapulae-syndrom. Zeitschrift fur Physikalische Medizin, Balneologie und Medische Klimatologie 1994; 13: 337-9.

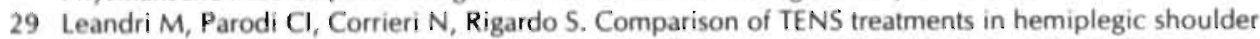
pain. Scandinavian Journal of Rehabilitation 1990;22:69-72.

30 Hoyer E, Roaldsen K, Stanghelle JK. The efficacy of Rebox II in hemiplegic patients with upper extremity dysfunction. Norwegian Physical Therapy lournal 1991;11:1-4.

31 Valtonen EJ, Lilius. HG. Doppelblind versuch über die wirkung der diadynamischen (Bernardschen ströme) bei verschiedenen schmerzzustănden. Zeitschrift fuer Physiotherapie 1974; 26: 133-6.

32 Heijden GJMG van der, Windt DAWM van der, Winter AF de. Physiotherapy for soft-tissue shoulder disorders: A systematic review of randomized clinical trials. Submitted for publication (Chapter 2).

33 Rey B, Gerber NJ. Shoulder pain trials. In: Physiotherapy: Controlled trials and facts. Slapbach P, Gerber NJ, (eds). Rheumatology (Vol 14), Karger, Basel 19911: 91-8.

34 Knipschild P, Leffers P, Feinstein AR. The qualification period, Journal of Clinical Epidemiology 1991; 44: $461-4$.

35 Sato A, Schmidt RF. Somatosympathetic reflexes: afferent fibers, central pathways, discharge characteristics. Physiological reviews 1973; 53: 916-45.

36 Devor M. Peripheral and central nervous system mechanisms of sympathetic related pain. Pain Clinic 1995; 8: 5-14.

37 Roberts W]. A hypothesis on the physiological basis for causalgia and related pains. Pain 1986; 24: 179-311.

38 Dunn F, Frizzel LA. Bioeffects of Ultrasoundtherapy. In: Therapeutic heat and cold. Lehman JF (ed). Williams and Wilkins, Baltimore 1990.

39 Norusis MJ. SPSS for Windows, Release 5.0. Chicago, SPSS Inc, 1992.

40 Minitab Inc. Minitab, Release 9. Lebanon, Sowers Printing Company, 1992.

41 Brown BW, Hollander M. Statistics. A biomedical introduction. Chapter 13. Analysis of the twosample location problem using ranks. John Wiley and Sons, New York, 1977.

42 Guyatt GH, Walter S, Norman G. Measuring change over time. Assessing the usefulness of evaluative instruments. Journal of Chronic Diseases 1987; 40: 171-8.

43 Jaeschke R, Singer J, Guyatt GH. A comparison of seven-point and visual analogue scales. Controlled Clinical Trials 1990; 11: 43-51. 
44 Carlsson AM. Assessment of chronic pain. 1. Aspects of reliability and validity of the visual analogue scale. Pain 1983; 16: 87-101.

45 Revill SI, Robinson 1O, Rosen M, Hogg MIJ. The reliability of a linear analogue for evaluating pain. Anaesthesia 1976; 31: 1191-8.

46 Scott JP, Huskinsson EC. Measurement of functional capacity with visual analogue scales Rheumatology and Rehabilitation 1977; 16: $257-9$.

47 Guyatt GH, Berman LB, Townsend M, Taylor DW. Should study subjects see their previous responses? Journal of Chronic Diseases 1985; 38: 1003-7.

48 Scott J, Huskinsson EC. Accuracy of subjective measurements made with or without previous scores: an important source of error in serial measurements of subjective status. Annals of the Rheumatic Diseases 1979; 38: 588-9.

49 Heijden GIMG van der, Leffers P, Bouter LM. Development and responsiveness of the Shoulder Disability Questionnaire. Submitted for publication (Chapter 6).

50 Heijden GIMG van der, Windt DAWM, Kleijnen J, Koes BW, Bouter LM. Steroid injections for shoulder disorders: a systematic review of randomized clinical trials. British journal of General Practice 1996;46:309-16 (Chapter 3).

51 Windt DAWM, Heijden GJMG van der, Scholten RJPM, Koes BW, Bouter LM. The efficacy of nonsteroidal anti-inflammatory drugs (NSwDS) for shoulder complaints. A systematic review. Journal of Clinical Epidemiology 1995;48:691-704 (Chapter 4). 


\section{Chapter 6}

\section{Shoulder disability questionnaire Design and responsiveness of a functional status measure}

GJMG van der Heijden ',2, P Leffers', LM Bouter'

1 Institute for Rehabilitation Research, Hoensbroek, The Netherlands

2 Department of Epidemiology, University Maastricht, The Netherlands

3 Institute for Research in Extramural medicine, Vrije Universiteit, Amsterdam, The Netherlands 


\section{Abstract}

The Shoulder Disability Questionnaire (SDQ) is a functional status measure covering 16 items that was designed to evaluate disability in patients with shoulder disorders.

According to 273 experienced physiotherapists and 47 researchers specialized in the field of shoulder disorders the 16 items are the problems most frequently mentioned by patients with shoulder disorders, having the largest impact for their functional status. In addition, these items are considered as most crucial in the evaluation of treatment outcome.

The responsiveness of the SDQ was evaluated for 180 patients with shoulder pain and/or restricted shoulder mobility, without underlying systemic disorders. They participated in a randomized placebo-controlled trial, in which ultrasounditherapy and electrotherapy appeared to be ineffective as adjuvants to standardized exercise therapy.

At baseline and at 6 weeks follow-up, patients completed the SDQ and rated severity of shoulder pain and their main complaint, while a research physiotherapist rated severity of symptoms and restriction of functional mobility. At 6 weeks follow-up patients also rated overall change since baseline: complete recovery, substantially improved and much improved was referred to as clinical improvement, little improved, unchanged and little worse as clinical stability, while much worse and substantially worse was referred to as clinical deterioration.

The SDQ appears to be a responsive measure in evaluating disability. According to the calibrated responsiveness ratio (CRR) and the area under the receiver operator characteristic curve (AUC) it discriminates accurately between clinicaliy stabie and improved subjects. The CRRS for the SDQ, shoulder pain, the main complaint and symptoms and functional mobility are $1.14,1.96,1.59,0.56$ and 0.40 respectively. Their AUCS are $0.72,0.80,0.79,0.76$ and 0.67 respectively. It would be worthwhile to evaluate the responsiveness of the SDQ in other populations and relative to that of other disability measures. 


\section{Introduction}

Shoulder disorders may limit functional status, i.e. the ability of patients to perform daily activities. Apart from alleviation of pain and improvement of functional mobility, improvement of functional status is an important goal in the treatment of patients with shoulder disorders. Therefore, functional status measures are essential in the evaluation of treatment outcome. Yet, in clinical trials on shoulder disorders little attention is given to functional status measurement ${ }^{1 \cdot 3}$.

It is fundamental that the components of functional status measures focus on the actual execution of activities that are important in daily life, and that the components together cover all crucial elements of functional status. Furthermore, functional status measures must be brief, take a short time to complete, and ideally should allow self-assessment and completion by patients. In addition, they must be responsive. This means they must be able to detect clinically relevant changes over time, i.e. changes which are not due to measurement error and biological variability. A summary score should facilitate statistical processing and simple, direct interpretation".

Several outcome measures in the evaluation of surgical intervention for specific shoulder disorders ${ }^{5-12}$ include an evaluation of functional status. However, they predominantly focus on assessment of symptoms, such as pain, restricted mobility, and decreased muscle power, that are correlates of disability. Their evaluation of functional status typically addresses the physician's perspecilve on the abitity io perform daily activities, instead of the patient's report of their actual execution. Little is known about the responsiveness and the applicability of such outcome measures, for evaluation of non-surgical interventions.

Almost simultaneously with the SDQ, the Croft Disability Questionnaire ${ }^{13}$ and the Shoulder Pain and Disability Index ${ }^{14}$ have been developed for evaluation of disability due to shoulder disorders. Both appear to focus on the perspective of disability of patients in primary care.

This paper describes the design of the Shoulder Disability Questionnaire (SDQ), a functional status measure for disability evaluation in patients with shoulder disorders. It also presents information on its responsiveness on the basis of secondary analysis of data from a randomized placebo-controlled clinical trial in which ultrasoundtherapy and electrotherapy turned out to be ineffective as adjuvants to standardized exercise therapy for soft-tissue shoulder disorders ${ }^{15}$.

\section{Questionnaire design}

\section{Item selection}

A pool of 60 candidate items, was selected from routine history of patients with shoulder disorders in physiotherapy and by reviewing various functional status measures. Suitable items had to refer to activities in daily life involving the upper extremities. In order to focus items on the shoulder we attached a subclause to each item that explicitly referred to the shoulder. Items, were phrased so that they addressed the actual execution of a particular activity, rather than focusing on the perceived ability to perform it. Items which included positive, negative or ambiguous expressions were 
rephrased neutrally. Likewise, items with limited applicability were rephrased in more general wording. For example, My shoulder hurts when I put a wallet in my backpocket was rephrased as My shoulder hurts when I reach towards my buttocks, while My shoulder hurts when I fasten my bra was changed into My shoulder hurts when I reach towards the back of my chest.

\section{Item reduction}

Item reduction was aimed at maximizing the validity of the SDQ according to the judgemental approach as described by Guyatt and co-workers ${ }^{4,16}$. We mailed the list of 60 candidate items to 273 experienced physiotherapists working in private primary care practices in the south of the Netherlands and to 47 researchers who had published of papers on shoulder disorders in Dutch medical journals (1990-1991). The addressees were asked to select 15 items concerning functional limitations mentioned most frequently by patients with shoulder disorders. They were asked to focus on symptoms and complaints, rather than on attribution of symptoms to an underlying disorder.

Next, they had to estimate the impact of every selected item on functional status (Likert scale: 1 to 5 : not at all limiting to extremely limiting). The respondents were encouraged to comment the list of items and to add any items they felt had been left out. The response to this mailing was $56 \%$ for physiotherapists and $60 \%$ for researchers. Items were ranked according to the weight-frequency product that was calculated from the returned questionnaires by multiplying the endorsement frequency by the mean impact. Guided by comments, unclear or confusing items were rephrased. Ranking of items revealed only minor differences between the 2 groups of respondents.

The 30 items with the highest overall weight-frequency product were selected for a second mailing, in which the 273 physiotherapists and 47 researchers were asked to select the 15 items they considered most crucial in the evaluation of treatment outcome. They had to estimate the sensitivity to change of every selected item of functional status (Likert scale: 1 to 5 : not at all sensitive to change to extremely sensitive to change). Again, the respondents were encouraged to comment the list of items and to add any items they felt had been left out. The response rate for this mailing was $55 \%$ for physiotherapists and $72 \%$ for researchers. Items were ranked according to the weight-frequency product calculated from the returned questionnaires by multiplying the endorsement frequency by the mean sensitivity to change. The draft SDQ consisted of the 20 items with the highest overall weight-frequency-product. The 2 groups of respondents showed virtually no differences in ranking of these items. The majority of the 20 items involved pushing, pulling, reaching, leaning or carrying.

\section{Finalization for clinical use}

Yes-no answer options were used, where "yes" means that the patient is limited with respect to the particular activity. To improve accuracy, the recall period in the patient instructions was limited to the past 24 hours, and the answer option "not applicable" was added, indicating that the activity of the particular item, e.g. carrying something, was not performed during the past 24 hours. The ratio of the number of items with an affirmative answer over the number of applicable items is multiplied by 100 . This ratio is used as summary score and ranges from maximum (100, i.e. affirmative answer to all applicable items) to no $(0)$ functional status limitation. 
In order to evaluate the applicability of the items and the appropriateness of the answer pattern, 12 patients treated by physiotherapists for shoulder disorders completed the draft SDQ. They were asked to comment on the format and item wording, and to add any items they felt were missing. Their comments resulted in refinements in the wording of 5 items. Eight items addressing similar upper extremity activities were combined: writing and typing; opening and closing a door; holding the steering wheel of the car or the handlebars of the bike; putting on a coat or a sweater. An English translation of the final version of the SDQ can be found in the appendix.

\section{Methods}

\section{Patients and data collection}

The responsiveness of the SDQ was evaluated in 180 patients, who participated in a randomized placebo-controlled trial about physiotherapy for patients with shoulder disorders. Between 1 May 1992 and 1 November 1994 they had been referred for physiotherapy with either or both [1] pain in the deltoid region that could be elicited or aggravated by shoulder movement and [2] a restricted range of shoulder movement. All patients received exercise therapy, while according to a 2 by 2 factorial randomization table 34 patients received both active treatments, 33 patients both dummy treatments, two groups of 39 patients. received one active and one dummy treatment, while an additional control group of 35. patients received no adjuvant treatment. Before randomisation patients with rheumatoid arthritis; polymyalgia; ankylosing spondylitis; malignancy; haemophilia; polyneuropathy; multiple sclerosis; stroke; motor and sensory deficits in the shoulder, upper limb, neck or thorax; referred pain from the cervico-thoracal spine or from internal organs; prior fractures or prior surgery of the shoulder, upper limb, cervico-thoracal spine or thorax were excluded. Furthermore, at the end of 2-week a qualification period with standardized exercise therapy, prior to randomisation, patients were excluded when they were free of symptoms, when they had a favourable or a poor prognosis or when they indicated reluctance to complete follow-up or to adhere to the allocated treatment ${ }^{15}$.

In addition to completion of the SDQ at the end of the qualification period and 6 weeks later, patients gave visual analogue scale (VAS) severity ratings for [1] the main complaint in the preceding week; [2] shoulder pain in the preceding week. Simultaneously, based on a standardized clinical assessment, the research physiotherapist gave VAS severity ratings for [3] symptoms and [4] functional mobility restriction. The legend of Table 1 provides a more detailed description of these measures. All ratings ranged from 0 (minimum) to 100 (maximum).

At 6 weeks, patients rated overall change since baseline on an 8 point Likert transitional scale. This rating was used as an external criterion for the analysis of responsiveness. Complete recovery, substantially improved and much improved was referred to as. clinical improvement, little improved, unchanged and little worse as clinical stability, while much worse and substantially worse was referred to as clinical deterioration. Data were analysed with SPSS for Windows (Version 6.1.2). 


\section{Ability to detect change}

We evaluated which individual SDQ items were capable of detecting change. For this purpose we plotted for each item the distribution of change in answer options since baseline, either improvement or deterioration, for all 180 patients.

We also explored potential floor and ceiling effects, i.e. the inability of an outcome measure to detect change towards the end of its scale ${ }^{17}$. The presence of a floor effect was studied in subjects with the lower quartile or the best SDQ baseline summary scores, by calculating the proportion of clinically improved subjects with SDQ score improvement since baseline. The presence of a ceiling effect was studied in subjects with the upper quartile or the worst SDQ baseline summary scores, by calculating the proportion of clinically deteriorated subjects with SDQ score deterioration since baseline.

\section{Responsiveness}

Responsiveness is the ability of an instrument to detect clinically important change over time $^{18}$. It implies the availability of an external criterion for clinically relevant change. We defined responsiveness as the ability of an instrument to discriminate between clinically stable and improved subjects. In the absence of a gold standard for clinical change, we consider the average change since baseline in clinically stable subjects to be the best estimate of the true value for stability.

We explored the responsiveness of the SDQ and other outcome measures by their distribution of change in score since baseline of clinically stable and improved subjects. The smaller the range of these distributions and the smaller their overlap, the larger the responsiveness of an outcome measure is. Because all outcome measures are used simultaneously in the same study population, we evaluate and compare their responsiveness by 2 parameters: the calibrated responsiveness ratio and the area under the receiver operator characteristic curve.

1 The calibrated responsiveness ratio (CRR) is the ratio of the difference between the median change in score since baseline for clinically improved and stable subjects, over the interquartile range $(I Q R)$ of this change in clinically stable subjects. Because the change in score since baseline of clinically stable and improved subjects of the compared outcome measures had non-Gaussian distributions we calculated nonparametric CRRS with medians and IQRs.

Responsiveness, above all, is a function of the variability in clinically stable subjects $^{19,20}$. Comparison of responsiveness of different outcome measures may, however, be complicated by systematic changes in score since baseline in clinically stable subjects. To avoid this, we calibrate the outcome measures for these changes. There is no uniform threshold for the CRR above which an outcome measure can be called responsive. The larger the CRR, the larger the responsiveness of the outcome measure. If an outcome measure has a CRR smaller than 1, the change in scores since baseline of improved subjects does not exceed all possible variance in stable subjects, and we consider it not responsive.

2 The area under the ROC curve. The area under the curve (AUC) for changes since baseline represents the probability of correct discrimination between pairs of clinically stable and improved subjects ${ }^{20,21}$. In this context, the ROC curve plots the true-positive proportion ( $\mathrm{Y}$-axis) against the false-positive proportion $\left(\mathrm{X}\right.$-axis) ${ }^{20,21}$ of clinically 
improved subjects with a change in score since baseline equal to or larger than a cutoff point in the score range. There is no uniform threshold for the Auc above which an outcome measure is responsive. However, if the AuC is equal to 0.5, i.e. the true and false positive proportions describe a $45^{\circ}$ line of identity throughout the score range, it means that the outcome measure does not discriminate between clinically stable and improved subjects. This indicates that the outcome measure is not responsive. The AUC approaches 1.0 if the ROC curve reaches higher and towards the left in the diagram, indicating that the outcome measure approaches perfect accuracy in discriminating between pairs of clinically stable and improved subjects ${ }^{20,21}$. Under the assumption of equal utility of true and false positive, the point most upper left in the diagram represents the best cut off point, i.e. the optimal trade off between true and false positive proportion. The use of such a cut off point may facilitate decisions concerning treatment of patients with shoulder disorders.

\section{Results}

\section{Subjects and ability to detect change}

Table 1 presents the clinical characteristics of the 180 included subjects, $92(51 \%)$ of whom were clinically improved and $82(46 \%)$ were clinically stable. All subjects could easily complete the SDQ; completion took between 5 and 10 minutes.

Very few subjects gave an affirmative answer at baseline for items 7 and 16. For all 180 subjects, a change in answer from 'yes' at baseline to 'no' 6 weeks later or vice versa, was most frequently reported for items 1, 2, 4, 6 and 12 to 14 , while the least change was reported for items 7, 10 and 16 (Figure 1).

Of the 59 subjects with the best (or lower quartile) SDQ baseline scores (0-63), the change in SDQ scores since baseline exceeded zero in $25(71 \%)$ of the 35 clinically improved subjects and in $8(33 \%)$ of the 24 non-improved subjects. This suggests that the SDQ is also able to distinguish between improved and non-improved subjects when there is relatively little functional status limitation at baseline. Therefore, an important floor effect for the SDQ summary score appears to be unlikely in the study population. Of the 40 subjects with the worst (or upper quartile) SDQ baseline scores (87-100), the SDQ scores since baseline deteriorated in none of the 6 clinically deteriorated subjects $(0 \%)$ and in 2 of the 34 non-deteriorated subjects $(6 \%)$. This suggests that the SDQ is not able to distinguish between deteriorated and non-deteriorated subjects with relatively severe baseline functional status limitation. Therefore, a ceiling effect for the SDQ summary score appears to be very likely in the study population.

\section{Responsiveness}

Figure 2 displays the distributions of change in score since baseline of clinically stable and improved subjects of the compared outcome measures. The median change in SDQ score since baseline for clinically stable subjects is small, while it is large for improved subjects. There is some overlap of the IQRs around these medians. For shoulder pain and main complaint there is no overlap of the IQRs around their medians (Figure 2). The non-parametric CRRS for the SDQ, the main complaint and shoulder pain are 1.14, 1.59 and 1.96 respectively. Since the CRRS of symptoms (0.56) and functional mobility $(0.40)$ are smaller than 1 , we consider these outcome measures as being not responsive. 
Table 1. Clinical characteristics of subjects included.

\begin{tabular}{|c|c|c|c|}
\hline & $\begin{array}{l}\text { All } \\
n-180\end{array}$ & $\begin{array}{l}\text { Stable } \\
n-82\end{array}$ & $\begin{array}{l}\text { Improved } \\
n=92\end{array}$ \\
\hline Age (mean $\pm s d)$ & $51 \pm 13$ & $51 \pm 12$ & $51 \pm 14$ \\
\hline Females $(\%)$ & 51 & $49 i$ & 52 \\
\hline \multicolumn{4}{|l|}{ Previous episodes (\%) } \\
\hline none & 56 & 44 & 65 \\
\hline $1-2$ & 27 & 30 & 26 \\
\hline$>2$ & 18 & 26 & 9 \\
\hline \multicolumn{4}{|l|}{ Co-existent disorders $(\%)$} \\
\hline cervical & 86 & 85 & 86 \\
\hline homolateral elbow & 68 & 70 & 66 \\
\hline \multicolumn{4}{|l|}{ Impaired shoulder $(\%)$} \\
\hline dominant & 50 & 50 & 51 \\
\hline right & 59 & 56 & 62 \\
\hline \multicolumn{4}{|l|}{ Duration prior to intake (\%) } \\
\hline 0 weeks $\leqslant 3$ months & 38 & 35 & 42 \\
\hline 3 months s 6 months & 27 & 30 & 22 \\
\hline 6 months $\leq 12$ months & 19 & 16 & 21 \\
\hline$>12$ months & 16 & 18 & 15 \\
\hline Radiating pain below elbow $(\%)$ & 73 & 67 & 76 \\
\hline \multicolumn{4}{|l|}{ Cause current episode $(\%)$} \\
\hline trauma & 12 & 26 & 39 \\
\hline unknown & 52 & 56 & 48 \\
\hline \multicolumn{4}{|l|}{ Onset current episode (\%) } \\
\hline acute & 32 & 26 & 39 \\
\hline gradual & 68 & 24 & 61 \\
\hline \multicolumn{4}{|l|}{ Symptoms prior to intake (\%) } \\
\hline stable & 10 & 5 & 14 \\
\hline increased & 71 & 72 & 68 \\
\hline decreased & 19 & 23 & 17 \\
\hline Prognostic grading*" & $49(25,69)$ & $51(30,73)$ & $43(25,66)$ \\
\hline SDQ' & $73(63,87)$ & $74(63,85)$ & $70(58,87)$ \\
\hline Shoulder pain's & $54(40,70)$ & $59(40,72)$ & $5.4(42,67)$ \\
\hline Main complaint" & $73(57,85)$ & $74(66,86)$ & $71(52,84)$ \\
\hline Symptoms". & $47(30,63)$ & $47(27,69)$ & $47(30,62)$ \\
\hline Functional mobility'. & $44(20,68)$ & $42(2 i, 69)$ & $39(18,67)$ \\
\hline
\end{tabular}

" Presented are medians with $25^{\text {th }}$ and $75^{\text {th }}$ percentiles between brackets.

- Prognostic grading by the research physiotherapist on a visual analogue scale (VAs; 0/100: best/worst), is based on symptom severity combined with presented clinical characteristics. Rating of symptom severity (VAS; 0/100: best/worst) was based on a standardized assessment, including history; inspection. of contour, muscle wasting and swelling: active and passive evaluation of range of motion and shoulder pain on abduction, flexion, internal and external rotation, extension and adduction; evaluation of the functional' mobility and active glenohumeral-scapulo-thoracic rhythm; evaluation of joint play and shoulder pain on accessory movements; evaluation of muscle weakness and shoulder pain on isometric muscle testing; and palpatory assessment of shoulder pain and tissue condition.

+ Shoulder Disability Questionnaire (0/100: best/worst).

₹ Severity rating by the patient for the shoulder pain during the preceding week (VAS; $0 / 100$ : best/worst).

5 Severity rating by the patient for the main complaint during the preceding week (VAS; 0/100: best/worst). The main complaint was defined as the major unavoidable painful and/or limited daily activity in which the shoulder is involved.

I Severity rating for restriction of active functional mobility by research physiotherapist (VAs; 0/100: best/worst), based on a standardized assessment of [1] glenohumeral-scapulo-thoracic thythm; reaching with the index finger towards [2] the heterolateral scapular angulus inferior and [3] the second thoracic processus spinosus; [4] flexion and [5] abduction. 


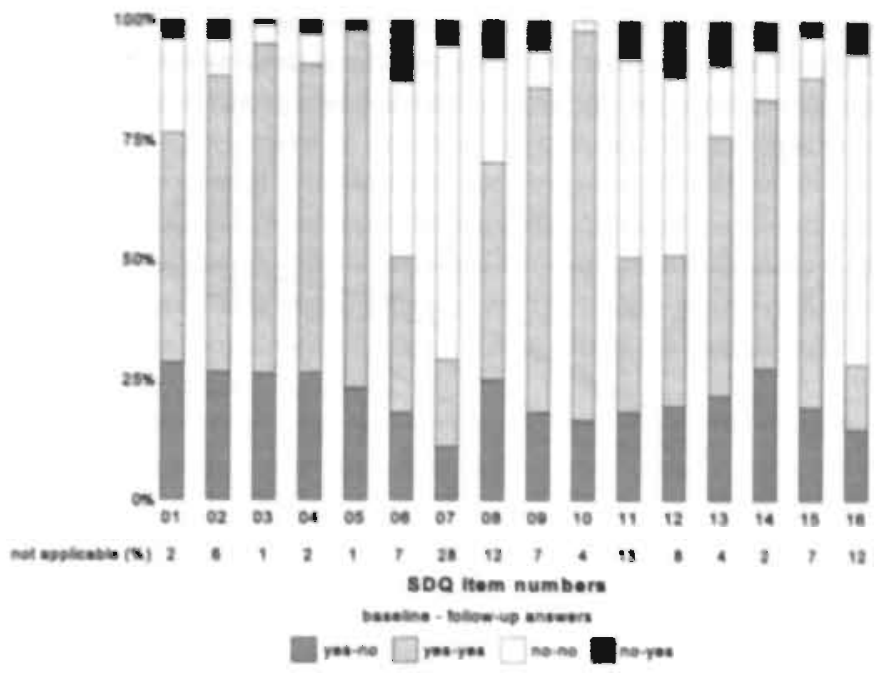

Figure 1. Bar chart for changes in answers between baseline and follow-up for 16 sOQ items in 180 subjects.

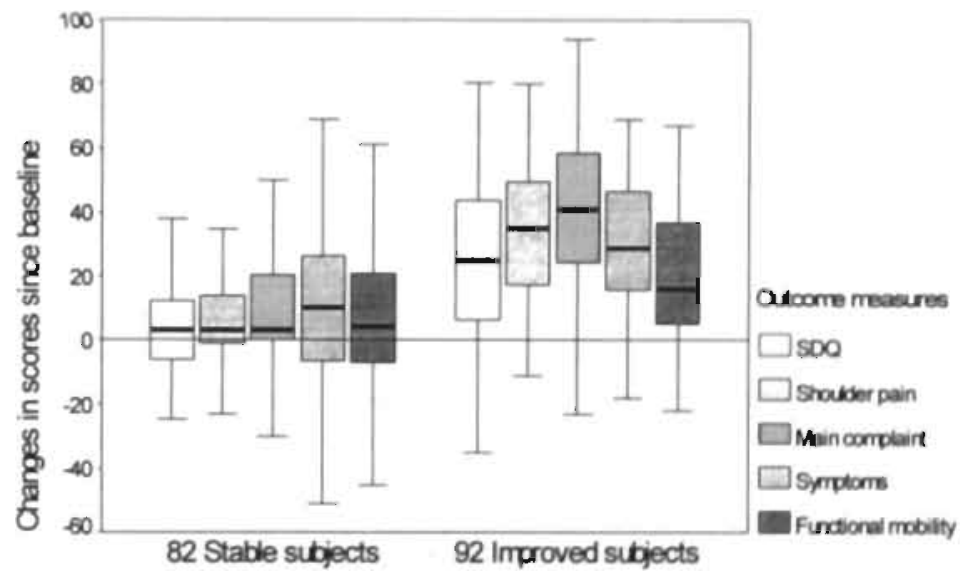

Boxes represent ranges between $25^{\text {th }}$ and $75^{\text {th }}$ percentiles, horizontal lines inside boxes represent medians, tails represent ranges between $5^{\mathrm{th}}$ and $25^{\mathrm{th}}$ and between $75^{\mathrm{th}}$ and $95^{\mathrm{th}}$ percentiles.

Figure 2. Box plot for changes in score since baseline of compared outcome measures for in stable subjects $(n-82)$ and improved subjects $(n-92)$.

Figure 3 displays the ROC curves for the compared outcome measures. We consider them all responsive, since their AUCS all exceed 0.5: SDQ: 0.72; shoulder pain: 0.80 ; main complaint: 0.79 ; symptoms: 0.76 ; and functional mobility: 0.67 . Under the assumption of equal utility of true and false positives, the optimal cutoff point for the SDQ is found between 20 and 60 points improvement. Below 20 points improvement the SDQ does not accurately discriminate between clinically stable and 
improved subjects. Below this cut off point the true-positive proportion drops abruptly, while the false positive proportion decreases only marginally. Above 60 points improvement the false-positive proportion increases sharply, while the true-positive proportion increases only marginally.

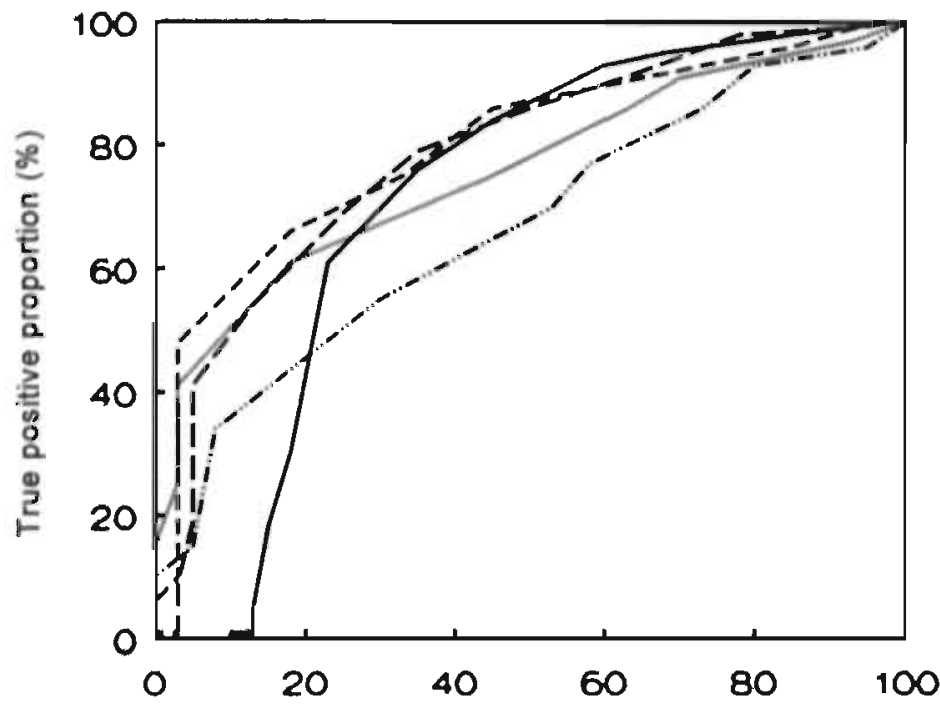

False positive proportion (\%)

outcome measure

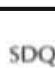

shoulder main

symptoms functional mobility

Figure 3. Receiver operator characteristic (roc) curves for stable subjects $(n-82)$ and improved subjects $(n-92)$ at multiple cut off points for changes in score since baseline of compared outcome measures.

\section{Discussion}

We wanted to know whether patients with shoulder disorders perceived overall change, and in particular if they noticed any change in their ability to perform daily activities in relation to their condition.

For this purpose we designed the SDQ, a 16 item functional status measure for patients with shoulder disorders, by selecting a number of daily activities. The selection was based on the functional limitations most frequently mentioned and judged crucial in the evaluation of treatment outcome by relevant health care professionals. The SDQ focusses on how symptoms and complaints of patients with shoulder disorders affect their ability to perform daily activities. We believe that the SDQ is a sensible functional status instrument for clinical practice and that it is convenient for patients since it is easy to complete and takes only little time to complete. The chosen answer options are easily quantifiable and interpretable, both on item level and as a summary score. 
There is no gold standard that provides a valid and reliable estimate for overall change in patients with shoulder disorders. In the absence of such a gold standard, we consider patients to be the best judges in the evaluation of overall change. We therefore included their assessment as an external criterion in the analysis of responsiveness. Although this external criterion appears to provide a clinically relevant difference it does not necessarily represent the minimal clinically relevant change. Nevertheless, the SDQ detected relatively small changes in scores since baseline for clinically stable subjects and relatively large changes for clinically improved subjects. The identification of a ceiling effect in the study population might be explained by the small number of clinically deteriorated subjects.

We consider the SDQ to be an outcome measure for the severity of functional status limitation in patients with shoulder disorders that is as responsive as any other common outcome measures for patients with shoulder disorders, such as severity of symptoms, functional mobility restriction, shoulder pain and the main complaint. The optimal cutoff point for accurate discrimination between clinically stable and improved subjects with the SDQ is found between 20 and 60 points improvement.

The relative ranking of the outcome measures according to the CRR and AUC is quite similar. Thus, our results are not the result of expressing responsiveness according to one or the other method. The most likely explanation for the differences in responsiveness between the compared outcome measures is the difference in the score change variance since baseline in clinically stable subjects. Differences in responsiveness might also be explained by the different aspects of shoulder disorders determined by the compared outcome measures. For example, the main complaint is an individually-tailored disability measure related to only one activity of daily life. In addition, these different aspects of shoulder disorders will have variable recovery patterns.. For example, shoulder pain is known to subside rapidly over a short time in many patients, while functional mobility restriction resolves only slowly. Finally, variation in recall period, e.g. 24 hours for the SDQ versus 1 week for the other outcome measures, might also affect responsiveness.

Two almost simultaneously developed functional status measures are comparable with the SDQ. The Disability Questionnaire includes 22 items with a yes-no answer scale and a 24 hour recall frame. The Shoulder Pain and Disability Index (SPADI), developed by Roach et al., consists of a separate 5 item pain scale and an 8 item disability scale, with the preceding week as the recal! frame. In order to make the SPADI suitable for telephone administration, the original visual analogue answer scales have been converted into 0-10 numerical scales. The SDQ, Disability Questionnaire and the SPADI al! include items that refer to problems with sleeping, moving the arm and dressing. The overlap with respect to item content is largest between the SDQ and the Disability Questionnaire. Responsiveness of the SPADI was established during a survey in general practice in North Carolina (USA): AUC 0.91 at 3 months follow-up ${ }^{22}$. Van der Windt et al. reported AUCS of 0.84 and 0.90 at 3 and 6 months follow-up respectively for the SDQ during a survey in general practice in the Netherlands ${ }^{23}$. In all studies a similar external criterion was used.

It may be possible that the SDQ is responsive in the trial population only and not in other populations. For the reason, it would be worthwhile to evaluate the 
responsiveness of the SDQ in other populations, and compare the results directly with the responsiveness of other shoulder disability measures ${ }^{5-14}$. Furthermore, since it has been shown to improve responsiveness of other disease specific functional status questionnaires 24,25 , revision of for instance the number of items included or a modification of their content should be given attention in future studies.

At the same time, item weights, such as VAS or Likert scales, might be used because they also are likely to improve responsiveness ${ }^{22}$. When such weights are multiplied by the frequency of item endorsement, they result in a frequency weight product per item. These products could be summed in a new SDQ composite score, comparable with the presented summary score that is based on summing affirmative item answers.

Although our results require confirmation by other investigators, they do suggest that the SDQ is ready for use in clinical trials in which investigators wish to determine the treatment effect on disability of patients with shoulder disorders.

\section{References}

1 Heijden GJMG van der, Windt DAWM van der, Winter AF de. Physiotherapy for soft-tissue shoulder disorders. A systematic review of randomized clinical trials. Submitted for publication (Chapter 2).

2 Heijden GIMG van der, Windt DAWM van der, Kleijnen J, Koes BW, Bouter LM. Steroid injections for shoulder disorders: a systematic review of randomized clinical trials. British Journal of General Practice 1996; 46: 309-316 (Chapter 3).

3 Windt DAWM van der, Heijden GIMG van der, Scholten RIPM, Koes BW, Bouter LM. The efficacy of non-steroidal anti-inflammatory drugs (NSAIDS) for shoulder complaints. A systematic review. Journal Clinical Epidemiology 1995; 48: 691-704 (Chapter 4).

4 Guyatt GH, Bombardier C, Tugwell PX. Measuring disease-specific quality of life in clinical trials. Canadian Medical Association journal 1986; 134: 889-895.

5 Imatani RJ, Hanlon II. Cady GW. Acute, complete acromio-clavicular separation. Journal of Bone and Joint Surgery 1975; 57-A: 328-332.

6 Warren RF, Ranawat CS, Inglis AE. Total shoulder replacement indications and results of the neer nonconstrained prosthesis. In: Inglis AE (ed). The American Academy of Orthopaedic Surgeons. Symposium on total joint replacement of the upper extremity. St Louis, CV Mosby, 1982: 56-67.

7 Constant CR, Murley AHG. A clinical method of functional assessment of the shoulder. Clinical Orthopaedics and Related Research 1987; 214: 160-164.

8 Swanson AB, Groot-Swanson G de, Sattel AB, cendo RD, Hynes D,Jar-Ning W. Biploar implant shoulder arthroplasty. Clinical Orthopaedics and Related Research 1989; 249: 227-247.

9 Amstutz HC, Sew Hoy AL, Clarke IC. UCLA anatomic total shoulder arthroplasty. Clinical Orthopaedics and Related Research $1981 ; 155:$ 7-20.

10 Neer CS. Displaced proximal humeral fractures. Part I. Classification and evaluation. Journal of Bone and loint Surgery 1970; 52-A: 1077-89.

11 Barret WP, Franklin JL, Jackins SE, Wyss CR, Matsen FA. Total shoulder arthroplasty, Journal of Bone and Joint Surgery 1987; 69-A: 865-872.

12 Ellman H, Hanker G, Bayer M. Repair of the rotator cuff. Journal of Bone and Joint Surgery 1986; 68A: $1136-44$.

13 Croft P, Pope D, Zonca M, O'Neill TO, Silman A. Measurement of shoulder related disability: results of a validation study. Annals of Rheumatic Diseases 1995; 53: 525-528.

14 Roach KE; Budiman-Mak E, Songsiridej N, Lertratanakul Y. Development of a shoulder pain -and disability index. Arthritis Care and Research 1991; 4: 143-9.

15 Heijden GIMG van der, Leffers P, Wolters PJMC, Verheijden JJD, Mameren H van, Houben JP, Bouter, LM, Knipschild PG. Efficacy of ultrasoundtherapy and electrotherapy for shoulder disorders. Results of a randomized placebo-controlled trial. Submitted for publication (Chapter 5).

16 Jaeschke R, Guyatt G. How to develop and validate a new quality of life instrument. In: Spilker B, ed. Quality of life measurements in clinical trials. Raven Press, New York, 1990: 47-57. 
17 Bindman AB, Keane D, Lurie N. Measuring health changes among severely ill patients. The floor phenomenon. Medical Care 1990; 28: 1142-1152.

18 Liang $\mathrm{MH}$. Evaluating measurement responsiveness, Journal of Rheumatology 1995; $22: 1191-1192$.

19 Guyatt G, Walter S, Norman G. Measuring change over time: Assessing the usefulness of evaluative instruments. Journal of Chronic Diseases 1987; 40: 171-178.

20 Deyo RA, Diehr P, Patrick DL. Reproducibility and responsiveness of health status measures. Statistics and strategies for evaluation. Controlled Clinical Trials 1991; 12: 142s-58s.

21 Hanley JA, McNeil B]. The meaning and use of the area under the receiver operating characteristic (ROC) curve. Radiology 1982; 143: 29-36.

22 Williams JW, Holleman DR, Simel DL. Measuring shoulder function with the shoulder Pain and Disability Index. Journal of Rheumatology 1995; 22: 727-732.

23 Windt DAWM van der, Heijden GJMG van der, Winter A de, Koes BW, Devillé W, Bouiter L. Validity and responsiveness of the Shoulder Disability Questionnaire. Submitted for publication.

24 Deyo RA. Comparative validity of the sickness impact profile and shorter scales for functional assessment for low-back pain. Spine 1986; 11: 951-4.

25 Patrick DL, Deyo RA, Atlas S], Singer DE, Chaplin A, Keller RB. Assessing health-related quality of life in patients with sciatica. Spine 1995; 20: 1899-908. 


\section{Appendix shoulder disability questionnaire}

How to complete the questionnaire When your shoulder hurts, you may experience problems performing your daily activities. This list contains 16 statements shoulder disorder patients have used to describe in what kind of situations they experience pain and what some of the effects may be. When you read the statements, you may find that some stand out because they apply to your situation today (past 24 hours). As you go through the list, think of how you felt today (past 24 hours). For each entry, check for yourself whether you performed the mentioned activity.

\section{Examples}

- You did not perform the activity during the past 24 hours, e.g.: you did not lie on your shoulder during the past 24 hours, put a check mark in the box for NA (not applicable).

NA YES NO

$\square \square \square$ My shoulder is painfuli when I lie on it.

- You did perform the activity during the past 24 hours, e.g. you opened or closed a door during the past 24 hours. If your shoulder was painful while you were opening or closing a door, put a check mark in the box for Yes.

NA YES NO

$\square \square$ My shoulder is painful when I open or close a door.

- You did perform the activity during the past 24 hours, e.g. you did lean on your elbow or hand during the past 24 hours. If your shoulder was not painful while you were leaning on your elbow or hand, put a check mark in the box for NO.

NA YES NO

$\square . \square$ My shoulder is painful when I lean on my elbow or hand.

\section{Shoulder Disability Questionnaire}

01 I wake up at night because of shoulder pain.

02 My shoulder is painful when I lie on it.

03 Because of pain in my shoulder I have trouble putting a coat or a sweater on.

04 My shoulder is painful during my usual daily activities.

05 My shoulder is painful when I lean on my elbow or hand.

06. My shoulder is painful when I move my arm.

07 My shoulder is painful when I write or type.

08. My shoulder is painful when I hold the steering wheel of my car or the handlebars of my bike.

09) My shoulder is painful when I lift and carry something.

10 My shoulder is painful when I reach or grasp above shoulder level.

11 My shoulder is painful when I open or close a door.

12 My shoulder is painful when I bring my hand towards the back of my head.

13 My shoulder is painful when I bring my hand towards my buttocks.

14 My shoulder is painful when I bring my hand towards my lower back.

15 I rub my painful shoulder more than once during the day.

16 Because of my shoulder pain I am more irritable and bad tempered with people than usual. 


\section{Chapter 7}

\section{General discussion}

In this final chapter we reflect on the findings of the present thesis. We present an overview and discussion of the 3 systematic reviews that we performed ${ }^{1-3}$ (Chapters. 2 through 4) and our study on the responsiveness of outcome measures ${ }^{4}$ (Chapter 6). Special attention is given to our clinical trial' ${ }^{5}$ (Chapter 5).

\section{Systematic reviews}

In general, randomized clinical trials offer the best possibility for a valid evaluation of treatment effects ${ }^{6}$. Although to date many clinical trials on NSAIDS, steroid injections and physiotherapy for shoulder disorders have been published, a sound review on their efficacy is lacking so far. Therefore, we systematically reviewed clinical trials on the efficacy of physiotherapy ${ }^{1}$, steroid injections ${ }^{2}$ and NSAIDS $^{3}$.

While the methods we have used for the selection of trials and for the assessment of their methods are to some extent arbitrary, they are fully explicit and in line with generally accepted requirements for the critical evaluation of efficacy studies ${ }^{6-10}$. With the methods assessment, we believe that we were able to discriminate between good and poor quality of methods. In all our three reviews we used identical criteria lists for the methods assessment. Our list is based on criteria lists of similar systematic reviews about musculoskeletal disorders". We adjusted the criteria to match the interventions and populations. Furthermore, we evaluated whether poor reporting hampered the methods assessment.

In all our 3 reviews it appeared that only few trials were adequately reported. Methods assessment was frequently hampered by insufficient reporting of the success of blinding of outcome measurement, parameters of the employed treatment and information on the operationalisation of the outcome measures. This poor reporting hindered the interpretation of the results of many trials and impeded pooled analysis of data. We believe that in future trials reporting of these aspects can easily be improved.

In the reviews about the efficacy of NSAIDS and steroid injections we used summed item weights in order to rank the trials according to the extent to which bias was considered to be likely. These weights are based on similar reviews. They are to some extent 
arbitrary. In Chapter 4 we report that the rank order of the trials on NSAIDS does not alter much when equal weights are used. In an additional analysis we found that the rank order of the trials on physiotherapy and steroid injections does also not alter much when weights are used. For our systematic review about the efficacy of physiotherapy, we therefore ranked the trials according to the number of validity criteria that were satisfied. In order to simplify description and the interpretation of results of this review we only present the criteria that were not satisfied or incompletely reported.

In all our reviews it appeareu that the quality of methods of most trials was rather poor. The validity of many trials is jeopardized by inadequate randomization procedures, disșimilarities of prognosis of groups at baseline, poor blinding of patients and therapișts for treatment identity, poor blinding of outcome assessments, too short follow-up, withdrawal from treatment, contamination, loss-to-follow-up and missing data. in addition, most studies lack sufficient statistical power due to rather small sample sizes.

So far, the efficacy of physiotherapy for shoulder disorders, electrotherapy (ET) included, has not at all been demonstrated, while ultrasoundtherapy (US) does not appear to be efficacious' (Chapter 2). The placebo-controlled trials with the highest quality of methods show a small effect in favour of steroid injections ${ }^{2}$ (Chapter 3 ) and NSAIDS $^{3}$ (Chapter 4) for shoulder disorders.

At present, a few new studies on the efficacy of steroid injections and physiotherapy for shoulder disorders are being carried out. Their results might add to the outcome of the respective reviews. Although we might have missed some published trials during our searches, it is not very likely that such trials would have altered the general conclusions of pur reviews.

\section{Shoulder disability questionnaire}

During the design of our trial there was no measure available for the evaluation of disability in patients with shoulder disorders in primary care physiotherapy. Therefore, we decided to design a Shoulder Disability Questionnaire (SDQ) ${ }^{4}$ (Chapter 6). The purpose of its development was to focus it on activities that are directly affected by shoulder disorders of patients in primary care physiotherapy. According to workers in the field of shoulder disorders the included items are most frequently mentioned by patients with shoulder disorders, having the largest impact on their functional status. In addition, they consider these items as being most crucial in the evaluation of treatment outcome.

We evaluated the responsiveness of the SDQ, i.e. the ability to detect clinically relevant change over time, in a secondary analysis of data of the 6 weeks follow-up of our clinica! trial. So far, a variety of methods has been used to evaluate the responsiveness of outcome measures. There appears to be no consensus about the best method. Moreover, the comparison of the responsiveness of outcome measures may be complicated by the lack of a gold standard for clinically important change. As it is, the definition of such change depends on the subjective judgement by either the clinician or the patient.

We compared the responsiveness of the SDQ, shoulder pain, the main complaint, symptoms, functional mobility in the same population. We used the patient rating for overall change since baseline at 6 weeks follow-up as an external criterion for clinically 
important change: improvement (complete recovery, substantially improved and much improved), stability (little improved, unchanged and little worse) and deterioration (much worse and substantially worse). We believe that this rating is a very important outcome measure and a valid estimate of recovery.

We found that the SDQ in fact is a responsive measure for evaluating disability; it accurately discriminates between clinically stable and improved subjects. The SDQ is slightly less responsive than shoulder pain and the main complaint only slightly more responsive than symptoms and functional mobility.

Almost simultaneously with the SDQ two comparable functional status measures have been developed: the Disability Questionnaire ${ }^{12}$ and the Shoulder Pain and Disability Index ${ }^{13}$. They also focus on patients in primary care and have a considerable overlap in content. Rather than developing yet another measure, researchers should directly compare the performance of these 3 new measures in future studies.

\section{Clinical trial}

The primary goal of the clinical trial's (Chapter 5) was to examine whether ultrsoundtherapy (US) and electrotherapy (ET) add to the effect of exercise therapy for shoulder disorders. A secondary goal was to study possible placebo effects. Our strategy in designing the trial was to increase the likelihood of finding a difference in favour of the active treatments by careful patient selection and by maximization of the potential contrast between active, dummy and no adjuvant treatments. The principle behind this strategy was, that if in this group of patients no effects could be detected in favour of these treatments, other patients were even less likely to benefit from them. It turned out that many patients improved over time, irrespectively of the treatment allocated. However, we found no differences between the groups, neither when active and dummy treatments were compared, nor when dummy treatments and no adjuvant treatment. were compared. This absence of effect was consistent for all outcome measures.

\section{Trial efficiency}

In order to increase its efficiency, our trial was designed as a 2 by 2 factorial design with an additional control group. For the same reason we tried to form a population of patients with a similar prognosis and who are most likely to benefit from US and ET. These patients were selected after a 2 week qualification period ${ }^{14}$, during which they received only standardized exercise therapy. For each session the therapeutic goal of exercise therapy had to include alleviation of pain and mobility improvement, while the range of techniques to be used was restricted. At the end of the qualification period we excluded patients who had an extremely favourable prognosis, patients who already were completely or nearly completely free of symptoms, as well as patients who had a very poor prognosis and patients who already had proved resistant to primary care treatment. These patients could not reasonably expect a major contribution of US and ET to the recovery of their shoulder disorders.

It turned out that the: patients who were excluded because of their favourable prognosis did indeed show a more beneficial outcome: their proportion of recovery was $43 \%$ at 6 . weeks follow-up. This was $11 \%$ higher than the proportion of recovery at 6 weeks for al! trial participants. These exclusions, have therefore certainly increased the precision 
of the trial results. With the 180 patients who were finally enrolled, the statistical power of our trial $(1-B)$ to detect the anticipated difference in favour of the active treatments of $25 \%$ above the recovery proportions of the dummy treatments exceeded $85 \%$ at $\alpha=5 \%$ $(2 \text {-sided })^{15}$. Hence, it seems unlikely that we have missed a large clinically relevant effect of US or ET.

\section{Recruitment problems}

Initially, 10 physiotherapy practices were invited to participate in the trial. Each practice was expected to recruit 30 patients within the planned recruitment period of 24 months. Before patient recruitment started, the number of referrals per practice was counted.

In accordance with Lasagna's law ${ }^{16}$, the anticipated accrual rate turned out be too optimistic. In order to augment accrual, 7 additional practices were invited to participate. During the conduct of the trial, however, 8 practices failed to recruit enough patients. In order to increase the monthly accrual rates these 8 practices were replaced. Finally, after an extension of the recruitment period with 6 months, 180 patients were enrolled.

\section{Patients}

All patients enrolled in this study showed clinical signs of shoulder entesopathies

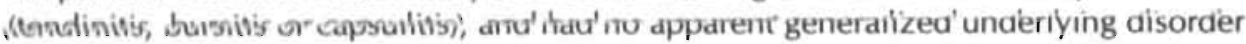
for their symptoms. The common pathological mechanism behind these differently labelled entesopathies appears to be an inflammatory reaction of soft-tissue, most often due to subacromial impingement of peri-articular structures ${ }^{17}$. Enrolment was not restricted to a subgroup of patients with a specific type of entesopathy, because US and ET are supposed to be effective for these soft-tissue shoulder disorders regardless of the anatomical site of the soft-tissue involved. Hence, it seems unlikely that the selection criteria are responsible for the fact that we have been unable to demonstrate any effect in favour of US and ET. Furthermore, after randomization the groups were quite similar regarding baseline values of outcome measures and prognostic indicators. Therefore, it is unlikely that the trial results, have been seriously biased by these potential confounders.

\section{Ultrasoundtherapy}

In laboratory research ultrasound application results in promotion of the cellular metabolic rate and increased visco-elastic properties of collagen ${ }^{18}$. In animal studies an exposure to $1 \mathrm{MHz}$ ultrasound with 50 Joules per $\mathrm{cm}^{2}$ is reported to be sufficient to increase tissue temperature ${ }^{19}$. This temperature increase is reported to be the mediating mechanism for acceleration of tissue repair, enhancement of soft-tissue flexibility, promotion of muscle relaxation and alleviation of inflammatory reactions of soft-tissue ${ }^{18-}$ ${ }^{20}$. In addition, US is supposed to reduce pain ${ }^{18}$. During the application of US on the shoulder girdle the described effects are expected to promote recovery from shoulder disorders.

The reports of randomized clinical trials that have been published so far, provide: little information about which type of US is, the most effective' (Chapter 2). The ultrasound frequency of $0.8 \mathrm{MHz}$ that has been applied in our trial is sufficient for penetration of the soft-tissue surrounding the glenohumeral joint. The employed exposure exceeds the 
50 Joules per $\mathrm{cm}^{2}$ threshold for thermal effects. Therefore, the employed dose should be sufficient to promote recovery from shoulder disorders. There is no consensus in the literature regarding the most effective parameters of ultrasound dosage, such as duty cycle, transducer size, session duration and frequency and number of sessions. The employed type of US, however, is the one most frequently used in current physiotherapy. Any beneficial effect in favour of active US could not be demonstrated. It is not likely that the benefit of an increased ultrasound exposure, if any, will outweigh the potential risk of tissue damage.

\section{Electrotherapy}

Transcutaneous stimulation using an electric current is reported to selectively excite large diameter cutaneous nerve fibres, evoke electric paraesthesia and is supposed to result in pain threshold elevation and muscle relaxation ${ }^{21}$. The principle of inhibition of transmission of nociceptive signals from small diameter nerves in the spinal dorsal horn, according to the gate control theory ${ }^{21}$ and the theory of sympatically maintained pain 22.23 provides the most plausible explanation for the mechanism behind these effects.

The recommendations regarding the most effective form of ET in the treatment of shoulder disorders vary widely with respect to intensity, duration and frequency of stimulation, the electrode position and the frequency and number of sessions. The reports of randomized clinical trials provide little information about what is supposed to be the most effective form of $E T^{1}$ (Chapter 2). The type of ET that was used in our trial, however, is generally applied in current primary care physiotherapy. Any beneficial effect in favour of active ET could not be demonstrated. Theoretically, types of ET other than the one we studied may be effective. Especially painful stimulation according to the concept of diffuse noxious inhibitory controls (DNIC) ${ }^{24}$ might offer an alternative, because it is based on a totally different mechanism. There is, however, no evidence from randomized clinical trials to substantiate the efficacy of such stimulation or of any other form of ET.

\section{Blinding}

Therapists were blinded for the identity of US. Because they received different instructions for active and dummy ET, therapists could not be blinded for the identity of ET. During all outcome assessments the research physiotherapist was blinded for the identity of all treatments.

Patients who know' that they received dummy treatment are generally expected to rate their outcome less favourably than patients with active treatment. Therefore, at 6 weeks follow-up patients were asked if they believed in the true nature of their treatment. According to these opinions, active and dummy US appeared equally convincing, while dummy ET appeared less convincing than active ET. Identification of the true nature of treatments appeared not to be related to their effect. Therefore, the potential unmasking of ET will not have resulted in bias of any importance. In addition, the results of this evaluation of the success of patient blinding support the credibility of both dummy treatments.

Since patients in the group without adjuvant treatments know that treatments are withheld from them, they are generally expected to rate their outcome relatively less 
favourably than the patients with dummy treatments. As no difference between any of the treatment groups was found for any outcome measure, we think that neither US nor ET has a substantial placebo effect. This lack of placebo effect might be explained by the decreased room for improvement for active and dummy treatments, due to the standardized exercise therapy. In addition, comparison of active and dummy treatments without exercise therapy might reveal an effect in favour of active treatments. But, given the absence of effects in the clinical trial, it is unlikely that they will contribute significantly to the recovery of shoulder disorders.

The lack of blinding of patients and therapists for adjuvant treatments on the one hand and no adjuvant treatments on the other, is generally expected to result in contamination by non-study treatments. For our study this also is expected to result in departures from the standardized exercise therapy employed in the group without adjuvant treatment. We found that virtually no contamination occurred in any of the groups. Hence, it is unlikely that contamination resulted in bias of any importance.

\section{Outcome assessment}

So far, it is unclear what the optimal timing of outcome assessment is in relation to the effects of US and ET. The first outcome assessment in our trial coincided with the end of the usual 6 weeks treatment period. Subsequently, 6 weeks and 3 months follow-up visits and 6,9 and 12 months follow-up postal questionnaires were planned. Nearly full participation was obtained for all outcome assessments and the loss-to-follow-up was only marginal.

Since there is no gold standard that provides a valid and reliable estimate for overall change in patients with shoulder disorders, we consider patients the best judges for the evaluation of overall change. Therefore, patient rating of overall recovery was used as the principal outcome measure. According to this principal outcome measure, but also according to all other outcome measures, many patients improved over time.

Nevertheless, no difference between treatment groups could be found for any of the outcome measures. Therefore, it is quite unlikely that we have missed a clinically relevant effect in favour of US or ET.

\section{Assessment of our clinical trial}

Our three systematic reviews on the available clinical trials on common primary treatments for shoulder disorders ${ }^{1.3}$ (Chapters 2 through 4 ) clearly show that very few trials are adequately reported and provide valid results. The assessors of the trials on physiotherapy for shoulder disorders' (Chapter 2) applied the criteria for validity and data abstraction to our clinical trial ${ }^{5}$ (Chapter 5). They found that our trial could be improved with respect to blinding of therapists for ET, and evaluation of success of blinding of therapists for US and of the research physiotherapist for identity of treatments. In addition, insufficient data about compliance with protocol for treatments were presented, no data on medical consumption as outcome measure were presented, while the group without US and ET was relatively small. Furthermore, it is obvious that it was not feasible to blind patients who did not receive additional US and ET.

From this critical evaluation of methods it appeared that we have indeed managed to. overcome the most important potential threats to validity. Hence, in our systematic 
review on the efficacy of physiotherapy for soft-tissue shoulder disorders our trial would have been ranked among the trials with the highest quality of methods.

\section{Conclusion}

During the design and conduct of the clinical trial we have been able to increase the statistical efficiency and at the same time overcome the most important potential threats to validity. Consequently, the results allow a clear conclusion: neither US nor ET prove to be effective as adjuvants to exercise therapy for shoulder disorders. Neither have these treatments been shown to have a placebo effect.

\section{Recommendations for clinical practice and future research}

The purpose of treatment of patients with shoulder disorders is to increase the extent and speed of recovery. Neither US nor ET as adjuvants to exercise therapy for shoulder disorders, turned out to be effective. Consequently, any further application of these adjuvant treatments in patients with shoulder disorders should be strongly discouraged. This can be done by updating treatment guidelines or by withholding reimbursement for US and ET.

Although exercise therapy appears to be the cornerstone of physiotherapy for shoulder disorders, there is only one hospital-based trial on its effectiveness. This trial revealed that exercise therapy was equally effective as surgery ${ }^{25}$.

Future clinical trials on the efficacy and cost-effectiveness of physiotherapy for shoulder disorders should focus exclusively on the effectiveness of exercise therapy. Since there are some indications for the efficacy of steroid injections and NSAIDS, priority should be given to a comparison with these treatments. Steroid injections and NSAIDS, however, have a relatively high risk of adverse effects. Therefore, frequently applied primary care treatment strategies that are less likely to be harmful, such as analgesics, advice and no treatment (e.g. rest, waiting list) would also be relevant options for comparison in future trials.

During the design and conduct of future trials specific attention should be given to the principles of improvement of validity and statistical efficiency. In addition, creative effort could be invested in the development of a credible dummy for exercise therapy that controls for hands-on therapy and therapeutic attention, including reassurance, support and transfer of knowledge.

\section{References}

1 Heijden GJMG van der, Windt DAWM van der, Winter AF de. Physiotherapy for soft-tissue shoulder disorders. A systematic review of randomized clinical trials. Submitted for publication (Chapter 2).

2 Heijden GJMG van der, Windt DAWM, Kleijnen J, Koes BW, Bouter LM, Knipschild PG. Steroid injections for șhoulder disorders: a systematic review of randomized clinical trials. British lournal of General Practice 1996; 46: 309-16 (Chapter 3).

3 Windt DAWM, Heijden GIMG van der, Scholten RJPM, Koes BW, Bouter LM. The efficacy of nonsteroidal anti-inflammatory drugs (NSADS) for shoulder complaints. A systematic review. Journal of Clinical Epidemiology 1995; 48: 691-704 (Chapter 4).

4 Heijden GIMG van der, Leffers P, Bouter LM. Shoulder Disability Questionnaire. Design and responsiveness of a functional status measure. Submitted for publication (Chapter 6 ). 
5 Heijden GJMG van der, Leffers P, Wolters, PJMC, Verheijden JJD, Mameren H van, Houben JP, Bouter LM, Knipschild PG. Efficacy of ultrasoundtherapy and electrotherapy for shoulder disorders. Results of a randomised placebo-controlled clinical trial. Submitted for publication. (Chapter 5).

6 Pocock SI. Clinical trials. Chichester, J.Wiley \& Sons, 1991.

7 Chalmers TC, Smith HIr, Blackburn B, Silverman B, Schroeder B, Reitman D, et al. A method for assessing the quality of a randomized control trial. Controlled Clinical Trials 1981; 2:31-49.

8 The standards of reporting trials group. A proposal for structures reporting of randomized controlled trials. JAMA 1994; 272: 1926-31.

9 Cho MK, Bero LA. Instruments for assessing the quality of drug studies published in medical literature. JAMA 1994; 272: 101-4.

10 Moher D, Jadad AJ, Nichol G, Penman M, Tugwell P, Walh S. Assessing the quality of randomized controlled trial: an annotated bibliography of scales and checklists. Controlled Clinical Trials 1995; 16: $62-73$.

11 Koes BW, Bouter LM, Beckerman H, Heijden GJMG, Knipschild. PG.. Physiotherapy exercises and back pain. British Medical Journal 1991; 302: 1572-6.

12 Croft P, Pope D, Zonca M, O'Neill TO, Silman A. Measurement of shoulder related disability: results of a validation study. Annals of Rheumatic Diseases 1995; 53: 525-528.

13 Roach KE, Budiman-Mak E, Songsiridej N, Lertratanakul Y. Development of a shoulder pain and disability index. Arthritis Care and Research 1991; 4: 143-9.

14 Knipschild P, Leffers P, Feinstein AR. The qualification period. Journal of Clinical Epidemiology 1991; 44: 461-4.

15 Gardner MJ, Altman DG. Statistics with confidence. Confidence intervals and statistical guidelines. London, British Medical Journal Publishers, 1989.

16 Gore SM. Assessing clinical trials: first steps. British Medical Journal 1981; 282: 1605-7.

17 Uthoff HK, Sarkar K. An algorithm for shoulder pain caused by soft-tissue disorders. Clinical Orthopaedics and Related Research 1990; 254: 121-7.

18 Maxwell L. Therapeutic ultrasound. Its effects on the cellular and molecular mechanisms of inflammation and repair. Physiotherapy 1992; 78: 421-6.

19 Dunn F, Frizzel LA. Bioeffects of Uitrasoundtherapy. In: Therapeutic heat and cold. Lehman JF (ed), Williams and Wilkins, Baltimore 1990.

20 Hayes KW. The use of ultrasoundtherapy to decrease pain and improve mobility. Critical Reviews in Physical and Rehabilitation Medicine 1992; 3: 271-87.

21 Devor M. Peripheral and central nervous system mechanisms of sympathetic related pain. Pain Clinic 1995; 8: 5-14.

22 Sato A, Schmidt RF. Somatosympathetic reflexes: afferent fibers, central pathways, discharge characteristics. Physiological reviews 1973; 53: 916-45.

23 Roberts WJ. A hypothesis on the physiological basis for causalgia and related pains. Pain 1986; 24 : 179-311.

24 Broucker TH de, Cesaro P, Willer JC, Lebars D. Diffuse noxious inhibitory controls in man. Brain 1990; 113: 1223-34.

25 Brox II, Staff PH, Ljunggren AE, Brevik II. Arthroscopic surgery compared with supervised exercises in patients with rotator cuff disease (stage II impingement syndrome) British Medical Journal 1993; 307: 899-903. 


\section{Summary}

This thesis deals with shoulder disorders, the central subject being a randomized placebo-controlled clinical trial on the efficacy of ultrasoundtherapy and electrotherapy as adjuvants to exercise therapy for patients with soft-tissue shoulder disorders in primary care physiotherapy.

Pain and stiffness in the deltoid region are the leading symptoms of patients with shoulder disorders. From the background information (Chapter 1) it appears that about $10 \%$ of the primary care population suffer from one or more episodes of shoulder disorders in the course of their life. The majority of all shoulder disorders is reported to be caused by entesopathies within the shoulder girdle, such as tendinitis, bursitis and capsulitis. An inflammatory reaction due to subacromial soft-tissue impingement appears to be the common pathological mechanism behind these entesopathies. About $50 \%$ of all patients with shoulder disorders consult a physician. They constitute the third most largest group of patients with locomotor disorders in primary care, after patients with low back and neck disorders. In the majority of all newly presented episodes in general practice symptoms disappear within a few weeks, while some episodes may last over 6 months and result in substantial limitation of daily activities, even up to a year or more.

Although patients with shoulder disorders are believed to benefit considerably from common primary care treatments for shoulder disorders, such as NSAIDS, steroid injections and physiotherapy, controversy on their efficacy persists. The evidence on their efficacy has, been evaluated in 3 separate reviews (Chapters 2 through 4).

Extensive searches for relevant publications yielded 20 randomized clinical trials on physiotherapy, 16 on steroid injections and 19 on NSAIDS. Most trials lack statistical power due to small sample sizes. In general, the systematic assessments revealed the rather poor quality of their methods. Methọds asșessment wạs frequently hampered by insufficient information about randomization procedures, prognostic similarity of groups at baseline, and contamination by co-interventions or poor compliance. The validity of many trials is jeopardized by treatment withdrawals, missing values, poor blinding of patients and therapists for treatment identity and poor blinding during outcome assessments. Therefore, conclusions on the efficacy of these treatments can only be based on the trials with high quality of methods.

While for both steroid injections and NSAIDS for shoulder disorders 3 t trials with acceptable methods favour their efficacy, the effects are rather small. None of the 6 trials on physiotherapy with acceptable methods showed physiotherapy to be effective for shoulder disorders. 
From the systematic review on physiotherapy (Chapter 2) it appears that ultrasoundtherapy is inefficacious, while electrotherapy (ET) so far has not been demonstrated to be effective. Nevertheless, physiotherapists from various countries frequently use US and ET in the treatment of shoulder disorders, commonly as adjuvants to exercise therapy. Therefore, it would be interesting to see the results of a new trial with an acceptable quality of methods and sufficient sample size.

The primary goal of the main study of this thesis (Chapter 5) was to examine whether US and ET add to the effect of exercise therapy for shoulder disorders. A secondary goal was to study possible placebo-effects. Between 1 May 1992 and 1 November 1994180 patients with shoulder pain or restricted shoulder mobility, without underlying systemic disorders, were enrolled in our study. They all received a maximum of 12 sessions of exercise therapy over a 6 week period and additionally were randomized in a 2 by 2 factorial design: (1) active ET plus active US; (2) active ET plus dummy US; (3) dummy ET plus active US; (4) dummy ET plus dummy US. In order to estimate the placebo effect of adjuvant US and ET, an extra group was added that received (5) no adjuvants. Both active and dummy treatments were given to 73 and 72 patients, respectively, while 35 patients received no adjuvants. The prognosis of groups appeared to be similar at baseline. Blinding of patients for treatment identity was successfully maintained. Outcome measurements were blinded for treatment identity. Measurement at 6 weeks and 3, 6, 9 and 12 months follow-up revealed no differences. At 6 weeks $20 \%$ of the patients without adjuvants, 23 and $22 \%$ with active and dummy ET, and 26 and $19 \%$ with active and dummy US reported complete recovery or substantial improvement. These proportions increased up to 3 months to approximately $40 \%$ and remained stable thereafter. In all foliow-up measurements, however, the absence of any large effect was consistent for all outcome measures.

During the design and conduct of the clinical trial it was also possible to overcome the most important potential threats to validity. Consequently, the results allow a clear conclusion: neither ultrasoundtherapy nor electrotherapy prove to be effective as adjuvants to exercise therapy for shoulder disorders. Neither have both treatments been shown to have a large placebo effect.

Chapter 6 describes the design of the shoulder disability questionnaire (SDQ), a novel functional status measure for shoulder disorders. The SDQ appears to be a clinically relevant and responsive measure for evaluating disability in our trial population. The general discussion (Chapter 7) provides a review of the findings that are presented in this thesis. Special attention is given to our clinical trial. Since we could not demonstrate any favourable effect of US and ET, it is recommended to refrain from further use of ultrasoundtherapy and electrotherapy in the treatment of shoulder disorders. Given the frequent use of exercise therapy, we would suggest to exclusively focus future trials on its efficacy and cost-effectiveness. In view of the results of our systematic reviews such trials should give priority to steroid injections and NSAIDS as comparators. In view of the cost-effectiveness of exercise therapy, other important alternatives for comparison would be analgesics, advice and no treatment (e.g. rest, waiting list). 


\section{Samenvatting}

Dit proefschrift gaat over schouderaandoeningen in de eerstelijnsgezondheidszorg. Het centrale onderwerp is een gerandomiseerde placebo-gecontroleerde effectstudie naar het effect van ultrageluidtherapie en elektrotherapie als aanvulling op bewegingstherapie bij patiënten in de eerstelijnsgezondheidszorg met aandoeningen van de weke delen van de schouder.

In Hoofdstuk 1 wordt de belangrijkste achtergrondinformatie over aandoeningen van de schouder samengevat. Pijn en stijfheid in de schoudergordel blijken de belangrijkste klachten van patiënten met schouderaandoeningen te zijn. Ongeveer $10 \%$ van de populatie in een huisartsenpraktijk blijkt gedurende hun leven een of meer episoden met schouderklachten door te maken. De meest frequent gerapporteerde oorzaak voor schouderklachten is een ontstekingsreactie van de weke delen (entesopathieèn) in de schoudergordel, zoals tendinitiden, bursitiden en capsulitiden. Een subacı niale inklemming van weke delen lijkt het meest waarschijnlijke oorzakelijke me .anisme voor deze ontstekingsreacties.

$\mathrm{Na}$ rugklachten en nekklachten vormen schouderklachten de derde grootste groep van alle aandoeningen aan het bewegingsapparaat in de eerstelijnsgezondheidszorg. In de meeste gevallen verdwijnen de klachten binnen enkele weken, maar in een beperkt aantal gevallen blijven de klachten 6 maanden tot meer dan een jaar bestaan, en leiden deze tot forse beperkingen in de dagelijkse bezigheden.

Aangenomen wordt dat patiënten met schouderklachten baat hebben bij gebruikelijke behandelingen in de eerstelijnsgezondheidszorg, zoals NSAIDS, steroïde injecties en fysiotherapie. Tot op heden bestaat er echter geen duidelijkheid over de effectiviteit van deze behandelvormen. In 3 afzonderlijke literatuurstudies (Hoofdstuk 2 tot en met 4) worden de beschikbare gerandomiseerde effectstudies samengevat en hun onderzoeksmethoden beoordeeld.

Uitgebreide zoekacties naar gerandomiseerde onderzoeken leverden 20 effectstudies op over fysiotherapie, 16 studies over steroïde injecties en 19 studies over NSAIDS. Vanwege hun kleine populatieomvang hebben vrijwel al deze studies een geringe statistische bewijskracht. Uit de systematische evaluatie van de onderzoeksmethoden bleek dat er frequent onduidelijkheid bestaat over bepaalde aspecten van de opzet en uitvoering van de studies. Zo ontbrak zeer frequent informatie over de randomisatieprocedure, prognostische vergelijkbaarheid van de groepen na randomisatie, en bestond er onduidelijkheid over toepassing van co-interventies en trouw aan het onderzoeksprotocol. Voorts vertoonden de opzet en uitvoering van de 
meeste studies belangrijke tekortkomingen, waardoor de interne validiteit van de studies werd aangetast. De meest frequent geconstateerde tekortkomingen betreffen het voortijdig staken van de toegewezen behandeling, ontbrekende waarden voor uitkomstmetingen, gebrekkige blindering van patiënten en behandelaars voor de identiteit van de toegewezen behandeling en gebrekkige blindering tijdens effectmetingen.

Over zowel steroïde injecties (Hoofdstuk 3) als NSAIDS (Hoofdstuk 4) zijn 3 studies met een acceptabele kwaliteit van onderzoeksmethoden beschikbaar waarvan de uitkomsten de effectiviteit van deze behandelvormen ondersteunen. De waargenomen effecten zijn echter nogal klein.

De 6 effectstudies over fysiotherapie bij schouderaandoeningen (Hoofdstuk 2) met een acceptabele kwaliteit van onderzoeksmethoden geven geen ondersteuning voor de effectiviteit ervan. Ultrageluidtherapie (UG) lijkt niet effectief te zijn, terwijl de effectiviteit van elektrotherapie (ET) bij patiënten met schouderaandoeningen tot op heden niet is aangetoond. Toch worden UG en ET in veel landen veelvuldig toegepast ter behandeling van patiënten met schouder-aandoeningen, gewoonlijk als aanvulling op bewegingstherapie. Derhalve is het interessant om een nieuwe gerandomiseerde studie uit te voeren.

Het doel van onze gerandomiseerde placebo-gecontroleerde effectstudie (Hoofdstuk 5) was om te onderzoeken of UG en ET als aanvulling op bewegingstherapie bijdragen aan het herstel van schouderaandoeningen. Een secundair doel was de bestudering van eventuele placebo-effecten. Tussen 1 mei 1992 and 1 november 1994 werden 180 patiënten voor deelname geselecteerd. Zij waren 18 jaar of ouder en hadden schouderpijn of glenohumerale bewegingsbeperking, alsmede klinische verschijnselen van entesopathieën (tendinitis, bursitis of capsulitis) van de schouder zonder aanwijsbaar onderliggend lijden. Deze patiënten ontvingen in 6 weken maximaal 12 sessies bewegingstherapie, en werden via een aselecte procedure toegewezen aan: actieve ET plus actieve UG; (2) actieve ET plus dummy UG; (3) dummy ET plus actieve UG; (4) dummy ET plus dummy UG. Om eventuele placebo-effecten van ET en UG te onderzoeken werd een extra groep gevormd zonder aanvullende therapievormen. Beide actieve en dummy therapievormen werden aan respectievelijk 73 and 72 patiënten toegewezen, terwij! 35 patiënten geen aanvullende therapievormen toegewezen kregen. Na randomisatie bleek de prognose van de groepen goed vergelijkbaar te zijn. Tijdens de effectmeting 6 weken na randomisatie bleken de patiënten goed geblindeerd te zijn ten aanzien van de identiteit van de aanvullende behandelvormen. Zes. weken na randomisatie bleek $20 \%$ van de patiënten zonder aanvullende behandelvormen, 23 en $22 \%$ met actieve en dummy ET, en 26 en $19 \%$ met actieve and dummy UG geheel hersteld of zeer veel verbeterd te zijn. Drie maanden na randomisatie bleken deze proporties ongeveer verdubbeld te zijn. Tot aan het einde van de followup na 12 maanden bleven deze proporties stabiel. De afwezigheid van effecten van enige omvang, was de gehele follow-up consistent voor alle uitkomstmaten.

Omdat tijdens de opzet en de uitvoering van dit onderzoek vertekening werd voorkomen, laat het duidelijke conclusies toe: noch ET noch UG blijken effectief te zijn als aanvulling op bewegingstherapie ter behandeling van patiënten met schouderaandoeningen. Een placebo effect blijkt voor beide therapievormen eveneens afwezig te zijn. 
Hoofdstuk 6 beschrijft de samenstelling van de Schouder Beperkingen Vragenlijst (SDQ), een nieuwe effectmaat ter bepaling van de functionele status van patiēnten met schouderaandoeningen. Tijdens ons effectonderzoek blijkt de SDQ een klinisch relevante en responsieve effectmaat te zijn.

In de afsluitende discussie (Hoofdstuk 7) worden de resultaten besproken van de hoofdstukken van dit proefschrift. Daarbij wordt extra aandacht geschonken aan de gerandomiseerde placebo-gecontroleerde studie naar de effectiviteit van UG en ET (Hoofdstuk 5). Aanbevolen wordt af te zien van verdere toepassing van ET en UG ter behandeling van personen met schouderaandoeningen.

Gegeven de frequente toepassing van bewegingstherapie, wordt aanbevolen toekomstig effectonderzoek inzake fysiotherapie bij schouderaandoeningen uitsluitend te richten op de werkzaamheid en doelmatigheid van deze therapievorm. Vanwege de indicaties inzake hun werkzaamheid vormen steroïde injecties en NSAIDS daarbij relevante interventies ter vergelijking met bewegingstherapie. Voor onderzoek naar de doelmatigheid van bewegingstherapie bij schouderaandoeningen zijn analgetica, adviezen en geen behandeling (bijvoorbeeld rust tijdens een wachtlijstperiode) eveneens relevante alternatieve interventies. 



\section{Dankwoord}

Allereerst ben ik dank verschuldigd aan de patiènten en de fysiotherapeuten die aan het effectonderzoek deelgenomen hebben. Hun trouw aan de onderzoeksvoorschriften en hun inzet was bepalend voor het welslagen van het effectonderzoek.

Ik dank de leden van de projectgroep:

Pieter Leffers, gaandeweg, raakte wij goed op elkaar ingespeeld. Door je inhoudelijke en mentale begeleiding leverde je een belangrijke bijdrage aan de opzet en uitvoering van het effectonderzoek. Je analytische instelling werkte dikwijls verhelderend. Bedankt voor de vruchtbare discussies over en je grote bijdrage aan de inhoud van dit proefschrift.

José Verheijden, door je humor, nuchterheid en enthousiasme ben je een prettige collega om mee samen te werken. Vooral tijdens de periode van gegevensverzameling hebben we samen veel werk verzet. Altijd was je bereid om ook de minder leuke klussen op je te nemen. Jouw professionele, vriendelijke en nauwgezette houding bij de afspraken met patiënten was bepalend voor de hoge respons op de follow-up. Pieter Wolters, je stond altịjd klaar met praktische adviezen. Je speelde een belangrijke rol bij de uitwerking van de protocollen voor de selectie en interventies van het effectonderzoek. Je enthousiaste bijdrage was belangrijk voor de geslaagde afloop van veel bijeenkomsten met de behandelaars.

Henk van Mameren, je kritische betrokkenheid was meer dan spreekwoordelijk. Je was altijd bereid tot overleg tiịdens de verschillende fasen van het effectonderzoek. Paul Knipschild, jij hebt de leden van de projectgroep ervan overtuigd dat een factoriele opzet en een kwalificatie periode de efficiëntie van ons effectonderzoek verhogen.

Jo Houben, met je humor relativeerde je regelmatig de dișcusșies tijdens de bijeenkomsten van de projectgroep.

De samenwerking met de leden van de voortgangsbegeleidingscommissie, mevrouw Dullemeijer-Smit, Pop Romijn-Liem, Cees de Geus, Rob Oostendorp en Cees Postema heb ik als prettig ervaren. Zij leverden met hun opmerkingen en adviezen een zinvolle bijdrage aan het effectonderzoek.

De medewerkers van Uniphy, bouwer en leverancier van de apparatuur voor de ultrageluidtherapie en elektrotherapie, werkten op professionele wijze en zonder voorbehoud mee aan het effectonderzoek. Het voorspoedig verloop van de aanpassing, levering, ijking en het onderhoud van de apparatuur vormden belangrijke voorwaarden voor het welslagen van het effectonderzoek. 
Lex Bouter, sinds mijn studentassistentschap heb ik het genoegen door jou begeleid te worden. Elke keer weer verbaas ik me over de snelheid en efficiëntie waarmee jij een bijdrage levert aan gezamelijke projecten. Je integere wijze van begeleiden waardeer ik zeer. Bedankt voor je adviezen en steun in de afgelopen jaren.

André Knottnerus, je luisterend oor, adviezen en steun ervaar ik als zeer stimulerend. Je brengt de naam van de onderzoeksschool CaRe in praktijk.

Voorts ben ik dank verschuldigd aan:

Daniëlle van der Windi, je leverde een waardevolle bijdrage aan verschillende hoofdstukken van dit proefschrift. Door je openheid, directheid en humor is het prettig om er met jou de schouders onder te zetten.

Marijke Moll, Annemie Mordant en Ellen Croes, jullie vingen patiënten op die voor deelname aangemeld werden als José of ik er niet waren. Ik zal jullie hulp en die van Harrie van Montfort bij de verwerking van de onderzoeksgegevens niet snel vergeten. Fons Kessels, je maakte telkens weer tijd vrij voor overleg over en commentaar op verschillende onderdelen van dit proefschrift.

Jos Kleijnen, Andrea de Winter en Rob Scholten, jullie investeerden veel tijd in de beoordeling van effectstudies ten behoeve van de systematische reviews in dit proefschrift.

Sandra Beurskens, je hielp me bij de samenstelling van het concept van de Schouder Beperkingen Vragenlijst.

Carina Oostveen, je haalde in zeer korte tijd vakkundig de engelse taal- en stijlfouten uit dit proefschrift.

Thum Aarts, je hielp bij de verwerking, van de onderzoeksgegevens, maar bovenal gaf in zeer korte tijd op professionele wijze dit proefschrift de gewenste lay-out.

Paranymfen, Bart Koes en Jan Biert, met jullie heb ik het vaak over onderzoek gehad, maar meer nog over andere zaken. Jullie hebben het ontstaan van dit proefschrift op de voet gevolgd.

Bart, het Maastrichterbrugstraat-gevoel zal ik niet snel vergeten. Onze goede samenwerking resulteert telkens weer in co-auteurschappen, nu weer van hoofdstukken in dit proefșchrift.

Jan, in 1976 in Utrecht kwam promoveren nog niet in onze gedachten op. Fietsen en klimmen sprak meer tot onze verbeelding. Nu is het dan zo ver; ook jii hoopt binnenkort te promoveren. Weldra hoop ik weer meer samen te kunnen fietsen.

Vader en moeder, bedankt voor jullie steun en vertrouwen. Altijd kan ik op jullie rerugvallen en vind ik een kritisch, luisterend oor. Ik hoop dat dit nog lang zo zal blijven.

Meta, Eva en Thijs, zonder jullie is dit proefschrift niet af. Jullie opgewektheid en vrolijke drukte brengen afleiding en ontspanning en maken het mij gemakkelijk om mijn werk te relativeren. Jullie aandacht, steun en vertrouwen zijn voor mij van groot belang. Meta, de ruimte die je mij hebt gegeven bleek vooral tijdens de eindspurt voor dit proefschrift cruciaal. Dank je wel. 


\section{Curriculum vitae}

Geert J.M.G. van der Heijden werd op 12 april 1958 te Oisterwijk geboren. Hij is in 1992 gehuwd met Meta de Graaff. Zij hebben twee kinderen, Eva en Thijs.

In 1974 behaalde hij het MAVO-diploma en in 1976 het HAVO-diploma, te Tilburg. Zijn opleiding fysiotherapie te Utrecht en Amsterdam werd in 1979 onderbroken door militaire dienst. Na het behalen van het diploma fysiotherapie in 1985, werkte hij korte tijd als fysiotherapeut in Engeland.

Vanaf 1986 studeerde hij aan de Faculteit der Gezondheidswetenschappen (GW) aan de Rijksuniversiteit Limburg (RL), te Maastricht. In 1990 behaalde hij in de afstudeerrichting Bewegingswetenschappen het GW-diploma met aanvullende examens. Tijdens de laatste 2 jaar van zijn studie publiceerde hij als student-assistent bij de vakgroep Epidemiologie enkele artikelen inzake literatuuronderzoek naar de effectiviteit van fysiotherapie.

Voor zijn afstudeerproject, een placebo-gecontroleerd onderzoek naar de effecten van tractie bij lage rugklachten, kreeg hij in 1992 de GW studentenprijs van de Stichting Wetenschapsbeoefening van de RL. Zijn voorstel voor het vervolg van dit onderzoek werd door het Fonds Ontwikkelingsgeneeskunde gesubsidieerd.

Zijn projectvoorstel voor een onderzoek naar de werkzaamheid van ultrageluidtherapie en elektrotherapie bij schouderklachten werd door de Ziekenfondsraad gesubsidieerd. Sinds 1990 voerde hij dit schouderonderzoek uit bij de vakgroep Epidemiologie van de RL. Daarnaast was hii als docent verbonden aan de GW afstudeerrichting Verkort Bewegingswetenschappen voor fysiotherapeuten.

Hiị kreeg ziịn epidemiologische scholing binnen de vakgroep Epidemiologie. Ook volgde hij cursussen over epidemiologisch onderzoek bij Rothman, Lanes, Lemeshow (1992) en Miettienen (1993). In 1993 volgde zijn registratie als Epidemioloog A.

Hij was voorzitter van de Maastrichtse Studenten Alpen Club (1986-1987) en lid van de gebruikersraad van het RL bureau studentensport 'Lichamelijke vorming en sport' (1987-1988). Ook was hij lid van de GW faculteitsraad (1994-1995).

Sinds augustus 1996, werkt hij bij het Instituut voor Revalidatie Vraagstukken te Hoensbroek. 



\section{List of publications}

- Hoving JW, Heijden GJMG van der. Effectiviteit van fysiotherapie en manuele therapie bij heupklachten. Een systematische review. Nederlands Tijdschrift voor fysiotherapie (In press).

- Assendelft WII, Koes BW, Heijden GIMG van der, Bouter LM. The effectiveness of chiropractic for the treatment of back pain. An update and attempt at statistical pooling. Joumal of Manipulative and Physiological Therapeutics (In press).

- Koes BW, Assendelft W]I. Heijden GJMG van der, Bouter LM. Spinal manipulation and mobilisation for low-back pain. An update systematic review of randomized clinical trials. Spine (In press).

- Heijden GJMG van der, Beurskens AJHM, Dirx MJM, Bouter LM, Lindeman E. Efficacy of lumbar traction: a randomised clinical trial. Physiotherapy 1995; 81: 29-35.

- Heijden GIMG van der, Beurskens AJHM, Koes BW, Assendelft WII, Vet HCW de, Bouter LM. The efficacy of traction for back and neck pain. A blinded review of randomized clinical trial methods. Physical Therapy; 1995; 75: 93-104.

- Heijden GIMG van der, Windt DAWM van der, Kleijnen JMP, Koes BW, Bouter LM. The efficacy of corticosteroid injections for shoulder complaints. A systematic review. British Journal of General Practice 1996; 46: 309-16.

- Windt DAWM van der, Heijden GJMG van der, Scholten RJPM, Koes BW, Bouter LM. The efficacy of non-steroidal anti-inflammatory drugs (NSAIDs) for shoulder complaints. A systematic review. Journal of Clinical Epidemiology 1995; 48: 691-704

- Beurskens AJHM, Vet HCW de, Köke AJA, Lindeman E, Regtop W, Heijden GJMG van der, Knipschild. PG. The efficacy of traction for lumbar back pain. Results of a randomized clinical trial. Lancet 1995; 346: 1596-1600.

- Beurskens AJHM, Heijden GJMG van der, Vet HCW de, Köke AJA, Lindeman E, Regtop W, Knipschild PG. The efficacy of traction for lumbar back pain. Design of a randomized clinical trial. Journal of Manipulative and Physiological Therapeutics 1995; 18: 141-7.

- Beurskens AJHM, Vet HCW de, Köke AJA, Heijden GJMG van der, Knipschild PC. Functional status instuments in clinical trials for low back pain. Spine 1995; 20: 101-28.

- Koes BW, Bouter LM, Heijden GJMG van der. Methodological quality of randomized clinical trials in low back pain. Spine 1995; 20: 228-35.

- Vet HCW de, Sijpkes P, Beurskens AJHM, Bie RA de, Heijden GJMG van der, Verhagen AP'. Research in physical therapy in Maastricht, The Netherlands. Activities in the department of Epidemiology, University of Limburg. Nederlands Tijdschrift voor Fysiotherapie. Special Issue 1995; 105: 17-9.

- Dirx MJM, Beurskens AJHM, Heijden van der GJMG, De Vet HCW. Lange termijn follow-up metingen bij clinical trials. Nederlands Tijdschrift voor Fysiotherapie 1994; 104: 140-147.

- Beckerman H, Bouter LM, Heijden GJMG van der, Bie RA de, Koes BW. The efficacy of physiotherapy for musculoskeletal disorders. Overview of the current state of knowledge. European lournal of Physical Medicine and Rehabilitation 1993; 3:236-41.

- Beckerman H, Bouter LM, Heijden GJMG van der, Bie RA de, Koes BW. The efficacy of physiotherapy' for musculoskeletal disorders. What can we learn from research? British Journal of General Practice 1993; 43: 73-7.

- Assendelft WIJ, Koes BW, Heijden GIMG van der, Bouter LM, Knipschild PG. The efficacy of chiropractic for back pain. Blinded review of relevant randomized clinical trials. Journal of Manipulative and Physiological Therapeutics 1992; 15:478-94.

- Bouter LM, Beckerman H, Heijden GJMG van der, Koes BW, RA de Bie. Effectiviteit van fysiotherapie; een samenvatting van 9 meta-analyses. Nederlands Tijdschrift voor Geneeskunde 1992; 136: 1058-61. Beurskens AJHM, Bouter LM, Heijden GIMG van der. Compliance-bepaling bij oefentherapie. Een beoordeling van de beschikbare meetinstrumenten. Nederlands Tijdschrift voor Fysiotherapie 1992; 102: $2-7$ : 
- Heijden GJMG van der, Bouter LM, Beckerman H, Bie RA de, Oostendorp RAB. Effectiviteit van fysiotherapie bij schouderklachten. Een geblindeerd literatuuronderzoek. Nederlands Tijdschrift voor Fysiotherapie 1992; 102: 38-46.

- Koes BW, Assendelft WIJ, Heijden GIMG van der, Bouter LM, Knipschild PG. Spinal manipulation and mobilisation for back and neck pain: a blinded review. British Medical Journal 1991; 303: 1298-303.

- Koes BW, Bouter LM, Beckerman $\mathrm{H}_{6}$ Heijden GJMG van der, Knipschild PG. Physiotherapy exercises and back pain: a blinded review. British Medical Journal 1991; 302: 1572-6.

- Koes BW, Assendelft WJJ, Heijden GJMG van der, Bouter LM, Knipschild PG. Effectiviteit van manipulatieve technieken bij rug-en nekklachten. Een kritisch overzicht van de gepubliceerde randomized clinical trials. Nederlands Tijdschrift voor Manuele Therapie 1991; 10: 83-9.

- Koes BW, Bouter LM, Beckerman H, Heijden GJMG van der, Knipschild PG. Oefentherapie bij lage rugklachten. Een geblindeerd literatuuronderzoek. Nederlands Tijdschrift voor Fysiotherapie 1991; 101: 229-34.

- Bouter LM, Heijden GJMG van der, Beckerman H. Het 'single case design' in de fysiotherapie. Nederlands Tijdschrift voor Fysiotherapie 1991; 101: 131-136.

- Heijden GJMG van der, Bouter LM, Terpstra-Lindeman E, Essers AHM, Wàltje EMH, Köke AJA, Roox GM, Waelen AMW. De effectiviteit van tractie bij lage rugklachten. De resultaten van een gerandomiseerde en geblindeerde pilotstudie. Nederlands Tijdschrift voor Fysiotherapie 1991; 101: $37-41$.

- Heijden GJMG van der, Bouter LM, Beckerman H, de Bie RA, Oostendorp RAB, Effectiviteit van ultrageluid bij aandoeningen van het bewegingsapparaat. Een op methodologische criteria gebaseerde geblindeerde review van gerandomiseerd patiëntgebonden onderzoek. Nederlands Tijdschrift voor Fysiotherapie 1991; 101: 169-177.

- Heijden GJMG van der, Bouter LM, Terpstra-Lindeman E, Essers AHM. De effectiviteit van tractie bij lage rugklachten. Deel 2. Patiènt-gebonden onderzoek. Nederlands Tijdschrift voor Fysiotherapie 1990; 100: 168-174.

- Heijden GJMG van der, Bouter LM, Terpstra-Lindeman E, Essers AHM. De effectiviteit van tractie bij lage rugklachten. Deel 1: Technieken en werkingsmechanismen. Nederlands Tijdschrift voor Fysiotherapie 1990; 100: 163-167.

- Heijden GJMG van der, Bouter LM, Knottnerus JA. De effectiviteit van interferentie, ultrareiz en diadynamische stromen bij aandoeningen van het bewegingsapparaat. Deel 2. Patiëntgebonden onderzoek. Nederlands Tijdschrift voor Fysiotherapie 1990; 100: 11-19.

- Heijden GJMG van der, Bouter LM, Knottnerus JA. De effectiviteit van interferentie, ultrareiz en diadynamische stromen bij aandoeningen van het bewegingsapparaat. Deel 1. De werkingsmechanismen. Nederlands Tijdschrift voor Fysiotherapie 1990; 100: 4-10. 



\section{Shoulder disorder treatment \\ Efficacy of ultrasoundtherapy and electrotherapy}

\section{Geert J.M.G. van der Heijden}

Shoulder disorders constitute a serious health problem. After low back and neck disorders, they constitute the third most largest group of all disorders of the locomotor system in primary care. Non-steroidal anti-inflammatory drugs (NSAIDS), steroid injections and physiotherapy are believed to promote their recovery.

This thesis reports on a randomized placebo-controlled clinical trial on the efficacy of ultrasoundtherapy and electrotherapy as adjuvants to exercise therapy for shoulder disorders in primary care physiotherapy in the Netherlands.

Furthermore, this thesis describes systematic reviews of randomized clinical trials on the efficacy of NSAIDS, steroid injections and physiotherapy for shoulder disorders, and it reports on the design and responsiveness of the Shoulder Disability Questionnaire.

Schouderaandoeningen vormen een veel voorkomend gezondheidsprobleem. In de groep met aandoeningen aan het bewegingsapparaat in de eerstelijnsgezondheidszorg nemen schouderaandoeningen dan ook een derde plaats in na aandoeningen van de lage rug en nek. Verondersteld wordt dat injecties met steroiden, niet-steroide ontstekingsremmende medicatie (NSAIDS) en fysiotherapie werkzame behandelvormen zijn voor schouderaandoeningen.

In dit proefschrift wordt een gerandomiseerd placebogecontroleerd effectonderzoek gerapporteerd naar de werkzaamheid van ultrageluidtherapie en elektrotherapie als aanvulling op bewegingstherapie bij schouderaandoeningen in de eerstelijnsfysiotherapie. Voorts worden systematische literatuurstudies inzake de werkzaamheid van injecties met steroiden, NSAIDS en fysiotherapie bij aandoeningen van de schouder, alsmede de ontwikkeling van de schouder beperkingen vragenlijst beschreven. 